\title{
The transcription factor BCL11A defines a distinctive subset of dopamine neurons in the developing and adult midbrain
}

Marianna Tolve ${ }^{1}$, Ayse Ulusoy ${ }^{2}$, Khondker Ushna Sameen Islam¹, Gabriela O. Bodea ${ }^{1 \S}$, Ece Öztürk ${ }^{1}$, Bianca Broske ${ }^{1}$, Astrid Mentani ${ }^{1}$, Antonia Wagener ${ }^{1}$, Karen van Loo ${ }^{3 \S}$, Stefan Britsch ${ }^{4}$, Pengtao Liu $^{5}$, Walid Khaled ${ }^{6}$, Stephan Baader ${ }^{7}$, Donato A. Di Monte ${ }^{2}$, Sandra Blaess ${ }^{1^{*}}$

${ }^{1}$ Neurodevelopmental Genetics, Institute of Reconstructive Neurobiology, University of Bonn School of Medicine \& University Hospital Bonn, Bonn, Germany

${ }^{2}$ German Center for Neurodegenerative Diseases (DZNE), Bonn, Germany

${ }^{3}$ Section for Translational Epilepsy Research, Department of Neuropathology, University of Bonn Medical Center, Bonn, Germany

${ }^{4}$ Institute of Molecular and Cellular Anatomy, Ulm University, Ulm, Germany

${ }^{5}$ School of Biomedical Sciences, Li Ka Shing Faculty of Medicine, The University of Hong Kong, China

${ }^{6}$ Department of Pharmacology, University of Cambridge, Cambridge, UK

${ }^{7}$ Institute of Anatomy, Anatomy and Cell Biology, University of Bonn, Bonn, Germany

${ }^{*}$ corresponding author

$\S$ Current address:

GB: Mater Research Institute-University of Queensland, Brisbane, Queensland, Australia Queensland Brain Institute, University of Queensland, Brisbane, Queensland, Australia. KvL: Department of Epileptology, Neurology, RWTH Aachen University, Aachen, Germany 


\begin{abstract}
Midbrain dopaminergic (mDA) neurons are diverse in their projection targets, impact on behavior and susceptibility to neurodegeneration. Little is known about the molecular mechanisms that establish this diversity in mDA neurons during development. We find that the transcription factor Bcl11a defines a subset of $\mathrm{mDA}$ neurons in the developing and adult murine brain. By combining intersectional labeling and viral-mediated tracing we show that Bcl11a-expressing mDA neurons form a highly specific subcircuit within the dopaminergic system. We demonstrate that Bcl11a-expressing mDA neurons in the substantia nigra (SN) are particularly vulnerable to neurodegeneration in an $\alpha$-synuclein overexpression model of Parkinson's disease. Inactivation of Bcl11a in developing mDA neurons results in anatomical changes, deficits in motor learning and a dramatic increase in the susceptibility to $\alpha$-synucleininduced degeneration in SN-mDA neurons. In summary, we identify an mDA subpopulation with highly distinctive characteristics defined by the expression of the transcription factor Bcl11a already during development.
\end{abstract}




\section{Introduction}

Midbrain dopaminergic neurons (mDA) are anatomically organized into the substantia nigra, ventral tegmental area (VTA) and retro-rubral field (RRF). These anatomically defined areas contain subpopulations of mDA neurons that are characterized by distinct molecular profiles, distinct connectivity and distinct impacts on dopamine-modulated behavior (Engelhard et al., 2019; Poulin et al., 2018; Poulin et al., 2020). The SN consists of the pars compacta (SNc), pars lateralis $(\mathrm{SNI})$ and pars reticularis $(\mathrm{SNr})$. The majority of $\mathrm{SN}-\mathrm{mDA}$ neurons is located in the SNc, a smaller population forms the SNI and only few mDA neurons are found in the SNr. SNI mDA neurons project to the tail of the striatum (TS) and have been shown to reinforce the avoidance of threatening stimuli (Menegas et al., 2018; Menegas et al., 2015). According to projection targets and functional output, the $\mathrm{SNc}$ is divided into a medial and lateral part. Medial SNc mDA neurons send their axons to the dorsomedial striatum (DMS) whereas projections of the lateral SNc target the dorsolateral striatum (DLS). Functionally, the firing of the DMS projecting mDA population may signal the valence of the outcome, while mDA neurons projecting to the DLS may signal a salience signal (appetitive or aversive) (Lerner et al., 2015). mDA neurons in the VTA project to the Nucleus accumbens (NAc), the olfactory tubercle (OT), prefrontal cortex (PFC) and amygdala. Similar to the SN, the VTA is anatomically divided into smaller domains, but here there is no clear relationship between the anatomical location of mDA cell bodies and the projection targets of VTA mDA neurons (Morales and Margolis, 2017). In addition to these anatomical mDA subgroups, mDA neurons have been defined based on their molecular profile. A comparative analysis of the currently available single cell gene expression studies led to the proposal that there are at least 7 molecularly-defined mDA subgroups. These do not necessarily correspond to mDA populations distinct by anatomical location, projection target and functional output (Poulin et al., 2020) and thus it is not clear to what extent these different levels of diversity can be reduced to a common denominator to define mDA diversity. Since anatomical position, molecular profile and connectivity are largely determined during development, a better understanding of the developmental factors that determine mDA subpopulations could deliver important new insights on how to define mDA subpopulations.

mDA neurons in the SNc degenerate in Parkinson's disease (PD), leading to the cardinal motor symptoms of the disease. mDA neurons in the VTA are much less affected by the neurodegeneration in PD, but even within the SNc, neurons are not homogenous in their vulnerability: SNc-mDA neurons in the ventral tier appear to be more vulnerable than the ones in the dorsal tier. This selective vulnerability is found both in humans and in various PD models in rodents (Kordower et al., 2013). In mouse, the more vulnerable population has been shown to express the enzyme ALDH1A1 (Aldehyde Dehydrogenase 1 Family Member A1), while the less vulnerable subpopulation expresses the Calcium-binding protein Calbindin1 (CALB1) (Liu 
et al., 2014; Poulin et al., 2014). Since loss of ALDH1A1 function makes SNc-mDA neurons even more prone to neurodegeneration, ALDH1A1 seems unlikely to be the functionally decisive factor in the increased vulnerability (Liu et al., 2014). Nevertheless, these insights suggest that susceptibility to neurodegeneration in mDA subgroups could be genetically and developmentally pre-determined (Schwamborn, 2018).

Since transcription factors are key regulators of cell specification programs, we set out to identify transcription factors that are expressed in subpopulations of $\mathrm{mDA}$ neurons in the developing and adult brain. We discovered that the $\mathrm{C} 2 \mathrm{H} 2$ zinc finger transcription factor $B C L 11 A$ ( $B$ cell CLL/lymphoma) is expressed in a subpopulation of $\mathrm{mDA}$ neurons from embryogenesis to adulthood. BCL11A, also known as CTIP1 (Chicken ovalbumin upstream promoter transcription factor-interacting proteins 1), is a transcriptional repressor and a dedicated subunit of the mammalian SWI/SNF complex, a polymorphic assembly of at least 14 subunits (encoded by 28 genes) that functions as an ATP-dependent chromatin remodeler (Kadoch et al., 2013; Simon et al., 2020). In the mouse, BCL11A regulates neuronal fate determination during cortex and spinal cord development (Simon et al., 2020). In humans, $\mathrm{BCL} 11 \mathrm{~A}$ haploinsufficiency results in neurodevelopmental disorders characterized by developmental delay, mild to severe intellectual disability and behavioral problems (Basak et al., 2015; Deciphering Developmental Disorders Study, 2015; Dias et al., 2016; Peron et al., 2019). While these studies point to the importance of $B C L 11 \mathrm{~A}$ in the development of the central nervous system (CNS), the function of BCL11A in development and maintenance of the dopaminergic system has not been examined.

We show here that the Bcl11a-expressing mDA neurons represent a previously uncharacterized subpopulation of mDA neurons, which does not correspond to any of the previously defined anatomical and molecular mDA subgroups but forms a highly distinct subcircuit within the dopaminergic system. Moreover, we demonstrate that Bcl11a appears to be required for the normal function of these mDA neurons, since conditional inactivation of Bcl11a in mDA neurons leads to deficits in motor learning in the conditional knock-out mice, although no significant loss of SN-mDA neurons or mDA projections could be detected in the mutant animals. Moreover, we find that Bc/11a expression characterizes a subpopulation of SNc neurons highly vulnerable to $\alpha$-synuclein-induced neurodegeneration and that, within these neurons, $\mathrm{Bcl11a-mediated} \mathrm{transcription} \mathrm{is} \mathrm{likely} \mathrm{to} \mathrm{activate} \mathrm{or} \mathrm{modulate} \mathrm{neuroprotective}$ pathways. In summary, our data demonstrate that Bcl11a expression defines a subset of mDA neurons with highly specific projection targets and that loss of BCL11A interferes with the functional integrity and resilience to injury of these neurons. 


\section{Results}

\section{Bcl11a is expressed in a subset of mDA neurons in the SN, VTA and RRF}

We initially identified $\mathrm{Bc} / 11 \mathrm{a}$ as a potential mDA-subset marker based on the expression pattern available on the Allen Brain Atlas (Developing Mouse Brain). To examine whether $\mathrm{Bcl11a}$ is indeed expressed in a subset of mDA neurons, we analyzed the expression of $\mathrm{Bcl11a}$ mRNA and BCL11A protein in combination with tyrosine hydroxylase $(\mathrm{TH})$, the rate limiting enzyme in dopamine synthesis. In the neonatal and adult brain, Bc/11a mRNA was expressed in a subset of SN, VTA, RRF and caudal linear nucleus (CLi) neurons. In the SN, Bc/11aexpressing mDA neurons were localized to the SNI and the medial and dorsal SNc. In the VTA, Bcl11a-positive neurons were found throughout the VTA (Figure 1A-F, data not shown). The distribution of neurons positive for $\mathrm{BCL} 11 \mathrm{~A}$ protein and $\mathrm{TH}$ was comparable to the distribution of $\mathrm{Bcl11a}$ /TH positive neurons in the neonatal brain and in the VTA of adult brains (Figure 1GL), but we could not detect BCL11A protein in mDA neurons in the SNc and SNI in the P30 brain (Figure 1J,L). Since Bcl11a mRNA is expressed in SN-mDA neurons at P30, albeit at lower levels than in the VTA, this may indicate that SN-mDA express BCL11A protein at lower levels than VTA-mDA and that these low protein levels are not detected by the anti-BCL11A antibody used in our study.

Next, we analyzed the distribution of $B c / 11 a$-expressing cells using $B c / 11 a^{l a c z}$ mice. In this mouse line, the lac $Z$ allele is knocked into the endogenous $B c / 11 a$ locus and $\beta$-gal expression is restricted to cells that express Bc/11a (Dias et al., 2016). Indeed, the distribution of $\beta$-gal positive mDA neurons in neonatal and adult brain was comparable to the one of mDA neurons expressing Bcl11a mRNA (Figure 1A-F, M-R, Supplemental Figure 1). To test whether $\beta$-gal reliably marks $B C L 11 A$-expressing neurons, we performed double labeling for $\beta$-gal and $B C L 11 A$ protein in neonatal and adult sections of the midbrain and found that the expression pattern of $\beta$-gal and BCL11A was largely overlapping in the VTA and in the cerebral cortex (Supplemental Figure 2). We then quantified the percentage of mDA neurons that express $B c / 11 a$ by counting $\beta$-gal and $\mathrm{TH}$ double-positive cells in Bcl11a-lacZ mice. $\beta$-gal was expressed in more than $40 \%$ of VTA-mDA neurons (neonatal: $45.84 \%+/-4.467$, adult: $42.84 \%$ $+/-1.326$ ), in about one fourth of SN-mDA neurons (neonatal: $32.07 \%+/-3.395$, adult: $22.63 \%$ $+/-2.179$ ) and in a third of RRF- and caudal linear nucleus (CLi)-mDA neurons (RRF: $30.97 \%$ +/- 2.757; CLi: 32.61\% +/- 1.933, only analyzed in adult brain) (Figure 1S,T). Additionally, nondopaminergic neurons expressing $\beta$-gal were found in the ventral midline of the midbrain, dorsal to the SN and within the VTA and SN area (Supplemental Figure 1).

To investigate the developmental time course of BCL11A expression in the ventral midbrain, we used immunostaining to analyze BCL11A protein expression between embryonic day 
109 (E)12.5 and E15.5. BCL11A was first expressed in the ventral midbrain at E12.5. At E12.5

110 and E13.5, BCL11A was mainly localized in the area just below the mDA progenitor domain

111 and in a few differentiated TH-expressing mDA neurons. At E14.5 and E15.5, expression was

112 found in a larger subset of mDA neurons, both in the forming SN and VTA (Supplemental

113 Figure 3). These data demonstrate that Bcl11a-expressing mDA neurons constitute a subset

114 of mDA neurons in the SN, VTA, RRF and CLi in the developing and adult brain.

Bc/11a-expressing mDA neurons contribute to several known subpopulations of mDA neurons

117 A number of recent studies have described several subtype markers for mDA neurons, such 118 as ALDH1A1, CALB1 and SOX6 (SRY-Box Transcription Factor 6). ALDH1A1 and CALB1 119 define complementary domains in the SNc (see introduction). In addition, ALDH1A1 is 120 expressed in the ventral VTA while CALB1 shows a wide-spread expression in the VTA 121 (Thompson et al., 2005; Wu et al., 2019). SOX6 expression is restricted to SN-mDA neurons 122 and to neurons of the lateral VTA (Panman et al., 2014; Poulin et al., 2018). Since Bcl11a123 expressing mDA neurons are broadly distributed within the mDA neuron-containing regions, 124 we next asked whether the Bcl11a positive mDA population falls in one of these characterized 125 subclasses. We used $B c / 11 a-l a c Z$ mice for this analysis and performed triple immunostaining 126 for $\beta$-gal, TH and the respective subset marker (ALDH1A1, CALB1 or SOX6) in the neonatal 127 (Figure 2A,B) and adult brain (Figure 2C,D). Triple labeling for $\beta$-gal, TH and CALB1 or $\beta$-gal, $128 \mathrm{TH}$ and SOX6 at P0 showed that $24.33 \%+/-3.810 \%$ of Bcl11a+ mDA neurons co-expressed 129 CALB1 and $41.53 \%+/-4.591 \%$ co-expressed SOX6 in the SN. In the VTA, 37.13\%+/$1303.883 \%$ of mDA neurons co-expressed CALB1 and $14.09 \%+/-1.771 \%$ co-expressed SOX6 131 at P0 (Figure 2E,F). At P30, triple labeling for $\beta$-gal, TH and CALB1 or ALDH1A1 showed that $13245.18 \%+/-5.903 \%$ of Bcl11a positive mDA neurons co-expressed CALB1 and 19.76\% +/$1331.342 \%$ co-expressed ALDH1A1 in the SN, while $71.09 \%+/-6.018 \%$ co-expressed CALB1 134 and $20.70 \%+/-3.337 \%$ co-expressed ALDH1A1 in the VTA (Figure 2G,H). Thus, the Bcl11a135 expressing mDA neurons do not clearly fall within one of these previously characterized mDA 136 subpopulations. Of note, even though Bc/11a-expressing mDA neurons are mainly localized 137 to the dorsal tier of the SNc and the SNI, which is typically characterized as CALB1-positive, 138 only about half of them express CALB1 in the adult brain.

140 Bc/11a-expressing mDA neurons form a subcircuit in the dopaminergic system

141 Next, we examined whether the Bcl11a-expressing subclass of mDA neurons contributes to 142 specific subcircuits in the mDA system. To investigate projection targets of $B c / 11 a$-expressing $143 \mathrm{mDA}$ neurons we used an intersectional genetic approach. This method combines a reporter 
144 allele or viral construct in which expression of a fluorescent reporter protein is driven by a

145 tetracycline response element (TRE) in a Cre-dependent manner (Madisen et al., 2015; Poulin

146 et al., 2018). To achieve specific activation of the reporter allele in mDA neurons we used a

$147 D a t^{t T A}$ (tetracycline trans-activator driven by the Dat promoter) mouse line in conjunction with

148 the Bc/11a ${ }^{\text {CreER }}$ mouse line (Chen et al., 2015; Poulin et al., 2018) and the intersectional

149 reporter mouse line Ai82D (Madisen et al., 2015) (Figure 3A,B). Since Bcl11a expression is

150 already restricted to subsets of $\mathrm{mDA}$ neurons in the developing brain (Supplemental Figure

151 3B-E), CreER was activated during embryogenesis by administering Tamoxifen to pregnant

152 females at E15.5. Distribution of the recombined (EGFP+) neurons in the adult brain was

153 similar to the distribution of Bc/11a-mRNA expressing mDA neurons or $\beta$-gal-expressing cells

154 in Bc/11a-lacZ mice at P0 and at P30 (Supplemental Figure 4; compare with Figure 1 and

155 Supplemental Figure 1). Analysis of the projection pattern established by the EGFP positive

156 fibers showed that the recombined mDA neurons establish a highly specific innervation pattern

157 in dopaminergic forebrain target areas. In target areas of VTA-mDA neurons (Morales and

158 Margolis, 2017), Bc/11a-expressing mDA neurons strongly innervated the OT and the ventral

159 and lateral shell of the NAc, but not the NAc core or the prefrontal cortex (Figure 3C-E and

160 data not shown). Moreover, Bc/11a-expressing mDA neurons showed a highly specific

161 projection pattern to the TS and the caudal DMS (Figure 3C-F). The TS is a known target of

$162 \mathrm{mDA}$ neurons in the SNI, while the DMS is innervated by mDA neurons in the medial SNc

163 (Lerner et al., 2015; Menegas et al., 2018; Poulin et al., 2018). Within these SN target areas,

164 the densest innervation originating from recombined mDA neurons was observed in the ventral

165 TS. Very sparse innervation was observed in the dorsolateral or rostral striatum.

166 In a next step, we investigated the projections of mDA neurons that express Bcl11a in the adult 167 brain to (1) clarify whether Bc/11a-expression defines the same subset of mDA neurons in the 168 embryonic and adult brain and (2) to clearly delineate the projection targets of Bcl11a169 expressing neurons in the SN versus Bc/11a-expressing neurons in the VTA. To restrict the 170 reporter activation to only Bcl11a-expressing neurons in either the SN or VTA, we introduced 171 reporter constructs by injecting recombinant adeno associated viruses (rAAV) into the SN or 172 VTA of adult animals. CreER was subsequently activated by the administration of Tamoxifen 173 to achieve recombination (Figure 4A,B; Supplemental Figure 5A,B). Here we took both an 174 intersectional approach, in which we introduced an intersectional reporter construct into $175 B c / 11 a^{C r e E R}$, Dat ${ }^{t T A}$ mice (Figure 4A,B) and a non-intersectional approach in which we delivered a Cre-dependent reporter construct in $B c / 11 a^{C r e E R}$ mice (Supplemental Figure 5A,B). Characterization of the VTA projection targets showed strong innervation of the OT and 178 the ventral and lateral shell of the NAc (Figure 4G-J, Supplemental Figure 5G-J), consistent 179 with the innervation pattern observed with the embryonic intersectional labeling (Figure 3). In 180 some animals $(n=7 / 10)$ in which VTA neurons were labeled more sparsely, the innervation 
181 pattern of Bc/11a-expressing VTA-mDA neurons in the OT showed a stripe-like pattern, 182 indicating that axons from single neurons might innervate specific domains within the OT

183 (Supplemental Figure 5I). Labeling of Bc/11a-expressing mDA neurons was scarcer in the 184 SN compared to the VTA (Figure 4C,D; Supplemental Figure 5C,D), consistent with a lower 185 percentage of Bc/11a-expressing mDA neurons in the SN than in the VTA (Figure 1; Figure 186 5). The sparse labeling allowed us to visualize patches of innervation likely derived from single SN axons (Brignani et al., 2020). These patches were restricted to the DMS and ventral TS, 188 consistent with the findings obtained with the embryonically-induced intersectional labeling of 189 Bc/11a-expressing neurons (Figure 3, Figure 4E,F; Supplemental Figure 5E,F). In 190 conclusion, these results show that Bcl11a expression defines a subset of mDA neurons in 191 embryogenesis and adulthood, which forms a highly specific subcircuit within the mDA system, 192 despite a broad anatomical distribution of this subset within the mDA territory.

193 Conditional gene inactivation of Bc/11a in mDA neurons results in a rostral-to-caudal shift of Bcl11a-mDA neurons from the VTA to the CLi

Since BCL11A is a transcription factor that has been shown to influence neuronal fate, neuronal morphology and migration (Simon et al., 2020), we investigated whether BCL11A is necessary for establishing and/or maintaining Bc/11a-expressing mDA neurons and their cell fate as well as their particular projection pattern. We generated a specific knock-out for Bc/11a in mDA neurons by crossing $B c / 11 a^{\text {flox }}$ mice with Dat ${ }^{\text {IRES-Cre }}$ mice (Bcl11a ckoflox; Genotype:

200 Dat ${ }^{I R E S-C r e /+}, B c / 11 a^{\text {flox/flox }}$ ) (Bäckman et al., 2006; John et al., 2012). In a subset of mice, we 201 introduced the $B c / 11 a^{l a c z}$ allele (a null allele, (Dias et al., 2016)) into the conditional knock-out 202 model (Bc/11a ckolacz; Genotype: Dat ${ }^{I R E S-C r e /+}, B c / 11 a^{\text {flox/lacz }}$ ) (Figure 5A). In Bc/11a ckolacz 203 mice, the $B c / 11 a$ expressing mDA population expresses $\beta$-gal even after inactivation of $B c / 11 a$, 204 giving us the possibility to analyze the effect of $B c / 11 a$ inactivation specifically in mDA neurons 205 that would normally express BCL11A (termed: Bcl11a-mDA neurons) (Figure 5B). To confirm 206 that Bcl11a expression was indeed absent in mDA neurons of Bcl11a ckoflox mice, we 207 performed immunostaining and RNAScope experiments showing that BCL11A protein 208 (Supplemental Figure 6) and Bcl11a mRNA (Supplemental Figure 7) were no longer 209 expressed in mDA neurons. On the other hand, as expected, Bcl11a was still expressed in 210 non-mDA neurons in the midbrain and the cerebral cortex (Supplemental Figure 6 and 7).

211 Despite the loss of BCL11A expression in mDA neurons, the anatomical organization of the $212 \mathrm{mDA}$ area in Bcl11a cko (both in $B c / 11 a$ cko $^{\text {flox }}$ and $B c / 11 a$ cko $^{\text {lacz }}$ ) mice was comparable to 213 controls (Figure 5C, D and data not shown). Quantification of the percentage of $\beta$-gal positive 214 TH neurons in the SN and VTA in PO Bcl11a ckolacZ and Bc/11-lacZ mice showed no significant 215 change in the number of Bcl11a-mDA neurons between mutant and control animals (Figure 
216 5E). However, at P30, the percentage of $\beta$-gal positive TH neurons was significantly decreased

217 in the VTA (average of three rostro-caudal levels corresponding to the levels in Supplemental

218 Figure $1 A, C, D)$ and significantly increased in the CLi (Figure 5F). When combining the

219 numbers of $\beta$-gal positive TH neurons for the CLi level and the three VTA levels, no significant

220 difference in the percentage of $\beta$-gal positive TH neurons could be detected between $B c / 11 a$

221 ckolacz and Bc/11-lacZ animals (Supplemental Figure 8A), indicating that the reduction of $\beta$ -

222 gal positive TH neurons in the VTA is likely due to a rostral-caudal shift in the position of

223 Bcl11a-mDA neurons rather than a loss of cells. To examine this further, we compared the

224 percentages of $\beta$-gal positive TH neurons at four rostral-caudal levels (three levels with VTA,

225 one level with $\mathrm{CLi}$ ). In addition to the significant increase in $\beta$-gal positive TH neurons in the

$226 \mathrm{CLi}$, we found that the percentage of $\beta$-gal positive TH neurons at the two rostral VTA levels

227 (level 1 and 2) was significantly decreased in Bc/11a ckolacz compared to control mice

228 (Supplemental Figure 8B). This resulted in a significant, systematic increase in the

229 percentage of $\beta$-gal positive TH neurons from rostral-to-caudal in Bcl11a ckolacz mice, while

230 there was a systematic decrease in $\beta$-gal positive TH neurons from rostral-to-caudal in control

231 animals (Supplemental Figure $\mathbf{8 C}$ ). The overall number of mDA neurons at the analyzed VTA

232 and CLi levels was not significantly different between $B c / 11 a \mathrm{cko}^{\mathrm{lacz}}$ and control mice (data not

233 shown). No significant change in the percentage of $\beta$-gal positive $\mathrm{TH}$ neurons could be

234 detected when comparing the rostral SN levels in control and Bcl11a ckolacz animals (data not

235 shown), suggesting that the rostro-caudal shift of Bcl11a-mDA neurons in Bc/11a ckolacz

236 animals is restricted to the VTA. Finally, stereological analysis of the total number of TH-

237 positive mDA neurons or Nissl-stained neurons in the SNc of 12 months old Bc/11a cko and

238 control mice did not show any evidence for cell loss in the Bc/11a cko mice (data not shown).

239 These data indicate that the specific inactivation of $B c / 11 a$ in mDA neurons does not interfere

240 with the generation or the survival of the Bcl11a-mDA neuronal population, but that it results

241 in altered rostral-caudal positioning of Bcl11a-mDA neurons in the VTA.

242 If BCL11A is important for determining the localization of $\mathrm{mDA}$ neurons, it may also influence

243 cell fate by regulating the expression of subset markers or the target specificity of Bcl11a-mDA

244 projections. Triple labeling for $\beta$-gal, TH and CALB1 at P0 and P30, for $\beta$-gal, TH and SOX6

245 at $\mathrm{P} 0$ and for $\beta$-gal, TH and ALDH1A1 at P30 and quantification of triple labeled cells in Bc/11a

$246 \mathrm{cko}^{\mathrm{lacz}}$ and control mice did not however reveal a significant change in the number of Bc/11a-

247 mDA neurons co-expressing these markers in $B c / 11 a$ cko ${ }^{\text {lacZ }}$ mice as compared to $B c / 11 a-l a c Z$

248 mice (Figure 6, compare with Figure 2). Next, we investigated whether inactivation of Bc/11a

249 affects the targeting of projections arising from Bcl11a-mDA neurons. To this end, we

250 examined the density of $\mathrm{TH}$ innervation in control and Bc/11a cko mice in the two areas with

251 the highest innervation density from Bcl11a-mDA neurons, the ventral TS and the OT. In

252 addition, we analyzed innervation density in the dorsal striatum and the dorsal TS. We found 
no significant difference in the density of the $\mathrm{TH}$ innervation in any of these areas when comparing control and Bcl11a cko mice (Supplemental Figure 8D-J). Taken together, these data suggest that the inactivation of $B c / 11 a$ and the resulting rostro-caudal shift in Bcl11a-mDA VTA neurons have no overt effect on the expression of known subset markers or the anatomical arrangement of Bcl11a-mDA projections.

\section{Inactivation of Bcl11a in mDA neurons results in motor learning deficits}

Inactivation of $B c / 11$ a results in a rostral-to-caudal shift of the anatomical position of Bcl11amDA neurons in the VTA, but not in the SN. To investigate whether the loss of Bcl11a leads to functional impairment in the mDA system, either as a consequence of the subtle anatomical changes in the VTA or by a direct impact on mDA function, we examined a range of behaviors in Bcl11a cko and control mice. We chose tests to assess potential mDA neuronal functions associated with VTA- and/or SN. In the open field, distance moved was not altered in Bc/11a cko mice as compared to controls, indicating that spontaneous motor behavior was not affected in the mutant mice (Figure 7A). Decreased dopamine release from the VTA is associated with anxiety- and depressive-like behavior, which can be assessed by monitoring the activity in the center of an open field (Yacoubi et al., 2003; Tye et al., 2013). Bc/11a cko mice did not show a change in the frequency of crossing into the center and time spent in center or border area in the open field, indicating that the Bcl11a cko mice did not have an increased level of anxiety or depressive behavior (Figure 7B,C). Since inhibition of VTA-mDA neurons has been shown to lead to a decreased preference for social novelty (Bariselli et al., 2018), we used a social recognition test to examine the ability of the Bc/11a cko mice to distinguish familiar and unfamiliar mice. We did not find a significant alteration in the behavior of Bcl11a cko mice as compared to control mice (data not shown). Next, we focused on tasks in which dopamine release from SN-mDA neurons is thought to play a prominent role. Dopamine release in the striatum is crucial for voluntary movement and motor skill learning (Dodson et al., 2016; Wu et al., 2019). Motor coordination and balance were examined by monitoring the ability of mice to cross a balance beam (Luong et al., 2011) and we found no difference in the performance of Bc/11a cko mice and control mice in this task (Figure 7 D). To examine whether motor skill learning is altered in Bcl11a cko mice, mice had to perform an accelerating rotarod test (Costa et al., 2004). In this task, control mice improved their performance over time, as reflected in a continuous increase in the time to fall over a 5-day

284 training period. In contrast, Bc/11a cko mice did not show any improvement in their performance over time, indicating that they were not able to learn this motor task within the trial period (Figure 7E). These results show that inactivation of $B c / 11 a$ in mDA neurons results in defects in skilled motor learning suggesting that mDA neurons may be functionally impaired in the absence of Bcl11a. 


\section{Loss of Bcl11a enhances neuronal vulnerability to $\alpha$-synuclein toxicity}

The next set of experiments was aimed at elucidating the role of BCL11A expression in the context of neuronal challenges and neurodegenerative processes affecting mDA neurons in the SNc. The protein $\alpha$-synuclein plays a key role in the pathogenesis of Parkinson's and other human neurodegenerative diseases (Goedert et al., 2013). Its overexpression in animal models is associated with Parkinson-like pathology, including the degeneration of SNc-mDA neurons (Ulusoy and Di Monte, 2012). Here, adult control $(n=5)$ and Bcl11a cko $(n=5)$ mice were challenged with a single intraparenchymal injection of rAAVs carrying the DNA for human a-synuclein (Figure 8A). The unilateral injection targeted the right SNc where it caused robust overexpression of human $\alpha$-synuclein within SNc-mDA neurons. No difference in overexpression was observed between control and Bcl11a cko mice after staining of SNcontaining midbrain sections with a specific antibody against human $\alpha$-synuclein (Figure 8B).

Midbrain sections were stained with a TH antibody, and immunoreactivity was compared in the left (intact side) and right (injected side) SNc of animals sacrificed 8 weeks after the rAAV injection. Labeling was overtly less robust in the lesioned right SNc of both control and Bc/11a cko mice. This loss of TH immunoreactivity appeared to be more pronounced, however, in sections from Bc/11a cko animals (Figure $\mathbf{8 C}$ ). The number of $\mathrm{TH}^{+}$neurons was then counted using a stereological method. Consistent with our previous quantification of Bcl11a-mDA neurons in Bcl11a cko and control animals (Figure 5), counts in the left (intact) SNc were similar between control and Bc/11a cko mice and were therefore averaged together as normal values $(5,988 \pm 79.4)$. Overexpression of $\alpha$-synuclein caused a $15 \%$ reduction of $\mathrm{TH}^{+}$cells in the lesioned right SNc of control mice, with cell counts averaging 5,086 \pm 292 . 8 . This loss was significantly more pronounced (4,231 \pm 208.2 cells) in Bcl11a cko mice (Figure 8D). The possibility that the decrease in neuronal counts after rAAV injection may reflect a downregulation of the phenotypic marker used for cell identification (i.e. $\mathrm{TH}$ ) rather than actual cell degeneration was ruled out by counting the total number of Nissl-stained neurons. This number declined by $12 \%$ (from $9,185 \pm 141.4$ to $8,070 \pm 525.6$ ) and $27 \%$ (to $6,741 \pm 326.1$ ) in the lesioned SNc of control and Bcl11a cko mice, respectively (Figure 8E). These findings reveal that vulnerability to $\alpha$-synuclein toxicity is markedly enhanced in the absence of $B c / 11 a$, supporting the notion that Bc/11a expression is associated with transcription of genetic information involved in neuroprotective pathways. were carried out in $B c / 11 a c^{c k} o^{\operatorname{lacz}}(n=4)$ and $B c / 11 a^{\text {floxllacz }}$ control $(n=4)$ mice. Similar to the results in $B c / 11 a$ animals without the lacZ allele, $\alpha$-synuclein toxicity caused a more severe 
3,349 \pm 193.3 cells) as compared to $B c / 11 a^{\text {floxllacz }}$ controls (from 5,906 to $5,114 \pm 47.9$ cells)

325 (Figure 8F, "total" values). In Bc/11 $a^{\text {flox/lacz }}$ mice, confocal stereological counts were able to 326 distinguish the effects of $\alpha$-synuclein overexpression on Bcl11a-expressing SNc-mDA neurons

327 (i.e. neurons that were both $\mathrm{TH}^{+}$and $\beta-g l^{+}$) vs. SNc-mDA devoid of $\mathrm{Bcl11a}$ (i.e. neurons that 328 were $\mathrm{TH}^{+}$but $\beta$-gall ${ }^{-}$). In these animals, counts of $\beta$-gal-positive and $\beta$-gal-negative mDA cells 329 revealed that $29 \%$ (from $1,919 \pm 78.3$ to $1,365 \pm 113.1$ cells) of Bcl11a-expressing cells 330 degenerated (Figure 8F, " $\beta$-gal(+)" values), whereas only 6\% (from 3,986 \pm 111.5 to 3,748 \pm 33195.1 cells) of $\beta$-gal-negative neurons were lost as a result of $\alpha$-synuclein overexpression 332 (Figure 8F, " $\beta-g a l(-)$ " values). These data indicate that Bcl11a expression characterizes a 333 subpopulation of nigral DA neurons highly susceptible to $\alpha$-synuclein-induced damage.

334 The number of $\beta$-gal-positive and $\beta$-gal-negative neurons was then counted in SNc of $B c / 11 a$ 335 ckolacz animals. Results showed more dramatic toxic effects, since $\alpha$-synuclein toxicity killed 336 almost $65 \%$ (from 1,919 to $664 \pm 117.0$ cells) of $\beta$-gal-positive (Figure 8F, " $\beta$-gal(+)" values) 337 and $33 \%$ (from 3,986 to $2,685 \pm 91.4$ cells) of $\beta$-gal-negative cells (Figure $8 \mathbf{F}$, " $\beta$-gal(-)" 338 values). Thus, in the absence of Bcl11a expression, $\beta$-gal-positive cells became even more 339 vulnerable to neurodegeneration, consistent with a protective role of Bc/11a-mediated 340 transcription. Interestingly, in $B c / 11 a c^{~} o^{\text {lacz }}$ mice, a more severe neurodegenerative effect was 341 observed not only on $\beta$-gal-positive but also $\beta$-gal-negative neurons. This latter finding 342 suggests that inactivation of Bc/11a expression may have cell non-autonomous effects and 343 result in widespread deleterious consequences for nigral tissue integrity.

Discussion

\section{Expression of Bcl11a defines a previously uncharacterized subset of mDA neurons}

347 mDA neurons are diverse in their gene expression, their anatomical location, their projection 348 targets, their electrophysiological and functional properties (Farassat et al., 2019; Morales and 349 Margolis, 2017; Poulin et al., 2020; Roeper, 2013). The link between anatomical position, gene 350 expression, projection target and function has come more and more into focus in recent years. 351 Several studies have shown that subsets of mDA neurons that share the expression of specific markers have also specific projection targets in the forebrain (Bimpisidis et al., 2019; Khan et al., 2017; Kramer et al., 2018; Poulin et al., 2018). Based on the currently available single-cell gene expression studies, it has been proposed that there are at least 7 molecularly defined mDA subgroups. Two of these subgroups are restricted to the $\mathrm{SN}$, one encompasses cells in the SNc, RRF and lateral VTA, one is restricted to the linear nucleus and the remaining three are distributed in the medioventral VTA (Poulin et al., 2020). How and whether such subsets are already defined during development remains however unclear. Here we show that the transcription factor BCL11A defines a subpopulation of $\mathrm{mDA}$ neurons starting in 
embryogenesis and throughout adulthood. Bcl11a-mDA neurons are widely distributed within the anatomically defined mDA nuclei, comprising about $40 \%$ of the VTA-mDA neurons and about $25 \%$ of the SN-mDA neurons. The Bcl11a-mDA population does not clearly fall into one of the molecularly defined populations described above (Poulin et al., 2020). Strikingly, despite the broad distribution of Bcl11a-mDA neurons across different anatomical and molecularly defined mDA subpopulations, Bcl11a-mDA neurons establish a highly selective innervation pattern within the mDA projection targets.

Bcl11a-mDA neurons form a highly specific subset in the midbrain dopaminergic system

370 Dopaminergic subcircuits may encode a precise behavioral output by targeting a set of 371 substructures within the classical dopaminergic projection targets and a number of studies 372 have shown that specific subcircuits within the mDA system regulate very specific aspects of behavior (Engelhard et al., 2019; Heymann et al., 2020; Menegas et al., 2018). Whether such behavioral modules are consistent with genetically determined populations is just starting to be examined (Heymann et al., 2020).

376 Bcl11a-mDA of the VTA project to the medial and ventral shell of the NAc and the OT while Bcl11a-mDA of the SN show a highly selective innervation of the ventral TS and the caudal DMS. This specific innervation pattern suggests that this genetically defined subpopulation may modulate a specific subset of dopamine-influenced behaviors.

380 From an evolutionary standpoint, the mDA system may consist of different modules with different functions that were built on top of a basic DA system mainly concerned with basic behavior just as food-seeking and reward behavior (Schultz, 2019). If there are such modules one would expect that they are genetically defined by the expression of specific transcription factors or sets of transcription factors. Bcl11a could potentially define such a behavioralanatomical module and it will be interesting to investigate in the future whether mDA neurons that are characterized by Bc/11a-expression in the SN and VTA form such a functional module within the mDA system.

\section{Function of BCL11A in developing and mature mDA neurons}

$B C L 11 \mathrm{~A}$ is a zinc finger transcription factor that acts mainly as a repressor but it is also part of an ATP dependent chromatin remodeling complex in neural tissue. Bcl11a is expressed in many types of neurons in almost every region of the CNS (Allen Brain Atlas), but its molecular

393 function has only been studied in a few regions so far (Simon et al., 2020). In the cortex, 394 BCL11A is important for the specification of cortical neurons that project to subcerebral areas 395 (Canovas et al., 2015; Woodworth et al., 2016) and it controls the acquisition of sensory area 396 identity and the establishment of sensory input fields (Greig et al., 2016). Moreover, BCL11A 
regulates the migration of cortical projecting neurons (Wiegreffe et al., 2015). In the dorsal spinal cord, BCL11A is required for neuronal morphogenesis and sensory circuit formation (John et al., 2012). Whether it functions purely as a transcriptional repressor or also as part of the chromatin remodeling complex in these neurons remains to be investigated. In mDA neurons, the inactivation of $B c / 11 a$ resulted in a rostral-to-caudal shift of Bcl11a-mDA cell bodies, suggesting that $B C L 11 \mathrm{~A}$ might play a role in regulating the expression of factors that control the migration of VTA-mDA neurons. In the cerebral cortex, BCL11A regulates cortical neuron migration by controlling the expression of the cell adhesion molecule Semaphorin $3 \mathrm{c}$ (Wiegreffe et al., 2015), but Semaphorin 3c is not expressed in mDA neurons (Kolk et al., 2009). Thus, it will be of great interest to investigate which other molecules are regulated by BCL11A in developing mDA neurons, in particular because little is known about the mechanisms underlying the migration of VTA-mDA neurons (Brignani and Pasterkamp, 2017). While the changes in cell body positioning appear to be restricted to the VTA, the loss of BCL11A results in SN-mDA neurons, which are functionally compromised and are more susceptible to neurodegeneration in the absence of $B C L 11 A$ as evident from the results of the behavioral analysis and the $\alpha$-synuclein overexpression experiments. The deficits in SN-mDA neurons demonstrate a novel role for BCL11A in regulating neuronal function and vulnerability that appears to be independent of its previously characterized role in cell fate specification. Whether the effect of BCL11A on SN-mDA neurons is a consequence of BCL11A acting during the development of mDA neurons by altering their molecular and functional profile and/or whether BCL11A regulates the function and vulnerability of mDA neurons acutely in the adult brain cannot be discerned from the current study. Given that BCL11A appears to be continuously expressed in the same mDA subpopulation starting soon after mDA differentiation and throughout adulthood, a role of BCL11A during mDA development seems likely. However, only the analysis of a mouse model, in which Bc/11a is inactivated in mDA neurons during adulthood, will address this point conclusively. In humans, pathogenic variants of BCL11A (mostly de novo mutations) result in 424 neurodevelopmental disorders that have recently been classified as BCL11A-related 425 intellectual disability (Peron et al., 2019). This syndrome is characterized by general 426 developmental delay, microcephaly, speech delay and behavioral problems as well as a 427 number of non-CNS related phenotypes. In some affected individuals, seizures or autism spectrum disorder have been reported (Peron et al., 2019). Given the widespread expression of $B C L 11 A$ in the brain, it is unclear if any of these neurological symptoms in patients are associated with functional deficits in the dopaminergic system. Moreover, there are no reports

431 of neurodegenerative phenotypes, but long-term observations of patients or case studies in 432 adult or aged patients are not available, due to the limited number of cases reported and the 433 bias towards diagnosis in childhood (Peron et al., 2019). 


\section{Consequences of Bcl11a-inactivation in mDA neurons on behavior}

436 Bcl11a cko mice show a defect in the learning of skilled motor behavior while spontaneous 437 motor behavior or motor coordination is not affected. Since Bc/11a is specifically inactivated in 438 mDA neurons in our mouse model, this particular behavioral phenotype must be caused by 439 functional changes in mDA neurons (rather than by deficits in the cerebellum or motor cortex 440 (Hikosaka et al., 2002; Li et al., 2017). Due to the highly specific innervation pattern of Bcl11a$441 \mathrm{mDA}$ neurons in the forebrain and the fact that Bcl11a-mDA neurons comprise only a subset 442 of mDA neurons, we were not able to address the nature of these functional changes, but we 443 assume that they ultimately result in altered dopamine release in the target areas of Bcl11a$444 \mathrm{mDA}$ neurons and that these alterations are severe enough to elicit a behavioral phenotype.

445 Learning of motor skills is thought to be mediated by dopamine release in the dorsal striatum. 446 It has been proposed that the plasticity in striatal medium spiny neurons that underlies initial skill learning during goal-directed actions requires dopamine release in the DMS, while dopamine release in the dorsolateral striatum (DLS) is important for optimal skill learning (the learning of sequential actions until a point is reached at which they can be performed with little effort or attention (Durieux et al., 2012; Graybiel, 2008). Based on this model and our observation that Bcl11a-mDA neurons in the SNc project to the DMS but not the DLS, the deficit in motor learning should have its origin in the inability of the mice to initiate the learning of skilled motor behavior. Interestingly, the ablation of Aldh1a1-expressing mDA neurons leads

454 to an impairment in motor skill learning on the rotarod that is similar to the one observed in Bcl11a cko mice even though Aldh1a1-expressing neurons project almost exclusively to the DLS (Wu et al., 2019). Thus, it is possible that reduced dopamine release in both DMS and DLS and thus defects in both phases of learning lead to a similar overall defect in the acquisition of skill learning.

459 Finally, we cannot completely exclude that impaired dopamine release from Bcl11a-mDA 460 neurons in the VTA may play a role in the inability of the Bc/11a cko mice to perform on the 461 rotarod since they might be less motivated to perform the task. However, the mice did not show 462 any deficits in any of the other tasks (balance beam, social recognition, open field) suggesting 463 that a deficit in motivated behavior is unlikely to be the cause of the inability to learn the rotarod 464 task.

\section{Vulnerability of Bcl11a neurons to degeneration}

467 The mDA neurons in the ventral tier of the SNc is the one most vulnerable to 468 neurodegeneration in Parkinson's disease and animal models of the disease (Kordower et al., 469 2013). Based on studies in rodents, this population appears to coincide with ALDH1A1- 
expressing mDA neurons (Poulin et al., 2014). Here we demonstrate that BCL11A neurons are highly susceptible to neurodegeneration in an a-synuclein overexpression model, even though only a small percentage overlaps with ALDH1A1-expressing mDA neurons. Our data suggest that BCL11A serves as a marker of highly vulnerable mDA neurons, which are located primarily in the dorsal tier of the SNc and project to the caudal DMS. The DMS corresponds roughly to the caudate nucleus in the human brain (Burton et al., 2015). Dopaminergic deficits within the striatum are unevenly distributed in Parkinson's disease patients and in general, neuroimaging studies show that the posterior putamen (corresponding to the DLS in rodents) has a more severe dopamine dysfunction than the caudate nucleus (Kish et al., 1988). This gradient of dopaminergic deficiency has been reported to be already apparent at early disease stages and to be largely maintained over the course of the disease (Nandhagopal et al., 2009). Nevertheless, some of the early symptoms associated with Parkinson's disease are assumed to be based on functional deficits of the caudate nucleus (REM sleep disorder, gait problems) and the most dorsorostral part of the caudate nucleus has been reported to have a strong reduction in dopamine levels in Parkinson's disease patients. A recent study thus re-examined the involvement of dopamine deficiencies in the early stage of Parkinson's disease and found a significant dopaminergic de-innervation of the caudate nucleus in about half of the patients (Pasquini et al., 2019). BCL11A is expressed in human mDA neurons (La Manno et al., 2016), but further studies will be necessary to evaluate which subpopulations express this transcription factor and whether the reduced dopaminergic innervation of the caudate nucleus in Parkinson's disease may be associated with a specific loss of BCL11A-expressing mDA neurons in patients.

While Bcl11a-mDA neurons are more susceptible to a-synuclein induced degeneration, $\mathrm{BCL} 11 \mathrm{~A}$ also acts as a neuroprotective factor in this population, since the loss of Bcl11a-mDA neurons is significantly more severe in Bcl11a ckolacZ mice than in Bcl11a-lacZ mice. A similar phenomenon has been observed for the ALDH1A1 expressing population: inactivation of ALDH1A1 increases the vulnerability of this population to neurodegeneration (Liu et al., 2014). This could be due to the particularly high vulnerability of these populations rather than to a specific function of these factors: any additional insult (i.e. loss of ALDH1A1 or BCL11A 499 function) during development or in the adult brain increases their vulnerability even further. 500 Alternatively, BCL11A could be modulating cell survival more directly, since it has been shown 501 to regulate expression of the anti-apoptotic factor $\mathrm{Bcl} 2$ in early B-lymphocytes and inactivation of $B c / 11 a$ in cortical projections neurons results in increased cell death in addition to deficits in migration and cell fate specification (Yu et al., 2012; Wiegreffe et al., 2015). 


\section{Mouse lines}

Bc/11alacz mice (Dias et al., 2016) were kindly provided by Pengtao Liu, School of Biomedical Sciences, The University of Hong Kong, China. Bcl11 flox mice (Wiegreffe et al., 2015) were kindly provided by Pengtao Liu, School of Biomedical Sciences, The University of Hong Kong, China; and Neal Copeland, Institute for Academic Medicine, Houston Methodist and obtained from Stefan Britsch, University of Ulm. Bcl11 ${ }^{C r e E R}$ mice (Pensa et al., under revision) were kindly provided by Walid Khaled, Department of Pharmacology, University of Cambridge. Bcl11a cko mice were generated by crossing Dat ${ }^{\text {IRES-Cre }}$ mice (Bäckman et al., 2006) with $B c / 11 a^{\text {flox }}$ mice (Genotype: Dat ${ }^{\text {RES-Cre/+}}, B c / 11 a^{\text {flox/flox }}$ ). In a subset of Bcl11a cko mice, the $B c / 11 a^{l a c z}$ null allele was introduced by crossing Dat ${ }^{\text {IRES-Cre }}$ mice with $B c / 11 a^{\text {flox/lacz }}$ mice (Genotype: Dat ${ }^{\text {RES-Cre/+ }}, B c / 11 a^{\text {flox/lacz }}$ ). Intersectional fate mapping experiments were performed by crossing $B c / 11 a^{C r e E R}$ mice with the Dat ${ }^{t T A}$ (tetracycline trans-activator driven by the Dat promoter) mouse line (Chen et al., 2015) and the intersectional reporter mouse line Ai82D (Ai82(TITL-GFP)-D (Madisen et al., 2015)) (Genotype: Bcl11a ${ }^{\mathrm{CreER/+}}$, Dat ${ }^{\mathrm{tTA}+\mathrm{t}}$ Ai82D ${ }^{T I T L-}$ ${ }^{G F P /+}$ ). For viral tracings, $B c / 11 a^{\mathrm{CreER/+}}$ or $\mathrm{Bc} 111 \mathrm{a}^{\mathrm{CreER/+}}$, Dat ${ }^{\mathrm{TA} /+}$ (intersectional) were used. Mice were housed in a controlled environment, with $12 \mathrm{hr}$ light/night cycles and ad libitum availability of food and water. Day of vaginal plug was recorded as E0.5. All experiments were performed in strict accordance with the regulations for the welfare of animals issued by the Federal Government of Germany, European Union legislation and the regulations of the University of Bonn. The protocol was approved by the Landesamt für Natur, Umwelt und Verbraucherschutz Nordrhein-Westfalen (Permit Number: 84-02.04.2014.A410, 84-02.04.2016.A238 and 8412.04.2015.A550).

\section{Tamoxifen administration}

530 Tamoxifen was administered by oral gavage to pregnant dams at E15.5 $(0.05 \mathrm{ml} / 10 \mathrm{~g}$ body 531 weight) or to adult mice $(0.075 \mathrm{ml} / 10 \mathrm{~g}$ body weight) to label Bc/11a-expressing neurons.

532 Tamoxifen (Sigma Aldrich) was prepared as a $20 \mathrm{mg} / \mathrm{mL}$ solution in corn oil (Sigma Aldrich).

\section{Tissue processing}

535 Pregnant females were sacrificed by cervical dislocation. Embryos were transferred into in ice 536 cold PBS, decapitated and dissected. P0 pups were decapitated and their brain dissected in 537 ice cold PBS. Heads (E12.5 - E15.5) or brains (P0) were fixed in 4\% paraformaldehyde (PFA) 538 overnight at $4^{\circ} \mathrm{C}$. Adult mice were anesthetized with an intraperitoneal injection of 539 Ketanest/Rampun or pentobarbital and subsequently perfused transcardially with phosphate 540 buffered saline (PBS), followed by 4\% PFA. The tissue was cryopreserved in OCT Tissue Tek 541 (Sakura). Embryonic and P0 tissue was cryosectioned at $14 \mu \mathrm{m}$ thickness and collected on 
542 glass slides, adult brains were cryosectioned at $40 \mu \mathrm{m}$ thickness and free-floating sections

543 were collected in anti-freeze solution.

544 For immunofluorescent staining, sections were re-fixed in 4\% PFA for $10 \mathrm{~min}$ at room 545 temperature (RT) and incubated in 10\% NDS in PBS plus 0.2\% Triton X-100 (Sigma-Aldrich) 546 (0.2\% PBT, used for embryonic and P0 tissue) or in $10 \%$ NDS in $0.5 \%$ PBT (adult tissue) for $5471 \mathrm{hr}$ at RT. Sections were incubated with primary antibody overnight at $4^{\circ} \mathrm{C}$ in $3 \% \mathrm{NDS}$ in $0.2 \%$ 548 PBT (embryonic and P0 tissue) or in 3\% NDS in $0.3 \%$ PBT (adult tissue). For staining with the 549 guinea pig anti-BCL11A antibody and in some cases for rabbit anti-TH antibody (Table 1) 550 sections were incubated in the primary antibody for $72 \mathrm{hr}$ at RT (guinea pig anti-BCL11A) or 551 at $4^{\circ} \mathrm{C}$ (rabbit anti-TH antibody). Sections were washed 3 times for $5-10$ min in $0.2 \%$ PBT 552 (embryonic and P0 tissue) or in 0.3\% PBT (adult tissue) and incubated for $2 \mathrm{hr}$ at RT in 553 secondary antibody in 3\% NDS in $0.2 \%$ PBT (embryonic and P0 tissue) or in $3 \%$ NDS in $0.3 \%$ 554 PBT (adult tissue). Sections were washed 3 times for 5-10 min in 0.2\% PBT (embryonic and 555 P0 tissue) or in 0.3\% PBT (adult tissue) and mounted with Aqua Polymount (Polysciences 556 Inc.). For the detection of BCL11A, biotinylated donkey anti-guinea pig antibody followed by 557 Cy3-Streptavidin was used.

558 Processing of tissue from mice overexpressing $\alpha$-synuclein involved post-fixation with $4 \%$ PFA 559 for $24 \mathrm{hr}$ followed by cryopreservation in $30 \%$ sucrose solution. Sections were cut at $35 \mu \mathrm{m}$ 560 thickness using a freezing microtome. Staining of these sections followed previously described 561 protocols (Helwig et al. 2016).

562 A list of primary and secondary antibodies is provided in Table 1.

Table1

\begin{tabular}{|c|c|c|c|}
\hline Antibody & Source & Identifier & Dilution \\
\hline goat anti- $\beta-$ gal & $\begin{array}{l}\text { Biogenesis, } \\
\text { Kinsgton,NH, } \\
\text { USA }\end{array}$ & $\begin{array}{l}\text { Validated in (Alvarez-Bolado et al., } \\
\text { 2012) }\end{array}$ & $\begin{array}{l}\text { IHC: } \\
1: 2000\end{array}$ \\
\hline $\begin{array}{l}\text { guinea pig anti- } \\
\text { BCL11A }\end{array}$ & $\begin{array}{l}\text { First described in } \\
\text { John et al. } 2012\end{array}$ & & $\begin{array}{l}\text { IHC: } \\
1: 2500\end{array}$ \\
\hline $\begin{array}{l}\text { mouse anti- } \\
\text { human } \alpha- \\
\text { synuclein }\end{array}$ & $\begin{array}{l}\text { Merck, Darmstadt, } \\
\text { DE }\end{array}$ & RRID: AB_310817 & $\begin{array}{l}\text { IHC: } \\
1: 20,000\end{array}$ \\
\hline mouse anti-TH & $\begin{array}{l}\text { Merck, Darmstadt, } \\
\text { DE }\end{array}$ & RRID:AB 2201528 & IHC: $1: 500$ \\
\hline $\begin{array}{l}\text { rabbit anti- } \\
\text { ALDH1A1 }\end{array}$ & $\begin{array}{l}\text { Sigma-Aldrich, St. } \\
\text { Louis, MO, USA }\end{array}$ & RRID:AB 1844722 & $\begin{array}{l}\text { IHC: } \\
1: 1000\end{array}$ \\
\hline $\begin{array}{l}\text { rabbit anti- } \\
\text { Calbindin }\end{array}$ & $\begin{array}{l}\text { Swant, Herford, } \\
\text { DE }\end{array}$ & RRID:AB 2314067 & $\begin{array}{l}\mathrm{IHC}: \\
1: 5000\end{array}$ \\
\hline rabbit anti-RFP & $\begin{array}{l}\text { Rockland-inc, } \\
\text { Hamburg, DE }\end{array}$ & RRID:AB 2209751 & $\begin{array}{l}\text { IHC: } \\
1: 1000\end{array}$ \\
\hline
\end{tabular}




\begin{tabular}{|c|c|c|c|}
\hline $\begin{array}{l}\text { rabbit anti- } \\
\text { SOX6 }\end{array}$ & $\begin{array}{l}\text { Abcam, } \\
\text { Cambridge, UK }\end{array}$ & RRID:AB 1143033 & IHC: $1: 500$ \\
\hline rabbit anti-TH & $\begin{array}{l}\text { Merck, Darmstadt, } \\
\text { DE }\end{array}$ & RRID:AB 390204 & $\begin{array}{l}\text { IHC: } 1: 500- \\
1: 1000\end{array}$ \\
\hline rat anti-GFP & $\begin{array}{l}\text { Nalacai Tesque, } \\
\text { Kyoto, JP }\end{array}$ & RRID:AB 10013361 & $\begin{array}{l}\text { IHC: } \\
1: 2000\end{array}$ \\
\hline $\begin{array}{l}\text { Cy3- } \\
\text { Streptavidin }\end{array}$ & $\begin{array}{l}\text { Jackson } \\
\text { ImmunoResearch, } \\
\text { Ely, } \\
\text { Cambridgeshire, } \\
\text { UK }\end{array}$ & RRID:AB 2337244 & $\begin{array}{l}\text { IHC: } \\
1: 1000\end{array}$ \\
\hline $\begin{array}{l}\text { donkey anti- } \\
\text { goat Cy3 }\end{array}$ & $\begin{array}{l}\text { Jackson } \\
\text { ImmunoResearch, } \\
\text { Ely, } \\
\text { Cambridgeshire, } \\
\text { UK }\end{array}$ & RRID:AB 2307351 & IHC: $1: 500$ \\
\hline $\begin{array}{l}\text { donkey anti- } \\
\text { guinea pig } \\
\text { Biotin }\end{array}$ & $\begin{array}{l}\text { Jackson } \\
\text { ImmunoResearch, } \\
\text { Ely, } \\
\text { Cambridgeshire, } \\
\text { UK }\end{array}$ & RRID:AB 2340451 & IHC: $1: 200$ \\
\hline $\begin{array}{l}\text { donkey anti } \\
\text { mouse-Alexa } \\
488\end{array}$ & $\begin{array}{l}\text { Thermo Fischer } \\
\text { Scientific, } \\
\text { Waltham, MA, } \\
\text { USA }\end{array}$ & RRID:AB 141607 & IHC: $1: 500$ \\
\hline $\begin{array}{l}\text { donkey anti } \\
\text { mouse-Alexa } \\
647\end{array}$ & $\begin{array}{l}\text { Thermo Fischer } \\
\text { Scientific, } \\
\text { Waltham, MA, } \\
\text { USA }\end{array}$ & RRID:AB 162542 & IHC: $1: 500$ \\
\hline $\begin{array}{l}\text { donkey anti } \\
\text { rabbit-Alexa } \\
488\end{array}$ & $\begin{array}{l}\text { Thermo Fischer } \\
\text { Scientific, } \\
\text { Waltham, MA, } \\
\text { USA }\end{array}$ & RRID:AB 2535792 & IHC: $1: 500$ \\
\hline $\begin{array}{l}\text { donkey anti } \\
\text { rabbit-Alexa } \\
546\end{array}$ & $\begin{array}{l}\text { Thermo Fischer } \\
\text { Scientific, } \\
\text { Waltham, MA, } \\
\text { USA }\end{array}$ & RRID:AB 2534016 & IHC: $1: 500$ \\
\hline $\begin{array}{l}\text { donkey anti } \\
\text { rabbit-Alexa } \\
647\end{array}$ & $\begin{array}{l}\text { Thermo Fischer } \\
\text { Scientific, } \\
\text { Waltham, MA, } \\
\text { USA }\end{array}$ & RRID:AB 2536183 & IHC: $1: 500$ \\
\hline $\begin{array}{l}\text { donkey anti rat- } \\
\text { Alexa } 488\end{array}$ & $\begin{array}{l}\text { Thermo Fischer } \\
\text { Scientific, } \\
\text { Waltham, MA, } \\
\text { USA }\end{array}$ & RRID:AB 2535794 & IHC: $1: 500$ \\
\hline
\end{tabular}

\section{RNAScope}

567 RNA in situ hybridization on frozen sections from P0 and adult mice was performed using 568 RNAscope Fluorescent Multiplex Detection Reagents (323110, ACDBio, Newark, CA, USA) 569 according to the instructions provided by the manufacturer for frozen tissue (User Manual: $570323100-U S M)$. Hybridized probe was detected with TSA Plus Cyanine 3 (NEL760001KT,

571 Perkin Elmer, Waltham, MA, USA). The probe for Bcl11a was designed by ACDBio (Cat No. 
563701-C3). Sections were counterstained with TH and Hoechst, then mounted with Aqua Polymount (Polysciences Inc., Warrington, PA, USA ).

\section{Stereotactic viral vector injection}

576 Viral tracing

$B c / 11 a^{\text {CreER }}$ and $B c / 11 a^{\text {CreER }}$, Dat ${ }^{\text {tTa }}$ mice (4-20 weeks old) were anesthetized with solution (AAV1/2-EF1 $\alpha-p T R E-F L E X-C h E T A-e Y F P$ or AAV1/2-EF1 $\alpha$-DIO-ChR2-eYFP (both

580 from UKB viral core facility, Bonn, DE) or AAV1/2-EF1a-DIO-ChR2-mCherry (Addgene, 581 Watertown, MA, USA)) was injected unilaterally into the SNc (from Bregma: anteroposterior

582 (AP), -2.3 mm; mediolateral (ML), $-1.1 \mathrm{~mm}$; dorsoventral (DV), $-4.1 \mathrm{~mm}$ ) or into the VTA (from 583 Bregma: AP, $-3.44 \mathrm{~mm}$; ML, $-0.48 \mathrm{~mm}$; DV, $-4.4 \mathrm{~mm}$ ) by. A $34 \mathrm{~g}$ beveled needle (WPI) and a 584 microinjection pump (WPI) were used to control the injection speed (100 nl/min). After the injection, the syringe was kept in place for $3 \mathrm{~min}$ and slowly retracted over $1 \mathrm{~min} .8$ days after viral injections, Tamoxifen was administered to the mice by oral gavage $(0.075 \mathrm{ml} / 10$ body weight) for 3 consecutive days. Two weeks after the last Tamoxifen administration, mice were perfused.

\section{Alpha-Synuclein overexpression}

591 Recombinant adeno-associated viral particles (serotype 2 genome and serotype 6 capsid)

592 were used to express human $\alpha$-synuclein in the mouse substantia nigra. Gene expression was controlled by the human Synapsin 1 promoter and enhanced using a woodchuck hepatitis virus post-transcriptional regulatory element and a polyA signal downstream to the a-synuclein sequence. AAV-vector production, purification, concentration, and titration were performed by Sirion Biotech (Martinsried, Germany). Mice were treated with a single $1.5 \mu$ injection of $4.0 \times 10^{12}$ genome copies $/ \mathrm{ml}$ using a stereotaxic frame with a mouse adapter (Stoelting, Wood Dale, IL, USA) under isoflurane anesthesia. Stereotaxic coordinates were $2.3 \mathrm{~mm}$ posterior and $1.1 \mathrm{~mm}$ lateral to bregma; injection depth was $4.1 \mathrm{~mm}$ relative to dura mater. The injection was made at a rate of $0.4 \mu \mathrm{l} / \mathrm{min}$ using a Hamilton syringe fitted to a glass capillary. The capillary was left in position for an additional 5 mins before being retracted.

\section{Image acquisition}

604 Images of fluorescently stained images were acquired at an inverted Zeiss AxioObserver Z1 605 equipped with structured illumination (ApoTome) and a Zeiss AxioCam MRm (Carl Zeiss, 606 Oberkochen, DE). At 10X (EC PInN 10x/0.3, Carl Zeiss, Oberkochen, DE) magnification, tile 607 images were acquired with conventional epifluorescence. At 20X (EC PInN 20x/0.5, Carl Zeiss, 608 Oberkochen, DE), 40X (PIn Apo 40x/1.3 Oil, Carl Zeiss, Oberkochen, DE) and 63X (PIn Apo 
$60963 x / 1.4$ Oil, Carl Zeiss, Oberkochen, DE) magnifications, structured illumination was used to

610 acquire tile images and z-stacks. Some of the images taken with the 20X objective and all the

611 images taken with the $40 \mathrm{X}$ and $63 \mathrm{X}$ objective are maximum intensity projections of z-stacks.

612 Tile images were stitched with Zen blue software (Zeiss, 2012).

613 Brightfield images were visualized with a Zeiss Axio Scope.A1 microscope, collected using 614 AxioCam 503 Color and processed with Zen blue software (Zen lite, 2019).

615 In situ hybridized sections at adult stages were imaged at an inverted Zeiss AxioObserver 616 equipped with a CSU-W1 Confocal scanner unit (50 $\mu \mathrm{m}$ pinhole disk, Yokogawa, Tokyo, JP). 617 At 40X (C-Apochromat, 40x/1.2 water, Zeiss) magnification, tile images and z-stacks were 618 acquired with laser lines $405 \mathrm{~nm}, 488 \mathrm{~nm}$ and $561 \mathrm{~nm}$. Images taken with the 40X objective 619 are maximum intensity projections of z-stacks. Tile images were stitched with VisiView 620 software (Visitron Systems, Puchheim, DE).

\section{Quantification of cell numbers}

$622 \mathrm{TH}^{+} \beta$-gal ${ }^{+}$neurons and additional subset markers

623 The percentage of Bcl11a-expressing mDA neurons in SN or VTA at P0 and P30 was 624 determined by quantifying $\mathrm{TH}^{+} \beta$-gal ${ }^{+}$neurons at four (P0) or three (P30) rostrocaudal midbrain 625 levels (Franklin and Paxinos, 2007). $\mathrm{TH}^{+} \beta$-gal ${ }^{+}$neurons in CLi and RRF in the adult brain 626 were analyzed separately from neurons in the SN or VTA. The number of $\mathrm{TH}^{+} \beta-$ gal ${ }^{+}$neurons 627 was counted unilaterally in the SN, VTA, RRF and CLi and normalized for the total number of $628 \mathrm{mDA}$ neurons per region separately. The analysis was performed on $\mathrm{n}=5 \mathrm{Bc} / 11 \mathrm{a}-\mathrm{lacZ}$ control 629 mice and $n=5 B c / 11 a$ cko ${ }^{\text {lacZ }}$ mice at $P 0$, and on $n=6 B c / 11 a-l a c Z$ (control) mice and $n=6 B c / 11 a$ $630 \mathrm{cko}^{\text {lacz }}$ mice at P30. The percentage of $B c / 11 a$-expressing mDA neurons co-expressing 631 additional subtype markers (SOX6 and CALB1 at P0; CALB1 and ALDH1A1 at P30) in SN or 632 VTA was determined by quantifying $\mathrm{TH}^{+} \beta-\mathrm{gal}^{+}$neurons at four rostrocaudal midbrain levels 633 (Franklin and Paxinos, 2007). The number of $\mathrm{TH}^{+} \beta-\mathrm{gal}^{+}$neurons co-expressing the respective 634 subset marker in these regions was counted unilaterally and the numbers were normalized for 635 the total number of $\mathrm{TH}^{+} \beta$-gal ${ }^{+}$mDA neurons in each region ( $\mathrm{SN}$ or VTA). This analysis was 636 performed for $n=5 B c / 11 a-l a c Z$ mice and $n=5 B c / 11 a$ ckolacz mice at $P 0$ and for $n=3 B c / 11 a-$ 637 lacZ mice and $\mathrm{n}=3 \mathrm{Bc} / 11 \mathrm{a}$ cko ${ }^{\mathrm{lacZ}}$ mice at P30.

\section{Stereology}

640 Analyses were performed on SNc samples by an investigator blinded to the sample codes. 641 Unbiased stereological estimates of the number of nigral neurons were obtained by counting 642 under brightfield or confocal microscopy. Samplings were performed on every fifth section 643 throughout the entire SNc. Delineations were made using a $4 x$ objective, and counting was 644 performed using a 63x Plan-Apo oil objective (Numerical aperture=1.4). A guard zone 645 thickness of $1 \mu \mathrm{m}$ was set at the top and bottom of each section. Cells were counted using the 
optical fractionator technique (Stereo Investigator software version 9, MBF Biosciences, Williston, VTA, USA) using a motorized Olympus microscope (IX2 UCB) equipped with an Olympus disk spinning unit (DSU) and a light sensitive EM-CCD camera. Coefficient of error was calculated according to (Gundersen and Jensen, 1987); values $<0.10$ were accepted.

\section{Analysis of TH fiber density}

$65240 \mu \mathrm{m}$ sections of 3 to 6 rostrocaudal levels of the striatum were stained for $\mathrm{TH}$ and 653 epifluorescence images were taken using and inverted Z1 Axioobserver microscope with 10X 654 objective. The mean grey value of the $\mathrm{TH}^{+}$striatal projections was calculated in the dorsal 655 striatum, OT and TS (divided into ventral and dorsal TS) with Fiji/lmageJ and normalized for 656 background fluorescence (corpus callosum which is devoid of $\mathrm{TH}^{+}$fibers or neurons). This 657 analysis was performed for $=3$ control mice and $n=3$ Bcl11a ckolacz mice at P30.

\section{Behavioral tests}

660 Male mice were kept ad libitum in groups of 2-3 animals in a 12-hour day/night rhythm on a 661 normal diet. The animals were transferred to the examination room for experimental purposes 662 and each one was housed in a separate cage. After a one-week acclimatization period in the 663 examination room, mice performed the rotarod test and beam walking assay (both tests in one 664 day) for five consecutive days, followed by the social recognition test and finally by the open665 field test.

\section{RotaRod}

668 The animals were taken out of the cage and were acclimated to the rotarod apparatus (Ugo 669 Basile, Gemonio, IT; Code no. 47600) in a 5-minute run on a rod rotating at a constant speed 670 of $8 \mathrm{rpm}$. Afterwards the animals went through three test runs per day, with a break of $30 \mathrm{~min}$ 671 between each run. In each test run, the animals had to balance on the rotating rod for $5 \mathrm{~min}$, 672 whereby the torque increased from 4 to $40 \mathrm{rpm}$ within $5 \mathrm{~min}$. The duration that each mouse 673 was able to stay on the rotating rod in each trial was recorded as the latency to fall. The three 674 test runs per day were repeated on 5 consecutive days. During the test, the rod was kept clean 675 and dry by wiping the mouse urine and feces off.

\section{Beam Walking Assay}

677 To examine fine motor skills independent of rotational movement (Luong et al., 2011), the 678 beam walking assay (balanced beam test) was used (Carter et al., 1999). Animals had to 679 balance from one platform over a $12 \mathrm{~mm}$ wide and $1 \mathrm{~m}$ long rod made of synthetic material to 680 another platform that held a box with a food reward. Beams were placed $50 \mathrm{~cm}$ above the 681 table. The time taken for the animals to cross the bar was measured. If animals did not reach 
682 the safety platform or took longer than $60 \mathrm{~s}$ to cross the beam, a maximum of $60 \mathrm{~s}$ was

683 assigned. The test was run for a period of 5 consecutive days.

684

685 Open-field test

686 In the open-field test, the mice were placed in an open arena $(30 \times 30 \times 30 \mathrm{~cm})$. They were

687 allowed to move freely for 5 minutes. The animals were recorded by Video (EthovisionXT,

688 Noldus, Wageningen, NL) and the running distance, the time spent in the border area, the

689 corners and the centre of the cage as well as crossings from the border to the center area

690 were measured. This test was initially run for a training period of 1 day, then after a 30-day

691 rest period another test run was performed. This test was run twice with a 30-day rest period

692 in between. Since both runs showed comparable results, the results were combined for the

693 final analysis.

\section{Statistical analysis}

695 Statistical analyses of cell numbers were done with GraphPad Prism (8.0) software using 696 unpaired t-test, Welch's t-test, one-way ANOVA followed by test for linear trend or one-way 697 ANOVA followed by Tukey's post hoc test for multiple comparisons.

698 Open field tests were evaluated by one-way analysis followed by Tukey's post hoc test for 699 multiple comparisons. Differences in the balanced beam test and rotarod were assessed by 700 two-way ANOVA taking time and genotype as numerical and categorical variables.

$701 \mathrm{P}$ values of less than 0.05 were considered statistically significant. Data are reported as mean 702 values \pm standard error of the mean (SEM). 


\section{References}

Alvarez-Bolado, G., Paul, F. A. and Blaess, S. (2012). Sonic hedgehog lineage in the mouse hypothalamus: From progenitor domains to hypothalamic regions. Neural development 7 , 4.

Bariselli, S., Hörnberg, H., Prévost-Solié, C., Musardo, S., Hatstatt-Burklé, L., Scheiffele, P. and Bellone, C. (2018). Role of VTA dopamine neurons and neuroligin 3 in sociability traits related to nonfamiliar conspecific interaction. Nat Commun 9, 3173-15.

Bäckman, C. M., Malik, N., Zhang, Y., Shan, L., Grinberg, A., Hoffer, B. J., Westphal, H. and Tomac, A. C. (2006). Characterization of a mouse strain expressing Cre recombinase from the 3' untranslated region of the dopamine transporter locus. genesis 44, 383-390.

Bimpisidis, Z., König, N., Stagkourakis, S., Zell, V., Vlcek, B., Dumas, S., Giros, B., Broberger, C., Hnasko, T. S. and Wallén-Mackenzie, A. (2019). The NeuroD6 Subtype of VTA Neurons Contributes to Psychostimulant Sensitization and Behavioral Reinforcement. eNeuro 6, ENEURO.0066-19.2019-31.

Brignani, S. and Pasterkamp, R. J. (2017). Neuronal Subset-Specific Migration and Axonal Wiring Mechanisms in the Developing Midbrain Dopamine System. Front Neuroanat 11, 494-18.

Brignani, S., Raj, D. D. A., Schmidt, E. R. E., Düdükcü, Ö., Adolfs, Y., De Ruiter, A. A., Rybiczka-Tesulov, M., Verhagen, M. G., van der Meer, C., Broekhoven, M. H., et al. (2020). Remotely Produced and Axon-Derived Netrin-1 Instructs GABAergic Neuron Migration and Dopaminergic Substantia Nigra Development. Neuron 107, 684-702.

Burton, A. C., Nakamura, K. and Roesch, M. R. (2015). From ventral-medial to dorsal-lateral striatum: Neural correlates of reward-guided decision-making. Neurobiol Learn Mem 117, 51-59.

Canovas, J., Berndt, F. A., Sepulveda, H., Aguilar, R., Veloso, F. A., Montecino, M., Oliva, C., Maass, J. C., Sierralta, J. and Kukuljan, M. (2015). The Specification of Cortical Subcerebral Projection Neurons Depends on the Direct Repression of TBR1 by CTIP1/BCL11a. J Neurosci 35, 7552-7564.

Carter, R. J., Lione, L. A., Humby, T., Mangiarini, L., Mahal, A., Bates, G. P., Dunnett, S. B. and Morton, A. J. (1999). Characterization of progressive motor deficits in mice transgenic for the human Huntington's disease mutation. J Neurosci 19, 3248-3257.

Chen, L., Xie, Z., Turkson, S. and Zhuang, X. (2015). A53T human a-synuclein overexpression in transgenic mice induces pervasive mitochondria macroautophagy defects preceding dopamine neuron degeneration. J Neurosci 35, 890-905.

Costa, R. M., Cohen, D. and Nicolelis, M. A. L. (2004). Differential Corticostriatal Plasticity during Fast and Slow Motor Skill Learning in Mice. Curr Biol 14, 1124-1134.

Dias, C., Estruch, S. B., Graham, S. A., McRae, J., Sawiak, S. J., Hurst, J. A., Joss, S. K., Holder, S. E., Morton, J. E. V., Turner, C., et al. (2016). BCL11A Haploinsufficiency Causes an Intellectual Disability Syndrome and Dysregulates Transcription. Am J Hum Genet 99, 253-274.

Dodson, P. D., Dreyer, J. K., Jennings, K. A., Syed, E. C. J., Wade-Martins, R., Cragg, S. J., Bolam, J. P. and Magill, P. J. (2016). Representation of spontaneous movement by 
dopaminergic neurons is cell-type selective and disrupted in parkinsonism. Proc Natl Acad Sci USA 113, E2180-E2188.

Engelhard, B., Finkelstein, J., Cox, J., Fleming, W., Jang, H. J., Ornelas, S., Koay, S. A., Thiberge, S. Y., Daw, N. D., Tank, D. W., et al. (2019). Specialized coding of sensory, motor and cognitive variables in VTA dopamine neurons. Nature 570, 509-513.

Franklin, K. B. J. and Paxinos, G. (2007). The Mouse Brain in Stereotaxic Coordinates, Third Edition. 3rd ed. Academic Press.

Goedert, M., Spillantini, M. G., Del Tredici, K. and Braak, H. (2013). 100 years of Lewy pathology. Nat Rev Neurol 9, 13-24.

Greig, L. C., Woodworth, M. B., Greppi, C. and Macklis, J. D. (2016). Ctip1 Controls Acquisition of Sensory Area Identity and Establishment of Sensory Input Fields in the Developing Neocortex. Neuron 90, 261-277.

Gundersen, H. J. and Jensen, E. B. (1987). The efficiency of systematic sampling in stereology and its prediction. J Microsc 147, 229-263.

Heymann, G., Jo, Y. S., Reichard, K. L., McFarland, N., Chavkin, C., Palmiter, R. D., Soden, M. E. and Zweifel, L. S. (2020). Synergy of Distinct Dopamine Projection Populations in Behavioral Reinforcement. Neuron 105, 909-920.e5.

Hikosaka, O., Nakamura, K., Sakai, K. and Nakahara, H. (2002). Central mechanisms of motor skill learning. Curr Opin Neurobiol 12, 217-222.

John, A., Brylka, H., Wiegreffe, C., Simon, R., Liu, P., Jüttner, R., Crenshaw, E. B., Luyten, F. P., Jenkins, N. A., Copeland, N. G., et al. (2012). Bcl11a is required for neuronal morphogenesis and sensory circuit formation in dorsal spinal cord development. Development 139, 1831-1841.

Kadoch, C., Hargreaves, D. C., Hodges, C., Elias, L., Ho, L., Ranish, J. and Crabtree, G. R. (2013). Proteomic and bioinformatic analysis of mammalian SWI/SNF complexes identifies extensive roles in human malignancy. Nat Genet 45, 592-601.

Khan, S., Stott, S. R. W., Chabrat, A., Truckenbrodt, A. M., Spencer-Dene, B., Nave, K. A., Guillemot, F., Lévesque, M. and Ang, S.-L. (2017). Survival of a Novel Subset of Midbrain Dopaminergic Neurons Projecting to the Lateral Septum Is Dependent on NeuroD Proteins. J Neurosci 37, 2305-2316.

Kish, S. J., Shannak, K. and Hornykiewicz, O. (1988). Uneven Pattern of Dopamine Loss in the Striatum of Patients with Idiopathic Parkinson's Disease. N Engl J Med 318, 876-880.

Kolk, S. M., Gunput, R.-A. F., Tran, T. S., Van den Heuvel, D. M. A., Prasad, A. A., Hellemons, A. J. C. G. M., Adolfs, Y., Ginty, D. D., Kolodkin, A. L., Burbach, J. P. H., et al. (2009). Semaphorin $3 \mathrm{~F}$ is a bifunctional guidance cue for dopaminergic axons and controls their fasciculation, channeling, rostral growth, and intracortical targeting. $J$ Neurosci 29, 12542-12557.

Kordower, J. H., Olanow, C. W., Dodiya, H. B., Chu, Y., Beach, T. G., Adler, C. H., Halliday, G. M. and Bartus, R. T. (2013). Disease duration and the integrity of the nigrostriatal system in Parkinson's disease. Brain 136, 2419-2431.

Kramer, D. J., Risso, D., Kosillo, P., Ngai, J. and Bateup, H. S. (2018). Combinatorial Expression of Grpand Neurod6Defines Dopamine Neuron Populations with Distinct Projection Patterns and Disease Vulnerability. eNeuro 5, ENEURO.0152-18.2018-16. 
La Manno, G., Gyllborg, D., Codeluppi, S., Nishimura, K., Saltó, C., Zeisel, A., Borm, L. E., Stott, S. R. W., Toledo, E. M., Villaescusa, J. C., et al. (2016). Molecular Diversity of Midbrain Development in Mouse, Human, and Stem Cells. Cell 167, 566-580.e19.

Lerner, T. N., Shilyansky, C., Davidson, T. J., Evans, K. E., Beier, K. T., Zalocusky, K. A., Crow, A. K., Malenka, R. C., Luo, L., Tomer, R., et al. (2015). Intact-Brain Analyses Reveal Distinct Information Carried by SNc Dopamine Subcircuits. Cell 162, 635-647.

Li, Q., Ko, H., Qian, Z.-M., Yan, L. Y. C., Chan, D. C. W., Arbuthnott, G., Ke, Y. and Yung, W.-H. (2017). Refinement of learned skilled movement representation in motor cortex deep output layer. Nat Commun 8, 8:15834.

Liu, G., Yu, J., Ding, J., Xie, C., Sun, L., Rudenko, I., Zheng, W., Sastry, N., Luo, J., Rudow, G., et al. (2014). Aldehyde dehydrogenase 1 defines and protects a nigrostriatal dopaminergic neuron subpopulation. J Clin Invest 124, 3032-3046.

Luong, T. N., Carlisle, H. J., Southwell, A. and Patterson, P. H. (2011). Assessment of Motor Balance and Coordination in Mice using the Balance Beam. J Vis Exp 49, 2376.

Madisen, L., Garner, A. R., Shimaoka, D., Chuong, A. S., Klapoetke, N. C., Li, L., van der Bourg, A., Niino, Y., Egolf, L., Monetti, C., et al. (2015). Transgenic mice for intersectional targeting of neural sensors and effectors with high specificity and performance. Neuron 85, 942-958.

Menegas, W., Akiti, K., Amo, R., Uchida, N. and Watabe-Uchida, M. (2018). Dopamine neurons projecting to the posterior striatum reinforce avoidance of threatening stimuli. Nat Neurosci 21, 1421-1430.

Menegas, W., Bergan, J. F., Ogawa, S. K., Isogai, Y., Umadevi Venkataraju, K., Osten, P., Uchida, N. and Watabe-Uchida, M. (2015). Dopamine neurons projecting to the posterior striatum form an anatomically distinct subclass. eLife 4, e10032.

Morales, M. and Margolis, E. B. (2017). Ventral tegmental area: cellular heterogeneity, connectivity and behaviour. Nat Rev Neurosci 18, 73-85.

Nandhagopal, R., Kuramoto, L., Schulzer, M., Mak, E., Cragg, J., Lee, C. S., McKenzie, J., McCormick, S., Samii, A., Troiano, A., et al. (2009). Longitudinal progression of sporadic Parkinson's disease: a multi-tracer positron emission tomography study. Brain 132, 2970-2979.

Panman, L., Papathanou, M., Laguna, A., Oosterveen, T., Volakakis, N., Acampora, D., Kurtsdotter, I., Yoshitake, T., Kehr, J., Joodmardi, E., et al. (2014). Sox6 and Otx2 control the specification of substantia nigra and ventral tegmental area dopamine neurons. CellReports 8, 1018-1025.

Pasquini, J., Durcan, R., Wiblin, L., Gersel Stokholm, M., Rochester, L., Brooks, D. J., Burn, D. and Pavese, N. (2019). Clinical implications of early caudate dysfunction in Parkinson's disease. J Neurol Neurosur Psychiatry 90, 1098-1104.

Peron, A., Bradbury, K., Viskochil, D. H. and Dias, C. (2019). BCL11A-Related Intellectual Disability - GeneReviews ${ }^{\circledR}$ - NCBI Bookshelf. 1-18.

Poulin, J.-F., Caronia, G., Hofer, C., Cui, Q., Helm, B., Ramakrishnan, C., Chan, C. S., Dombeck, D. A., Deisseroth, K. and Awatramani, R. (2018). Mapping projections of molecularly defined dopamine neuron subtypes using intersectional genetic approaches. Nat Neurosci 21, 1260-1271. 
Poulin, J.-F., Gaertner, Z., Moreno-Ramos, O. A. and Awatramani, R. (2020). Classification of Midbrain Dopamine Neurons Using Single-Cell Gene Expression Profiling Approaches. Trends Neurosci 43, 155-169.

Poulin, J.-F., Zou, J., Drouin-Ouellet, J., Kim, K.-Y. A., Cicchetti, F. and Awatramani, R. B. (2014). Defining Midbrain Dopaminergic Neuron Diversity by Single-Cell Gene Expression Profiling. CellReports 9, 930-943.

Schultz, W. (2019). Recent advances in understanding the role of phasic dopamine activity. F1000Res 8, 1680-12.

Schwamborn, J. C. (2018). Is Parkinson's Disease a Neurodevelopmental Disorder and Will Brain Organoids Help Us to Understand It? Stem Cells Dev 27, 968-975.

Simon, R., Wiegreffe, C. and Britsch, S. (2020). Bcl11 Transcription Factors Regulate Cortical Development and Function. Front Mol Neurosci 13, 51.

Thompson, L., Barraud, P., Andersson, E., Kirik, D. and Björklund, A. (2005). Identification of dopaminergic neurons of nigral and ventral tegmental area subtypes in grafts of fetal ventral mesencephalon based on cell morphology, protein expression, and efferent projections. J Neurosci 25, 6467-6477.

Tye, K. M., Mirzabekov, J. J., Warden, M. R., Ferenczi, E. A., Tsai, H.-C., Finkelstein, J., Kim, S.-Y., Adhikari, A., Thompson, K. R., Andalman, A. S., et al. (2013). Dopamine neurons modulate neural encoding and expression of depression-related behaviour. Nature 493, 537-541.

Ulusoy, A. and Di Monte, D. A. (2012). a-Synuclein Elevation in Human Neurodegenerative Diseases: Experimental, Pathogenetic, and Therapeutic Implications. Mol Neurobiol 47, 484-494.

Wiegreffe, C., Simon, R., Peschkes, K., Kling, C., Strehle, M., Cheng, J., Srivatsa, S., Liu, P., Jenkins, N. A., Copeland, N. G., et al. (2015). Bcl11a (Ctip1) Controls Migration of Cortical Projection Neurons through Regulation of Sema3c. Neuron 87, 311-325.

Woodworth, M. B., Greig, L. C., Liu, K. X., Ippolito, G. C., Tucker, H. O. and Macklis, J. D. (2016). Ctip1 Regulates the Balance between Specification of Distinct Projection Neuron Subtypes in Deep Cortical Layers. CellReports 15, 999-1012.

Wu, J., Kung, J., Dong, J., Chang, L., Xie, C., Habib, A., Hawes, S., Yang, N., Chen, V., Liu, Z., et al. (2019). Distinct Connectivity and Functionality of Aldehyde Dehydrogenase 1a1-Positive Nigrostriatal Dopaminergic Neurons in Motor Learning. CellReports 28, 1167-1181.e7.

Yacoubi, El, M., Bouali, S., Popa, D., Naudon, L., Leroux-Nicollet, I., Hamon, M., Costentin, J., Adrien, J. and Vaugeois, J.-M. (2003). Behavioral, neurochemical, and electrophysiological characterization of a genetic mouse model of depression. Proc Natl Acad Sci USA 100, 6227-6232.

Yu, Y., Wang, J., Khaled, W., Burke, S., Li, P., Chen, X., Yang, W., Jenkins, N. A., Copeland, N. G., Zhang, S., et al. (2012). Bcl11a is essential for lymphoid development and negatively regulates p53. J Exp Med 209, 2467-2483. 


\section{Figure Legends}

879 Figure 1 Bcl11a is expressed in a subset of SN, VTA, RRF and CLi neurons. (A-F') 880 Immunofluorescent staining for TH and RNAscope for Bcl11a mRNA on P0 (A-C') and P30 881 (D-F') coronal sections. (B,C) Higher magnification of the boxed areas in $A$; $(\mathbf{E}, \mathbf{F})$ Higher 882 magnification of the boxed areas in D. ( $\left(\mathbf{B}^{\prime}, \mathbf{C}^{\prime}, \mathbf{E}^{\prime}, \mathrm{F}^{\prime}\right)$ Higher magnification of the boxed area in 883 B,C,E,F. Note that SN-mDA neurons express lower levels of Bc/11a mRNA than VTA-mDA 884 neurons as evident by the density of fluorescent dots within the TH positive cell. (G-L) 885 Immunofluorescent staining for BCL11A and TH on P0 (G-I) and P30 (J-L) coronal sections. $886 \mathbf{( H , I ) ~ H i g h e r ~ m a g n i f i c a t i o n ~ o f ~ t h e ~ b o x e d ~ a r e a ~ i n ~} \mathrm{G} ;(\mathbf{K}, \mathbf{L})$ higher magnification of the boxed area 887 in J. The immunostaining for BCL11A failed to detect the protein in the SN at P30. (M-R) 888 Immunofluorescent staining for $\beta$-gal and TH on coronal sections of P0 (M-O) and P30 (P-R) 889 Bcl11a-lacZ mice. (N,O) Higher magnification of the boxed area in $M$; $(\mathbf{Q}, \mathbf{R})$ higher 890 magnification of the boxed area in P. Filled arrowheads indicate cells that are double positive 891 for $\mathrm{TH}$ and $\mathrm{BCL} 11 \mathrm{~A} / \mathrm{Bc} / 11 \mathrm{a} / \mathrm{\beta}$-gal, empty arrowheads indicate cells that express $892 \mathrm{BCL} 11 \mathrm{~A} / \mathrm{BC} / 11 \mathrm{a} / \mathrm{\beta}$-gal but are TH negative. (S,T) Percentage of TH-expressing neurons that 893 are positive for $\beta$-gal in Bcl11a-lacZ mice at $\mathrm{P0}(\mathbf{S} ; \mathrm{n}=5$ mice) and $\mathrm{P} 30$ ( $\mathbf{T} ; \mathrm{n}=6$ mice). Error 894 bars indicate mean +/- SEM. Scale bars: $200 \mu \mathrm{m}$ (A,G-G',M-M'), $500 \mu \mathrm{m}$ (D,J-J',P-P'), $25 \mu \mathrm{m}$ 895 (B,C,E,E',F,F',H,I,K,L,N,O,Q,R), $10 \mu \mathrm{m}$ (B',C').

896 Figure $2 \mathrm{Bcl11}$-expressing mDA neurons are a distinct mDA subset that does not correspond 897 to previously defined mDA neuronal subpopulations. (A,B) Triple immunostaining for $\mathrm{TH}$ 898 (blue), $\beta$-gal (red) and CALB1 (green) (A) or SOX6 (green) (B) in P0 Bcl11a-lacZ mice. (A'899 A"',,B'-B'"') Higher magnification of the boxed area in A,B. (C,D) Triple immunostaining for TH 900 (blue), $\beta$-gal (red) and CALB1 (green) (C) or ALDH1A1 (green) (D) in P30 Bcl11a-lacZ mice. 901 (C'-C'"',D'-D'"') Higher magnification of the boxed area in C, D. Filled arrowheads indicate TH $^{+}$ $902 \beta$-gal ${ }^{+}$cells expressing the respective subset markers, unfilled arrowheads indicate $\mathrm{TH}^{+} \beta$-gal ${ }^{+}$ 903 cells negative for the respective subset marker. (E-H) Percentage of $\mathrm{TH}^{+} \beta$-gal ${ }^{+}$neurons that 904 are positive for the respective subset marker at $P 0(E, F n=5$ mice) and at $P 30$ ( $G, H, n=3$ mice).

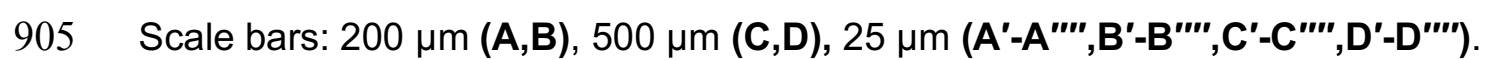

906 Figure 3 Bcl11a-expressing mDA neurons contribute projections to subcircuits of the 907 dopaminergic system. (A) Schematic showing the intersectional fate mapping strategy to label 908 Bcl11a-expressing mDA neurons and their projections. A $B c / 11 a^{C r e E R}$ mouse line was used in 909 combination with $D a t^{t T A}$ mice and an intersectional reporter mouse line (Ai82D). EFGP is 910 expressed only in cells positive for both CreER and tTa and only after CreER is activated by 911 administration of Tamoxifen. (B) Schematic showing the experimental timeline. (C-F") 912 Immunostaining for TH and EGFP in rostrocaudal levels of the striatal region showing that 913 Bc/11a-expressing mDA neurons innervate specific subdomains of dopaminergic projection 
914 targets including the olfactory tubercle (OT, C-E"), the Nucleus Accumbens (NAc)shell (C-D") 915 the dorsomedial striatum (DMS, C-E") and the tail of the striatum (TS) (F-F"). Note that the 916 most ventral part of the TS shows the highest density of EGFP positive fibers (F-F"). Mice 917 analysed ( $\mathrm{n}=8$ mice). Scale bar: $500 \mu \mathrm{m}$ (C-F").

918 Figure 4 Bcl11a-expressing mDA neurons of the VTA and SN show a specific innervation 919 pattern of forebrain targets. (A) Schematic showing injection of rAAV with an intersectional 920 reporter construct into the SN or VTA of $B c / 11 a^{\mathrm{CreER/+}}$; Dat ${ }^{t T A /+}$ mice. (B)Schematic showing the 921 experimental timeline. Tamoxifen administration 8 days after the virus injection results in 922 expression of the reporter protein (EGFP) in Bcl11a-expressing mDA neurons. (C-F') 923 Immunostaining for TH and EGFP in the SN (C-D') and the striatum (E-F'). (E-F') EGFP fibers 924 in the TS. (F,F') Higher magnification of the boxed area in E. (G-J) Immunostaining for TH and 925 the reporter protein in the VTA $\left(\mathbf{G}-\mathbf{H}^{\prime}\right)$ and NAc and OT (I-J). Yellow arrows indicate $\mathrm{TH}^{+}$ reporter protein ${ }^{+}$neurons. Mice analyzed $(n=2$ mice for $S N$ injections, $n=3$ mice for VTA injections) Scale bars: $500 \mu \mathrm{m}$ (C,G,I), $250 \mu \mathrm{m}$ (E,F,J), $25 \mu \mathrm{m}\left(\mathbf{D}, \mathbf{D}^{\prime}, \mathbf{H}^{\prime} \mathbf{H}^{\prime}\right)$.

Figure $5 \mathrm{BCL} 11 \mathrm{~A}$ is necessary for establishing the correct rostro-caudal position of $\mathrm{Bc} / 11 \mathrm{a}$ expressing mDA neurons in the VTA and CLi. (A) Conditional gene inactivation of Bcl11a in mDA neurons. Bcl11a cko mice were generated by crossing Dat ${ }^{\text {IRES-Cre }}$ mice either with $B c / 11 a^{\text {floxfllox }}$ mice (Genotype: Dat ${ }^{\text {RES-Cre/+ }}, B c / 11 a^{\text {floxflox }}$, termed $B c / 11 a$ cko $^{\text {flox }}$ ) or with $B c / 11 a^{\text {flox/lacz }}$ mice (Genotype: Dat ${ }^{I R E S-C r e /+}, B c / 11 a^{\text {flox/lacz }}$, termed: Bcl11a ckolacz). (B) In Bcl11a ckolacz mice, $\beta$-gal is a marker for Bcl11a-mDA neurons even after BCL11A expression is abolished. (C-D") Immunofluorescent staining for $\beta$-gal and TH on coronal sections of PO (C-

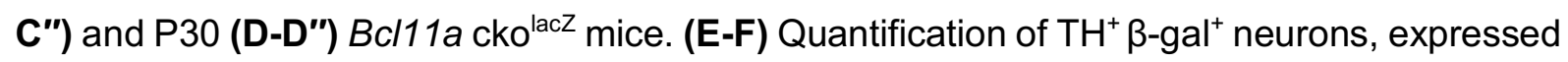
as percentage of control (Bcl11a-lacZ mice, control values are shown in Figure 1S,T). (E) There is no significant difference in the percentage of mDA neurons expressing $\beta$-gal in $B c / 11 a$ ckolacz mice $(n=5)$ compared to Bcl11a-lacZ mice $(n=5)$ at $P 0$, indicating that Bcl11a-mDA neurons are established even in absence of BCL11A. (F) At P30, Bcl11a-mDA neurons are significantly decreased in the VTA and significantly increased in the CLi of $B c / 11$ a ckolacz mice $(n=6)$ as compared to Bc/11a-lacZ $(n=6)$ indicating a shift in the distribution of Bcl11a-mDA neurons in absence of BCL11A (F-G). Significance was determined by Welch's t-test. * $p<$

$9430.05,{ }^{* *} p<0.01$. Error bars indicate mean +/- SEM. Scale bars: $200 \mu \mathrm{m}$ (C-C") and $500 \mu \mathrm{m}$ 944 (D-D'").

946 Figure 6 Expression of mDA subset markers in Bc/11a-expressing mDA neurons is not altered 947 in absence of BCL11A. (A,B) Triple immunostaining for TH (blue), $\beta$-gal (red) and CALB1 948 (green) (A) or SOX6 (green) (B) in P0 Bcl11a ckolacz mice. (C,D) Triple immunostaining for TH 949 (blue), $\beta$-gal (red) and CALB1 (green) (C) or ALDH1A1 (green) (D) in P30 Bcl11a ckolacz mice. 
950 (E,F) Quantification of triple positive neurons, expressed as percentage of control (Bc/11a-lacZ 951 mice, control values are shown in Figure $2 \mathrm{E}-\mathrm{H}$ ). There is no significant difference in the 952 percentage of $\mathrm{TH}^{+} \beta$-gal ${ }^{+} \mathrm{mDA}$ neurons expressing the analyzed subset markers in $\mathrm{Bcl11a}$ 953 ckolacz mice compared to $B c / 11 a-l a c Z$ mice at $\mathrm{P} 0$ or $\mathrm{P} 30$. $\mathrm{N}=5$ cko and $\mathrm{n}=5$ control mice were 954 analyzed at $\mathrm{P} 0, \mathrm{n}=3$ cko and $\mathrm{n}=3$ control mice were analyzed at P30. Significance was 955 determined by Welch's t-test. Error bars indicate mean +/- SEM. Scale bars: $200 \mu \mathrm{m}$ (A,B), ; $956500 \mu \mathrm{m}(\mathbf{E}-\mathrm{F})$.

957 Figure 7 Inactivation of $B c / 11 a$ in mDA neurons results in specific defects in motor behavior. 958 (A-C) Open field test (5-minute time window) revealed no significant difference between $959 B c / 11 a$ cko $^{\text {flox }}$ (cko) and control mice (ctr) in distance moved (A), in time spent in the center or 960 border area (B) or the frequency of entering the center (C). (D) Mice had to balance on a beam 961 towards a food reward. The test was performed on 5 consecutive days. There was no 962 significant difference between Bc/11a cko and control mice in their ability to cross a balance 963 beam in any of the trials. (E) The rotarod test revealed that Bc/11a cko mice were not able to 964 learn the motor task, since unlike in control mice the time to fall did not increase in Bc/11a cko 965 mice within the 5 days of the trial period. Bcl11a cko $(n=12)$ and control mice $(n=13)$. 966 Significance was determined by two-way ANOVA. ${ }^{* * *} p<0.001,{ }^{* * *} p<0.0001 . p=7.226 \mathrm{e}-10$ 967 for genotype, $p=0.0002017$ for days and $p=0.0076354$ for interdependence between days and 968 genotypes. Error bars indicate mean +/- SEM.

969 Figure 8 Bcl11a cko mice show increased neuronal vulnerability to a-synuclein toxicity. (A) 970 Mice received a unilateral intraparenchymal injection of adeno-associated viral vectors (AAVs) 971 carrying the DNA for human a-synuclein (ha-syn) into the SNc. Animals were sacrificed 8 972 weeks after this treatment. (B) Midbrain coronal sections comprising the SNc (delineated with 973 dotted lines at low magnification) were immunostained with anti-human $\alpha$-synuclein. 974 Representative images from a control and a Bcl11a cko animal show neuronal expression of 975 the transduced protein at low magnification (left panels). The right panels show a higher 976 magnification of the boxed areas. (C) Midbrain sections were immunostained with anti-TH and 977 counterstained with cresyl violet. Representative images from a control and a Bcl11a cko 978 animal show TH-positive nigral neurons on right side of the brain lesioned with ha-syn-AAVs 979 and on the contralateral intact side. (D,E) TH-immunoreactive (D) and Nissl-stained (E) 980 neurons were counted stereologically in the intact (left) and lesioned (right) SNc of control $981 \quad(n=5)$ and Bcl11a cko ( $n=5)$ mice. Intact side values from control and cko animals were pooled 982 together (dark gray bars). Light gray and empty bars show average values from the lesioned 983 side of control (ctr) and cko mice, respectively. (F) Midbrain sections from Bcl11a-lacZ control $984(\mathrm{n}=4)$ and $B c / 11 \mathrm{a} \mathrm{cko}^{\mathrm{lacZ}}(\mathrm{n}=4)$ mice were stained with anti-TH and anti- $\beta$-gal. Total neurons 985 ( $\beta$-gal negative and $\beta$-gal positive TH cells), $\beta$-gal(-) neurons (TH cells devoid of $\beta$-gal 
986 immunoreactivity) and $\beta$-gal(+) neurons (cells immunoreactive for both $\mathrm{TH}$ and $\beta$-gal) were

987 counted using confocal stereology. Counts made in the intact SNc showed no difference

988 between the two groups of animals. They were therefore pooled together (blue bars). Red and

989 yellow bars show average values from the lesioned side of Bc/11a-lacZ and Bc/11a ckolacz

990 mice, respectively. Significance was determined by one-way ANOVA followed by Tukey's post

991 hoc test for multiple comparisons. Error bars indicate mean +/- SEM. Scale bars: $100 \mu \mathrm{m}$ (low

992 magnification panels in B; C); $20 \mu \mathrm{m}$ (higher magnification panels in B).

993

994 


\section{Supplemental Figure Legends}

996 Supplemental Figure $1 \mathrm{Bcl11a}$ is expressed in a subset of neurons in the SN, VTA, caudal 997 linear nucleus (CLi) and retrorubral field (RRF) of the adult mouse brain. (A-E') 998 Immunofluorescent staining for $\mathrm{TH}$ and $\beta$-gal on coronal sections at different rostrocaudal 999 levels of P30 Bc/11a-lacZ mice. Bcl11a-expressing mDA neurons are found throughout the 1000 VTA, except for the most medial regions (A-D"). Bcl11a-expressing mDA neurons of the SN 1001 are mainly located in the medial SNc (rostral levels) and the dorsal tier of the SNc (more caudal 1002 sections) and the SNI (A-D"). Bcl11a-expressing mDA neurons are also located in the CLi and 1003 RRF (E-E"). Scale bar: $500 \mu m\left(A-E^{\prime \prime}\right)$.

1004 Supplemental Figure 2 Overlap of BCL11A and $\beta$-gal expression in the ventral midbrain and cerebral cortex. (A-B"'") Triple immunofluorescent staining for TH (blue), BCL11A (red) and $\beta$ gal (green) in the ventral midbrain of P0 (A-A'"') and P30 (B-B'"') Bcl11a-lacZ mice. (A'-A'"', B'-B'"') Higher magnification of the boxed area in A,B. (C-D"',') Triple immunofluorescent staining for Hoechst (blue), BCL11A (red) and $\beta$-gal (green) in cerebral cortex of P0 (C-C'"') and P30 (D-D'"') Bcl11a-lacZ mice. (C'-C'"', D'-D'"') Higher magnification of the boxed area in C,D. Scale bars: $200 \mu \mathrm{m}$ (A,C), $500 \mu \mathrm{m}$ (B,D) and $25 \mu \mathrm{m}$ (A'-A'"',B'-B'"',,C'-C'"',,D'-D'"'').

Supplemental Figure $3 \mathrm{BCL} 11 \mathrm{~A}$ expression in the ventral midbrain starts at E12.5. (A-E") Immunofluorescent staining for TH and BCL11A on E12.5 (A-A"), E14.5 (B-C") and E15.5 (DE") coronal sections. At E12.5, BCL11A is mainly expressed in differentiated neurons just below the mDA progenitor domain and in a few TH-expressing mDA neurons (A-A"). At E14.5 and $\mathrm{E} 15.5, \mathrm{BCL} 11 \mathrm{~A}$ expression is found in a larger subset of mDA neurons, both in the forming VTA and SN (B-E"). (C-C", E-E") Higher magnification of the boxed area in B-B", D-D". Scale bar: $100 \mu m(A-E ")$.

1018 Supplemental Figure 4 Distribution of recombined neurons in the ventral midbrain using the intersectional fate mapping approach. (A) Schematic showing the intersectional fate mapping strategy to label Bc/11a-expressing mDA neurons and their projections. (B) Schematic of a sagittal section through the adult mouse brain. Red lines indicate the rostrocaudal levels of the coronal sections shown in B-F". (C-G") Immunofluorescent staining for TH and EGFP. Recombined neurons positive for EGFP were found in the SN and VTA (C-F") as well as in the CLi and RRF (G-G"). Distribution of recombined cells is comparable to the distribution of

$1025 \beta$-gal positive cells in Bc/11a-lacZ mice (compare with Suppl. Figure 1). $n=8$ mice. Scale bar: $1026500 \mu \mathrm{m}$ (B-F").

1027 Supplemental Figure 5 Bcl11a-expressing neurons of the VTA and SN show a specific 1028 innervation pattern of forebrain targets. (A) Schematic showing injection of rAAV:double floxed 
1029 Channelrhodopsin2 (ChR2)-mCherry or rAAV:double floxed ChR2-EYFP into the SN or VTA

1030 of $B c / 11 a^{C r e E R /+}$ mice. (B) Schematic showing the experimental timeline. Tamoxifen 1031 administration 8 days after the virus injection leads to sparse expression of the reporter protein

1032 (mCherry or EYFP) in Bc/11a-expressing neurons. (C-F') Immunofluorescent staining for TH 1033 and mCherry in the SN (C-D') and the striatum (E-F'). (E-F') A cluster of mCherry ${ }^{+}$-fibers in the 1034 dorsomedial striatum (DMS). (F-F') Higher magnification of the boxed area in E. (G-J) 1035 Immunofluorescent staining for TH and EYFP in the VTA (G-H') and in the nucleus accumbens 1036 (NAc) and the olfactory tubercle (OT) (I-J). (J) Higher magnification of the boxed area in I. 1037 Yellow arrows indicate $\mathrm{TH}^{+}$reporter protein ${ }^{+}$neurons, white arrows indicate $\mathrm{TH}^{-}$reporter 1038 protein $^{+}$neurons (D,H). $n=7$ mice for VTA injections, $n=1$ mouse for SN injection. Scale bars: $1039500 \mu \mathrm{m}$ (C,E,I), $250 \mu \mathrm{m}(\mathbf{G})$ and $25 \mu \mathrm{m}\left(\mathbf{F}-\mathbf{F}^{\prime}, \mathbf{J}\right)$.

1040 Supplemental Figure 6 BCL11A expression is absent in mDA neurons of Bcl11a cko mice.

1041 (A) Schematic showing conditional gene inactivation of Bc/11a in mDA neurons. Conditional 1042 knock-out mice were generated by crossing $B c / 11 a^{\text {flox/flox }}$ mice with Dat ${ }^{1 R E S-C r e /+}$ mice (Bc/11a 1043 cko $^{\text {flox }}$ ). (B) In Bcl11a cko flox mice, BCL11A expression is absent in mDA neurons. (C-H") 1044 Immunofluorescent staining for BCL11A and TH on control (C-D') and Bcl11a cko flox (E-F") 1045 coronal sections of the adult brain. BCL11A expression is present in mDA neurons of control 1046 mice (C-D'"', G, yellow arrowheads), but it is absent in mDA neurons of Bcl11a cko flox mice (E1047 F", H). BCL11A is still expressed in non-dopaminergic neurons of the Bc/11a cko flox mice 1048 midbrain (E-F", G, white arrowheads). (D-D",F-F") Higher magnification of the boxed area in 1049 C,E. (G-G",H-H") Higher magnification of the boxed area in D,F. Yellow arrowheads indicate 1050 cells that are double positive for BCL11A and TH (D,D",G,G"), white arrowheads indicate cells 1051 that are BCL11A positive but TH negative (F,F",G,G",H,H"). (I-J) Immunofluorescent staining 1052 for BCL11A and Hoechst in control (I) and Bc/11a cko ${ }^{\text {flox }}(\mathrm{J})$ cerebral cortex. As expected, $1053 \mathrm{BCL} 11 \mathrm{~A}$ is still expressed in cerebral cortex neurons of $B c / 11$ a cko ${ }^{\text {flox }}$ mice $(\mathrm{J})$. Scale bars: 500 $1054 \mu \mathrm{m}$ (C-C",E-E'), $250 \mu \mathrm{m}$ (D-D",F-F") and $25 \mu \mathrm{m}$ (G-J).

1055 Supplemental Figure $7 \mathrm{Bc} / 11 \mathrm{a}$ mRNA is no longer expressed in mDA neurons of $B c / 11 a$ cko mice. (A-D) Immunofluorescent staining for TH and RNAscope for Bcl11a on Bcl11a cko flox coronal sections of the adult brain. Bc/11a mRNA expression is still expressed in non1058 dopaminergic neurons of the Bc/11a cko flox mice VTA (A-A",C) and SN (B-B",D). (C-D) Higher 1059 magnification of the boxed area in A,B. White arrowheads indicate cells that are expressing 1060 Bcl11a mRNA but that are TH negative. (E,E') Immunofluorescent staining for Hoechst and 1061 RNAscope for Bc/11a in Bcl11a cko ${ }^{\text {flox }}$ cerebral cortex. As expected, cerebral cortex neurons 1062 of $B c / 11 a$ cko $^{\text {flox }}$ mice are still expressing Bcl11a mRNA. (E') Higher magnification of the boxed 1063 area in E. Scale bars: $250 \mu \mathrm{m}$ (A-B'), $200 \mu \mathrm{m}$ (E) and $25 \mu \mathrm{m}$ (C,D,E'). 
Supplemental Figure 8 Bcl11a inactivation does affect rostro-caudal position of Bcl11a-mDA neurons but not the targeting of projections to areas innervated by Bc/11a-expressing mDA neurons. (A) Quantification combining three rostrocaudal VTA levels and the CLi. No significant difference in the percentage of $\beta$-gal positive $\mathrm{TH}$ neurons could be detected between $B c / 11 a c^{c k} o^{l a c z}$ and $B c / 11-l a c Z$ animals. Statistical significance was determined by unpaired t-test. (B) Percentage of $\beta$-gal positive TH neurons normalized to control three rostrocaudal VTA levels and the CLi (the CLi data are included for easier comparison the same values are also shown in Figure 5F). The percentage of $\beta$-gal positive TH neurons at the two rostral VTA levels (level 1 and 2) was significantly decreased in Bc/11a ckolacZ compared to control mice, while there was a significant increase in the CLi. Statistical significance was determined by Welch's t-test. (C) In control animals, there is a systematic decrease in $\beta$-gal positive $\mathrm{TH}$ neurons from rostral-to-caudal (level1 to $\mathrm{CLi}$ ), while there is a systematic increase in the percentage of $\beta$-gal positive TH neurons from rostral-to-caudal in $\mathrm{Bcl} / 1 \mathrm{a}$ ckolacz mice Statistical significance was determined by one-way ANOVA followed by a test for linear trend. (D-G) Immunofluorescent staining for TH on striatal sections of control (D,F) and Bc/11a ckolacz (E,G) mice. (H-J) Quantification of TH-positive fiber density in dorsal striatum (DS) (H), olfactory tubercle (OT) (I) and ventral ( $v$ ) and dorsal $(\mathrm{d})$ TS $(\mathrm{J})$ of control ( $\mathrm{n}=3$ mice) and Bc/11a cko mice ( $\mathrm{n}=3$ mice) shows no difference in the density of TH innervation between the two groups. Statistical significance was determined by unpaired t-test. Error bars indicate mean $+/-$ SEM. Scale bar: $500 \mu \mathrm{m}$ (A-D).

\section{Acknowledgment:}

This work was supported by the German Research Foundation (BL 767/2-1, BL 767/3-1, BL 767/4-1, 417960915 to Sandra Blaess), the SFB 1089 (to MT and Sandra Blaess), the Maria von Linden-Program (University of Bonn, to Sandra Blaess), and the Ministerium für Kultur und Wissenschaft des Landes Nordrhein-Westfalen (Rückkehrer-Programm to Sandra Blaess). Stefan Britsch has been supported by grants from the DFG (BR 2215/1-1, 2215/1-2). We thank Neal Copeland and Nancy Jenkins for agreeing to provide the Bcl11a floxed mouse line; the UKB microscopy core facility for support with imaging, the UKB virus core for providing AAVs; Milan Pabst and Heinz Beck for support with stereotactical injections, Alesja Dernst, Philipp Grunwald and Julian Wirtz for technical support and Norisa Meli for critical reading of the manuscript.

\section{Contributions to the paper:}

1098 Marianna Tolve, Data curation, Formal analysis, Validation, Investigation, Visualization, 1099 Methodology, Writing-original draft, Writing—review and editing; Ayse Ulusoy, Data 
1100 curation, Formal analysis, Validation, Investigation, Visualization, Methodology, Writing-

1101 review and editing; Khondker Ushna Sameen Islam; Investigation, Visualization,

1102 Methodology, Writing—review and editing; Gabriela O. Bodea, Investigation, Visualization,

1103 Methodology, Writing—review and editing; Ece Öztürk, Bianca Broske, Astrid Mentani,

1104 Antonia Wagener, Investigation, Writing—review and editing; Stefan Britsch, Pengtao Liu,

1105 Walid Khaled, Karen van Loo, Resources, Writing-review and editing; Stephan Baader,

1106 Data curation, Formal analysis, Validation, Resources, Methodology, Writing—review and

1107 editing; Donato A. Di Monte, Data curation, Formal analysis, Validation, Resources, Writing-

1108 review and editing; Sandra Blaess Conceptualization, Resources, Data curation, Formal

1109 analysis, Supervision, Funding acquisition, Validation, Methodology, Project administration,

1110 Writing- original draft, Writing—review and editing 
bioRxiv preprint doi: https://doi.org/10.1101/2020.10.06.327940; this version posted October 7, 2020. The copyright holder for this preprint (which was not certified by peer review) is the author/funder, who has granted bioRxiv a license to display the preprint in perpetuity. It is THBcl19a
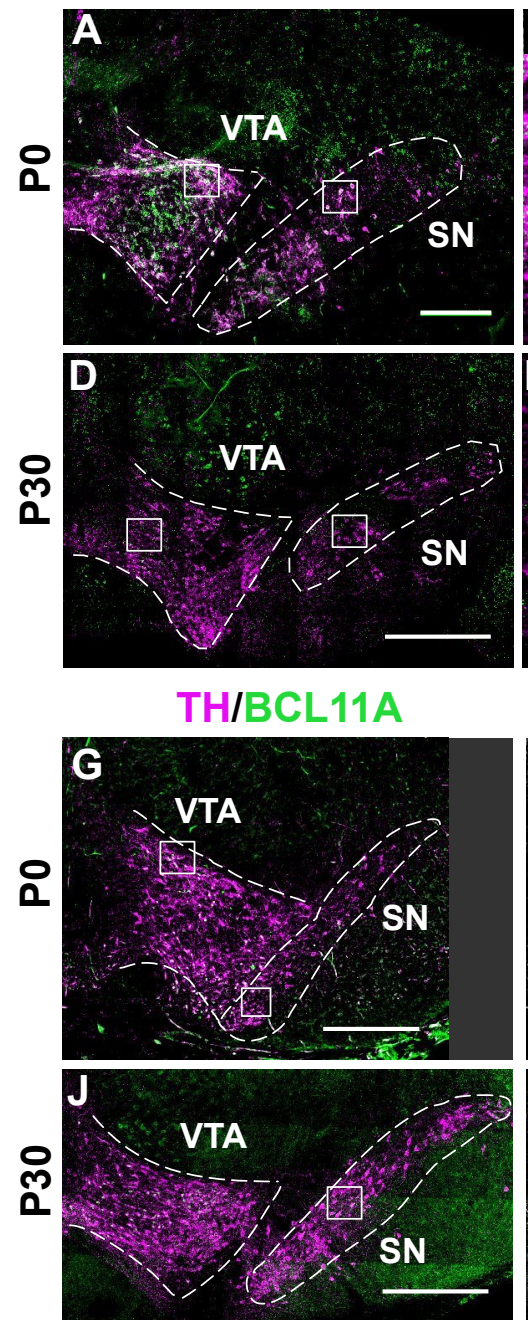

TH/ $\beta$-gal
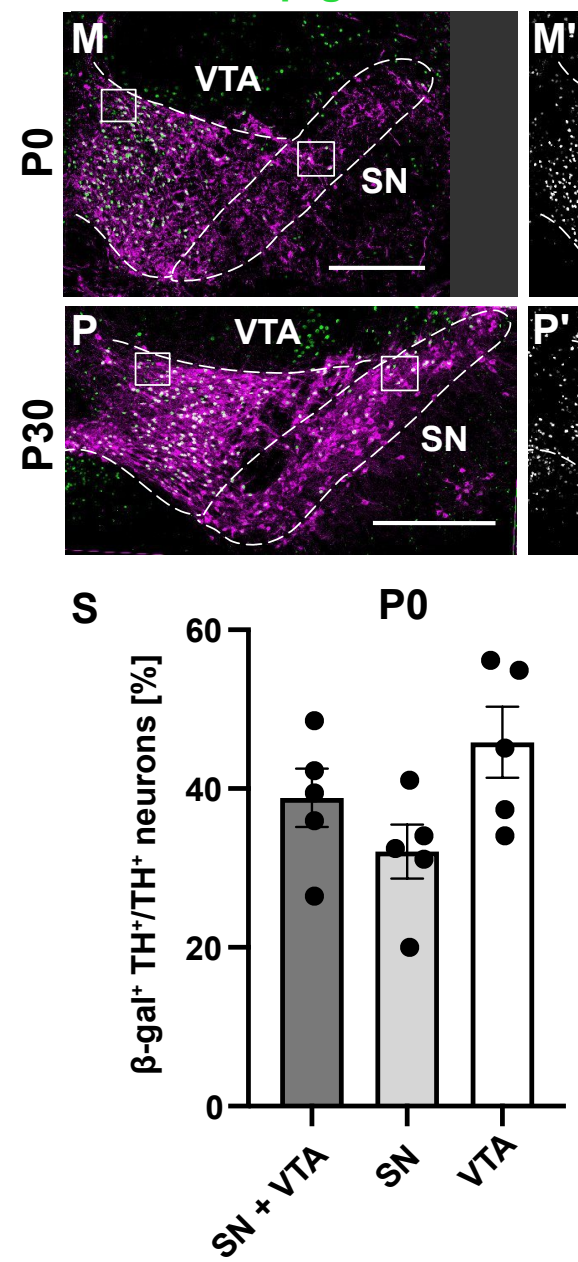

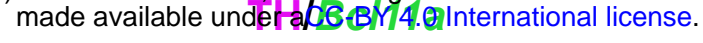
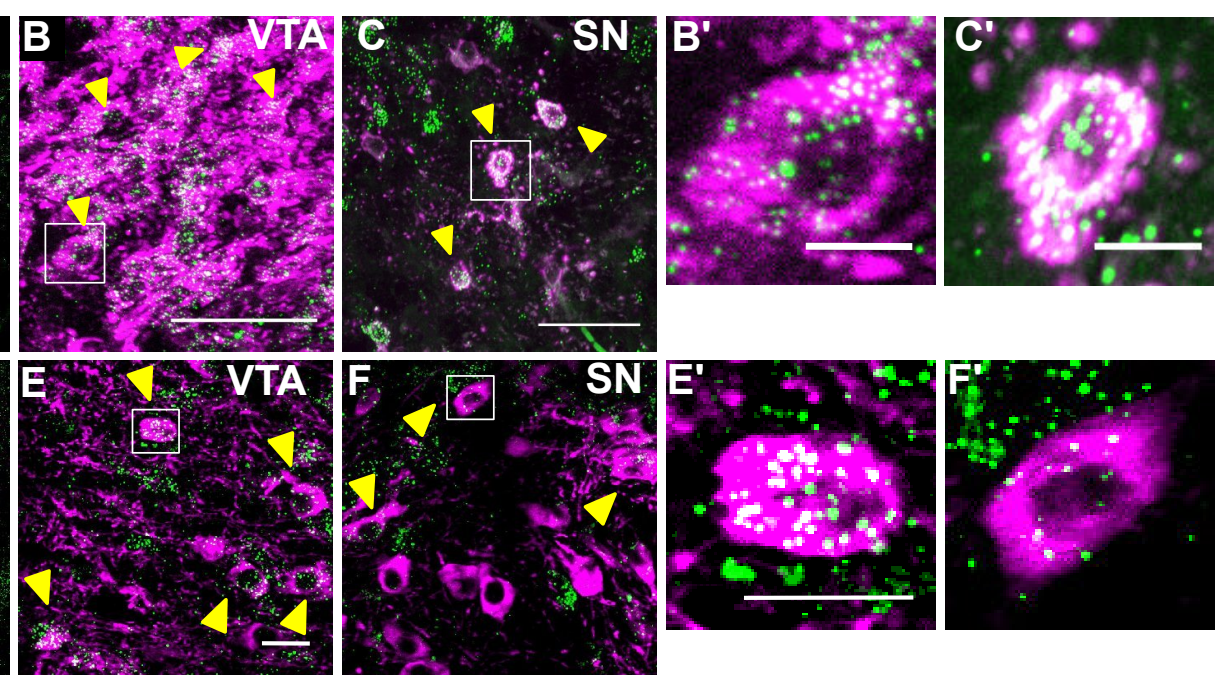

TH/BCL11A

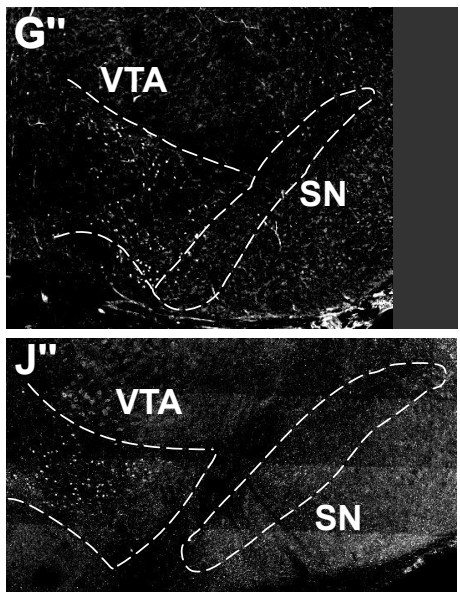

$\beta$-gal

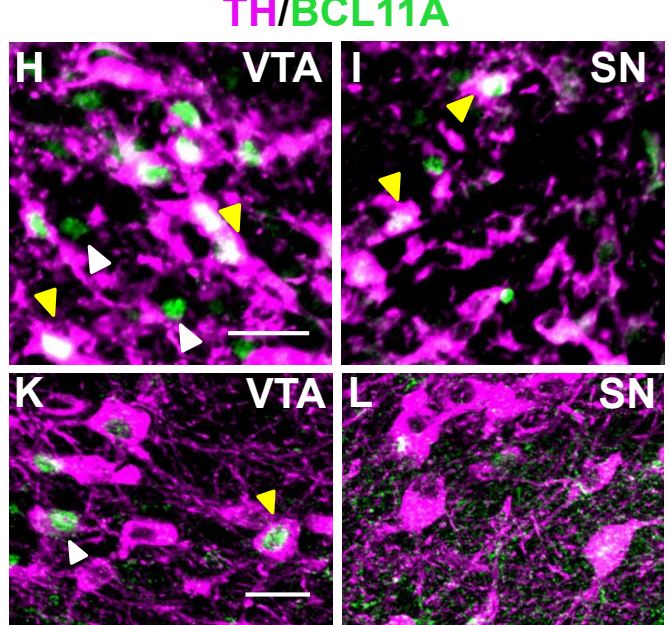

$\mathrm{TH} / \beta=\mathrm{gal}$
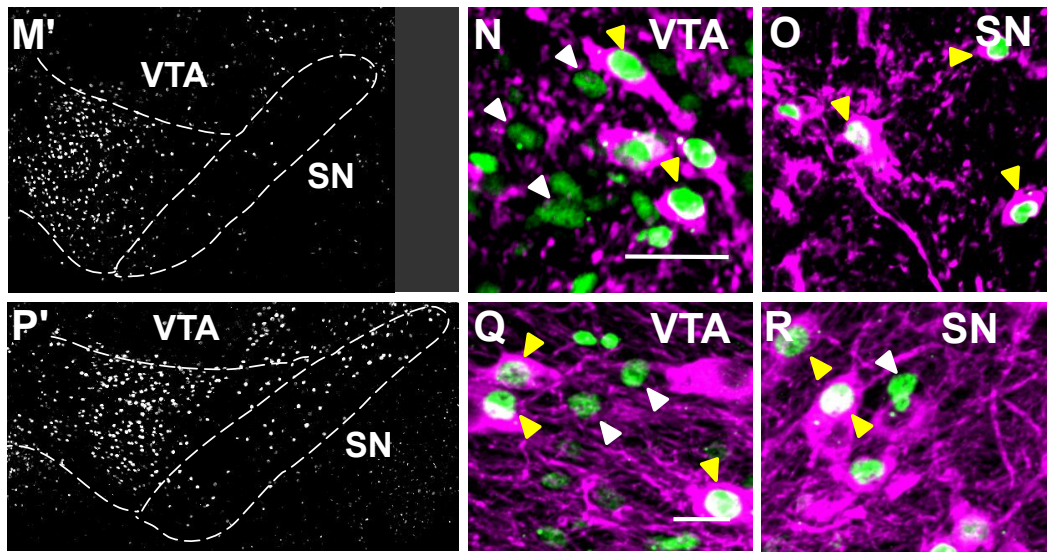

$\mathbf{T}$

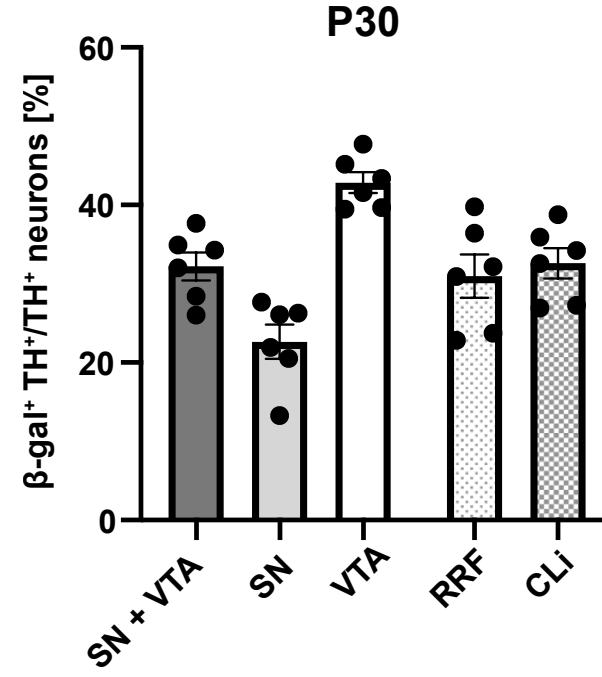



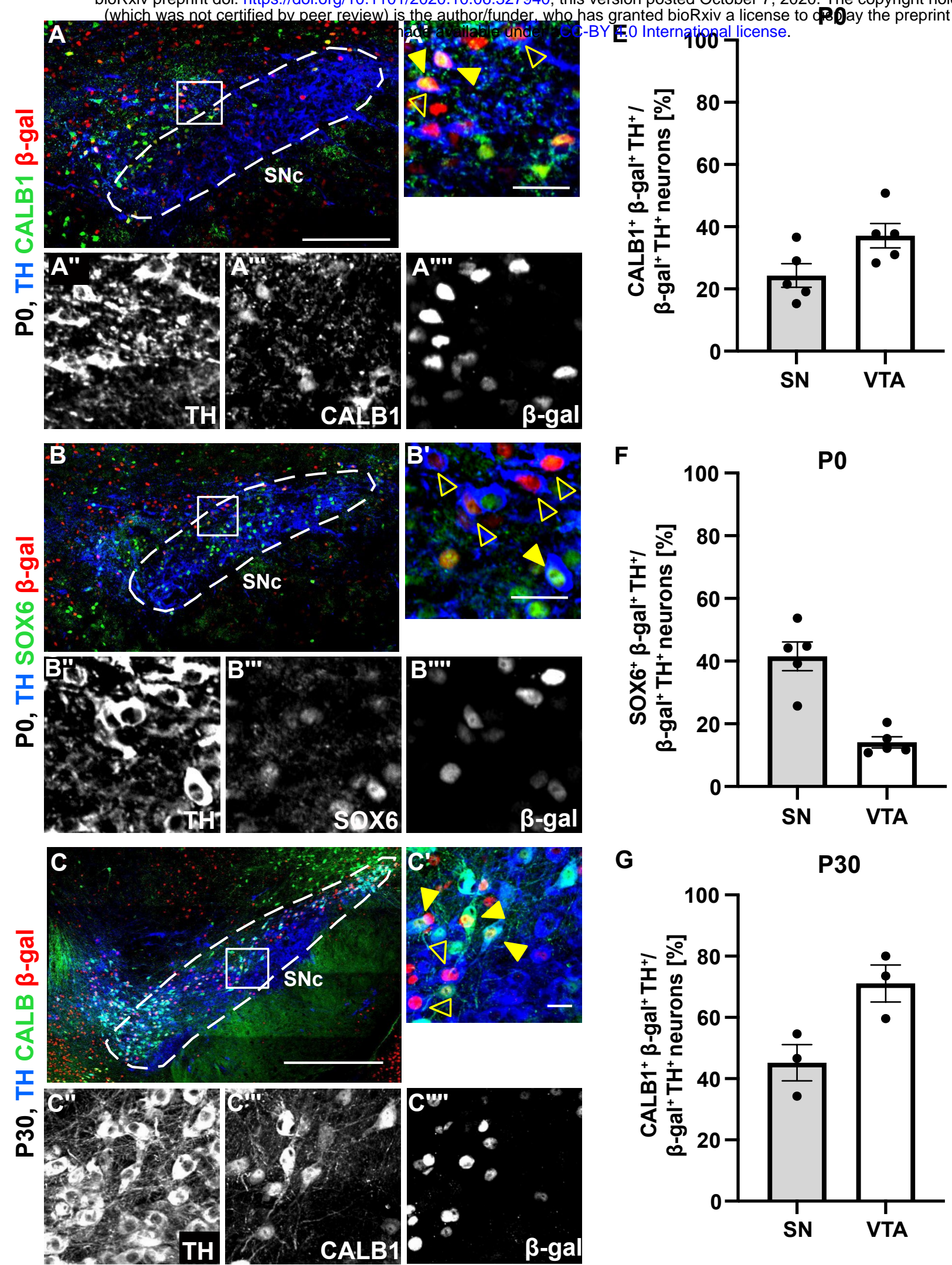

G

P30
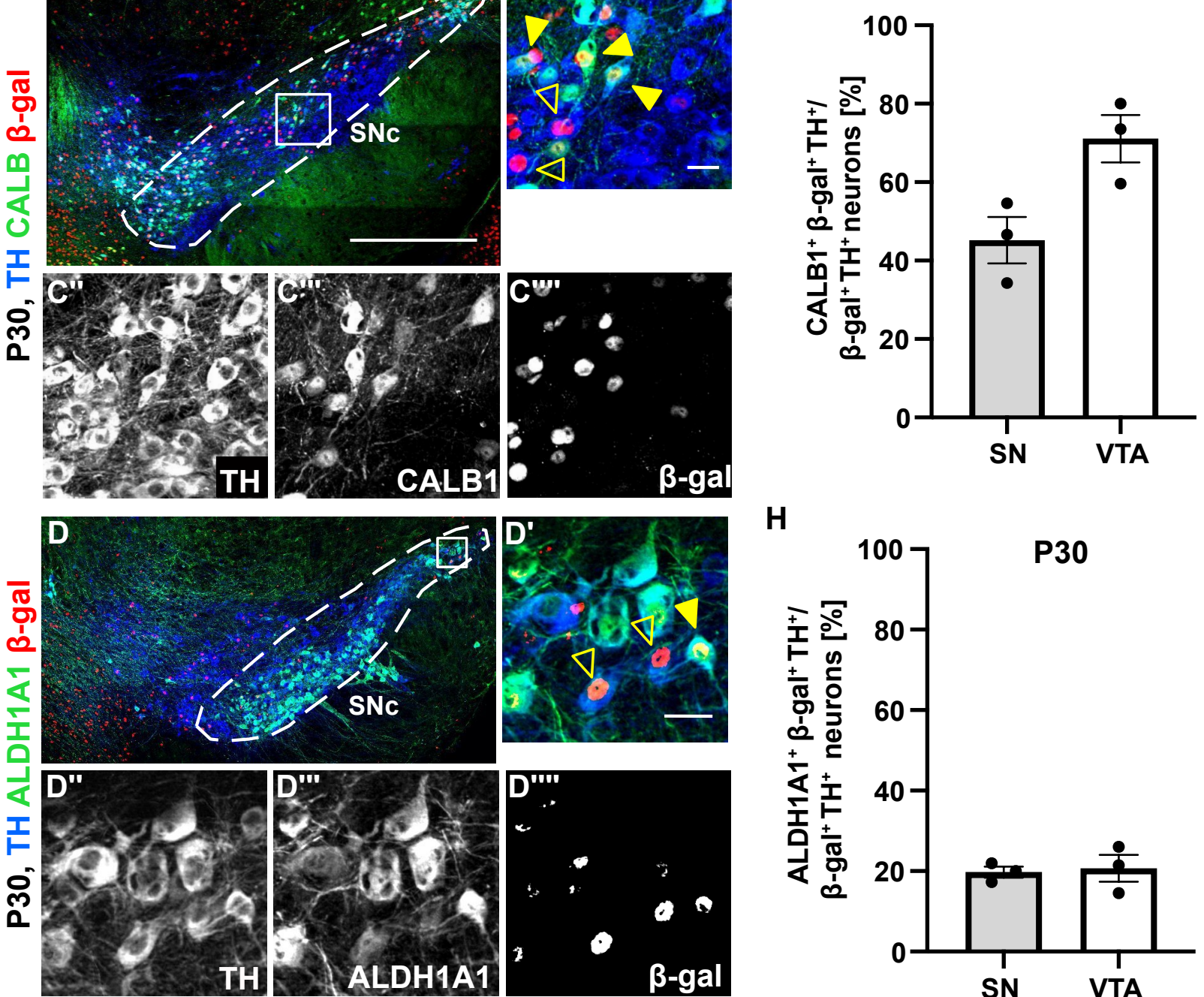

H

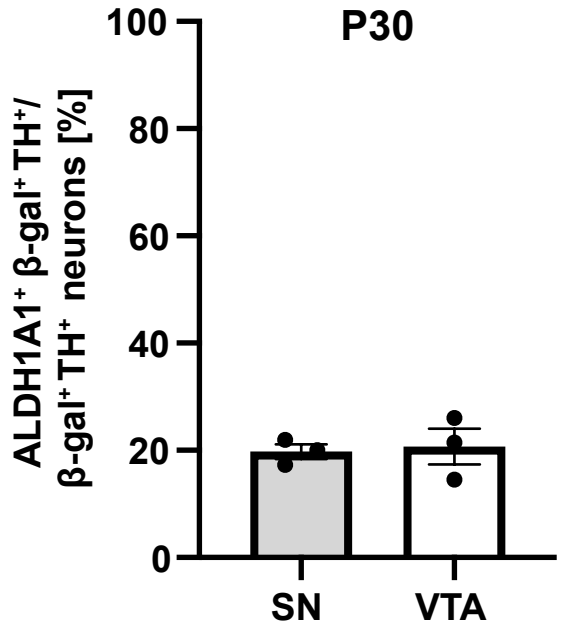


bioRxiv preprint doi: https://doi.org/10.1101/2020.10.06.327940; this version posted October 7, 2020. The copyright holder for this preprint

(which was not certified by peer review) is the author/funder, who has granted bioRxiv a license to display the preprint in perpetuity. It is made available under aCC-BY 4.0 International license.

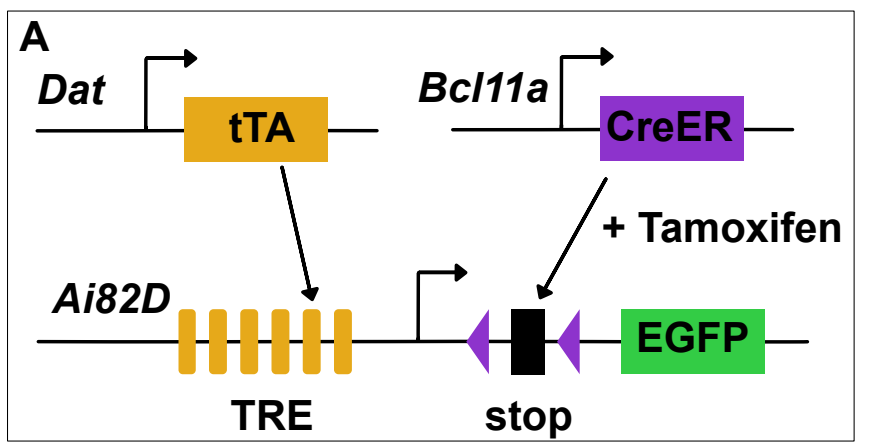

\section{B Experimental timeline}
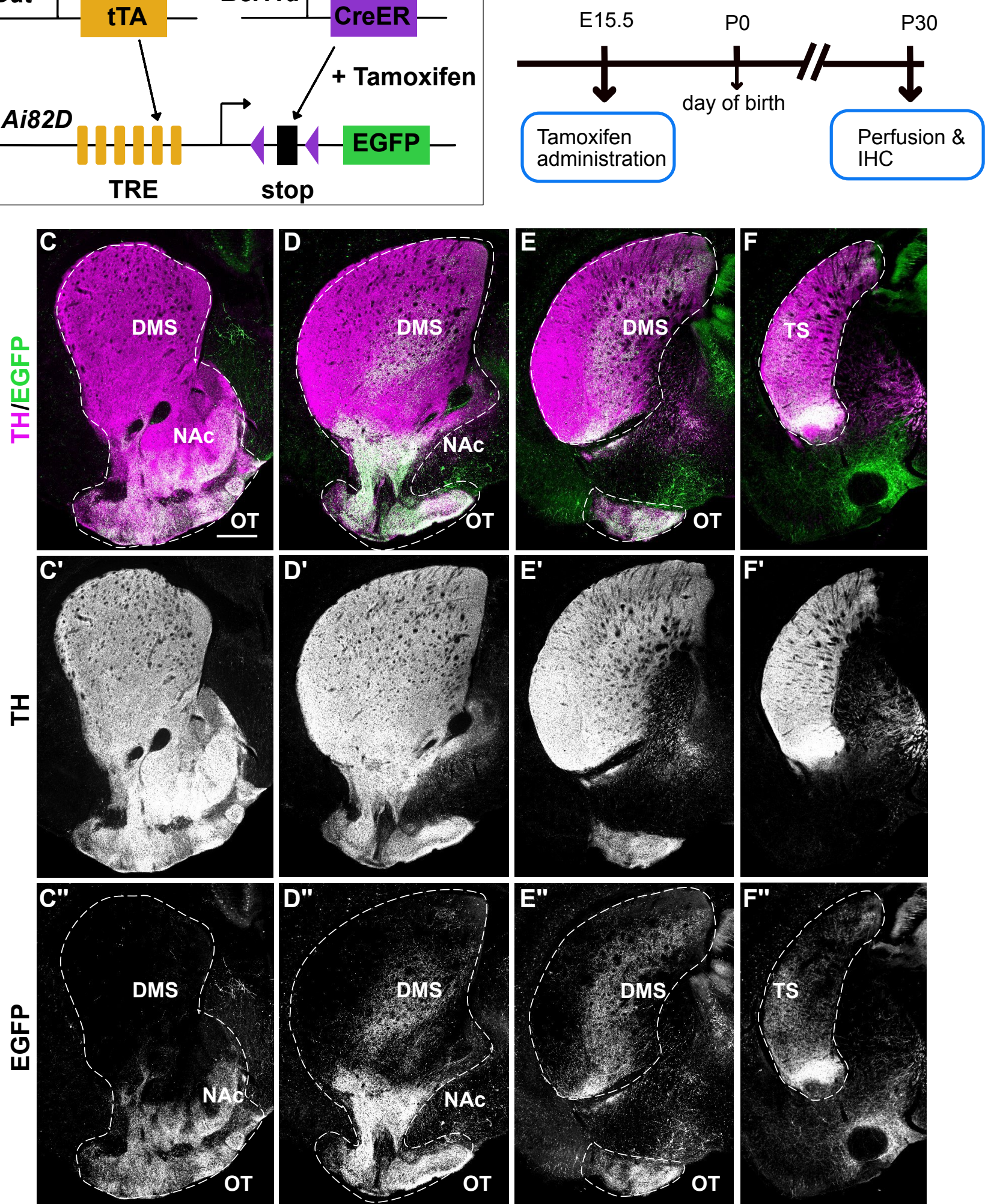

Rostral 
bioRxiv preprint doi: https://doi.org/10.1101/2020.10.06.327940; this version posted October 7, 2020. The copyright holder for this preprint

(which was not certified by peer review) is the author/funder, who has granted bioRxiv a license to display the preprint in perpetuity. It is

A $ᄃ$ EF-1 $\alpha=:=A=$ ChETA-EYFP $=$ WPRE polyA B Experimental timeline

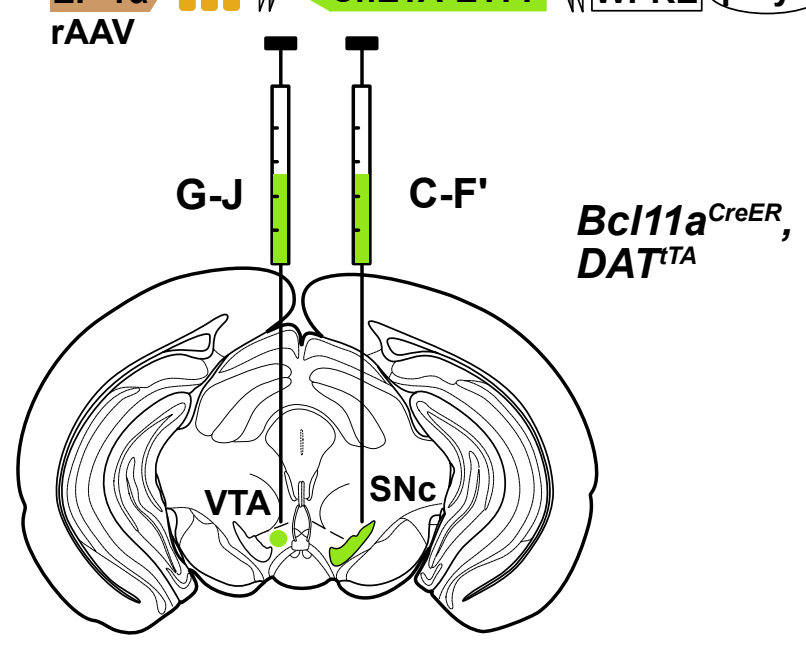

012345678910

25
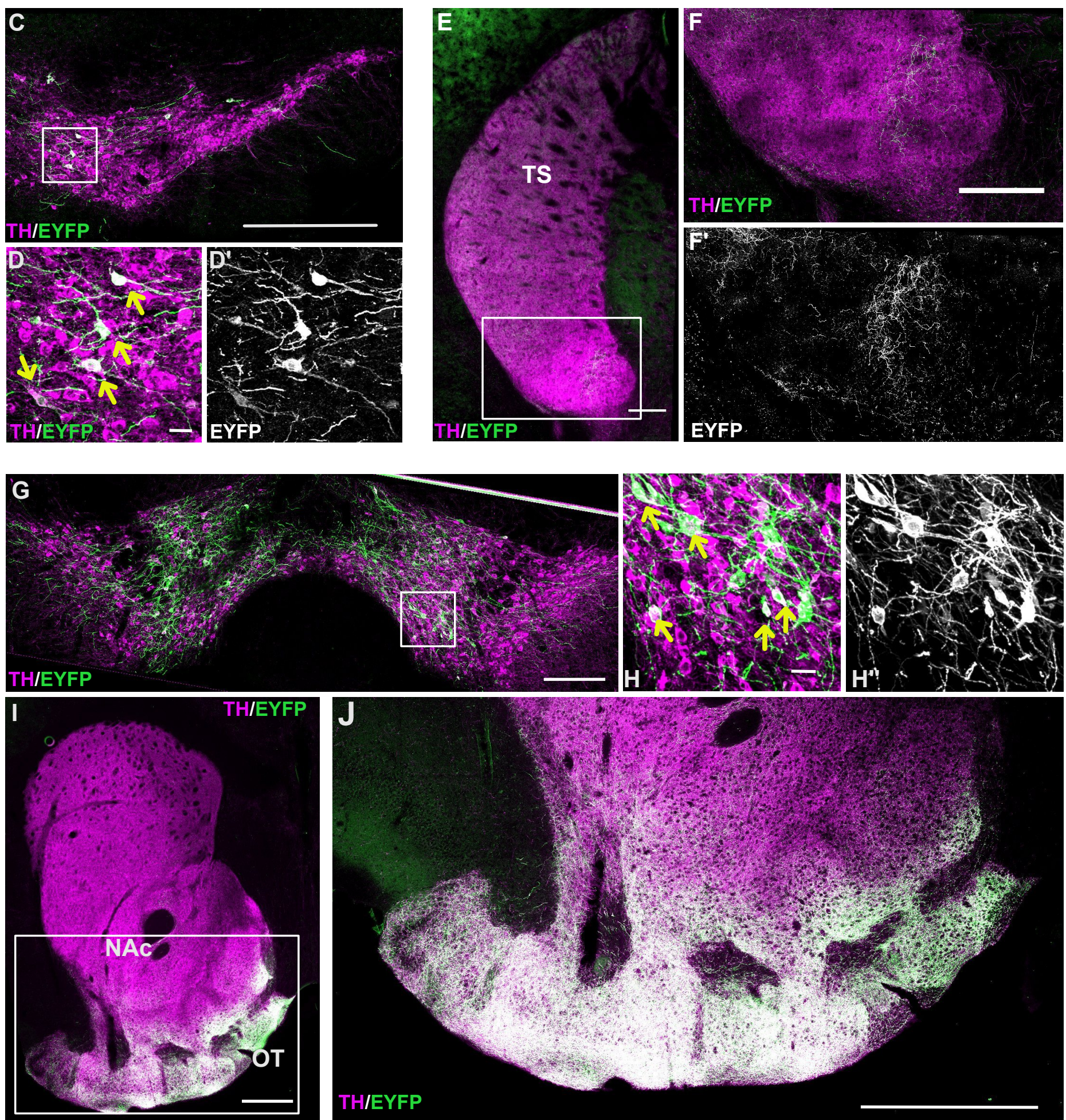

Figure 4 


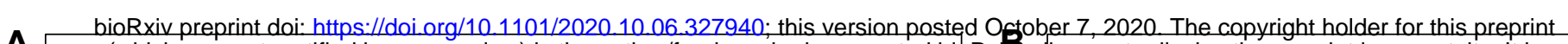

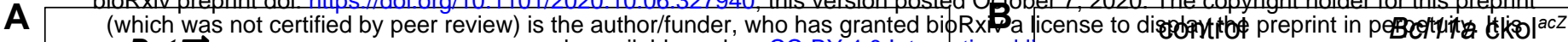
Dat $\longrightarrow$ made available under ACC-BY 4.0 International Ilcense.

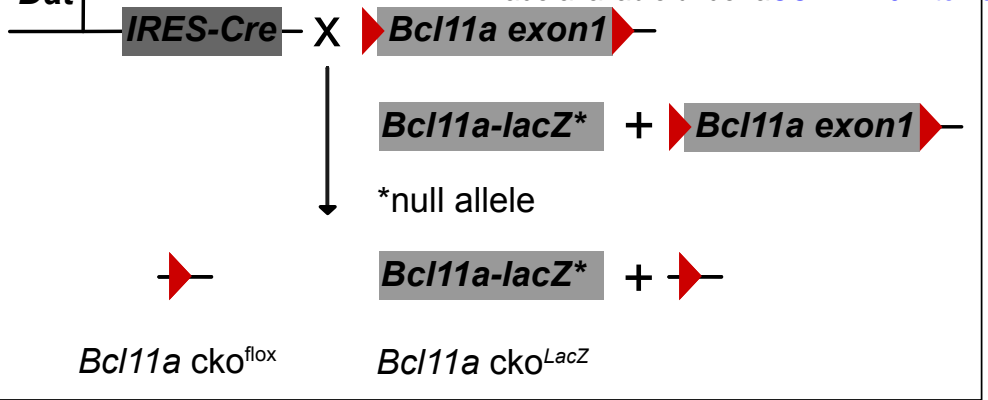
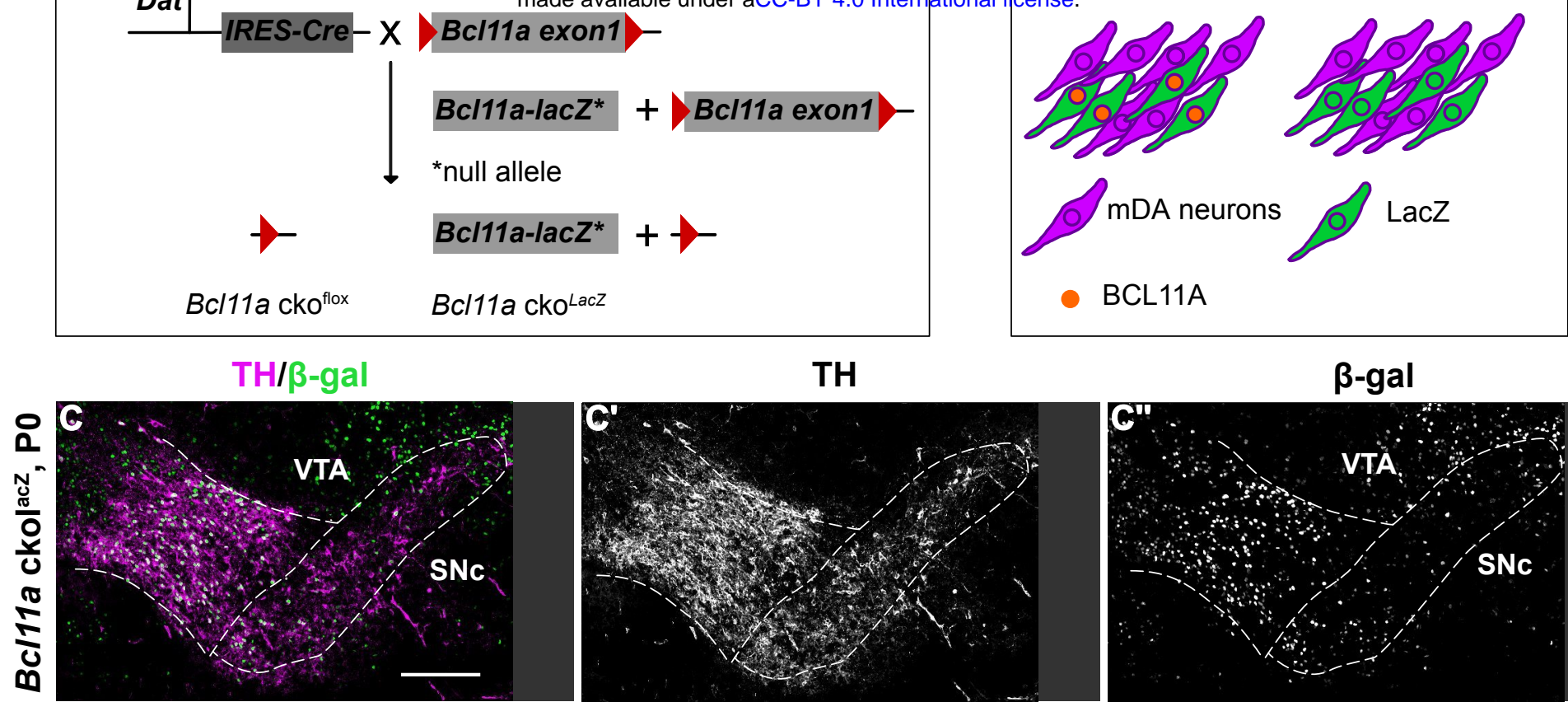

TH

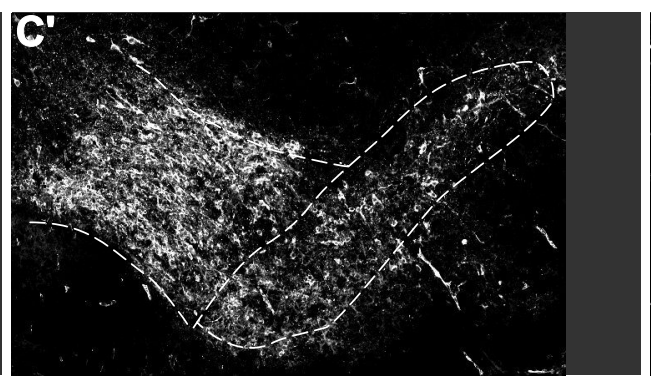

B-gal
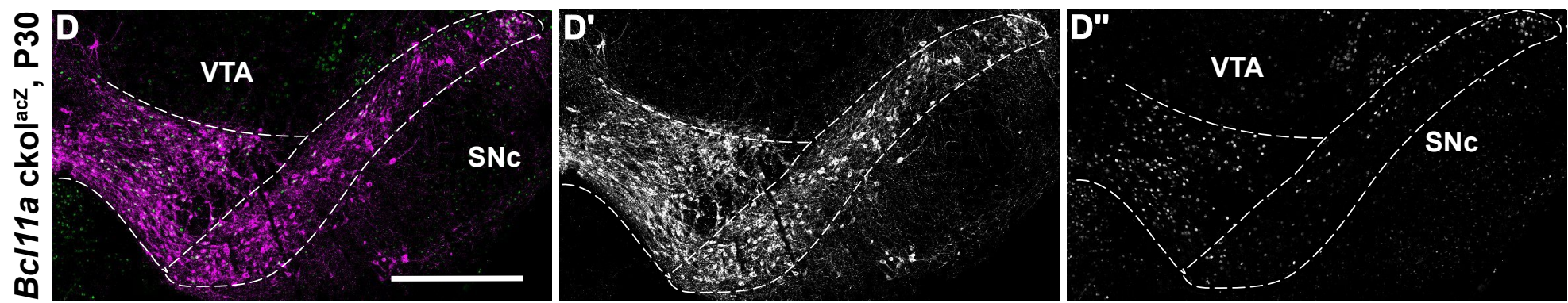

$\mathbf{E}$

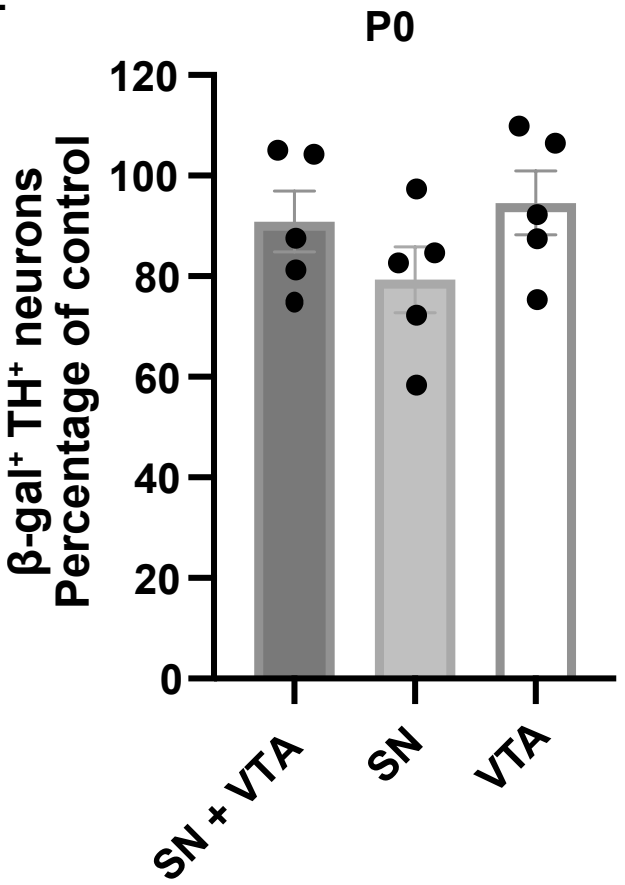

$\mathbf{F}$

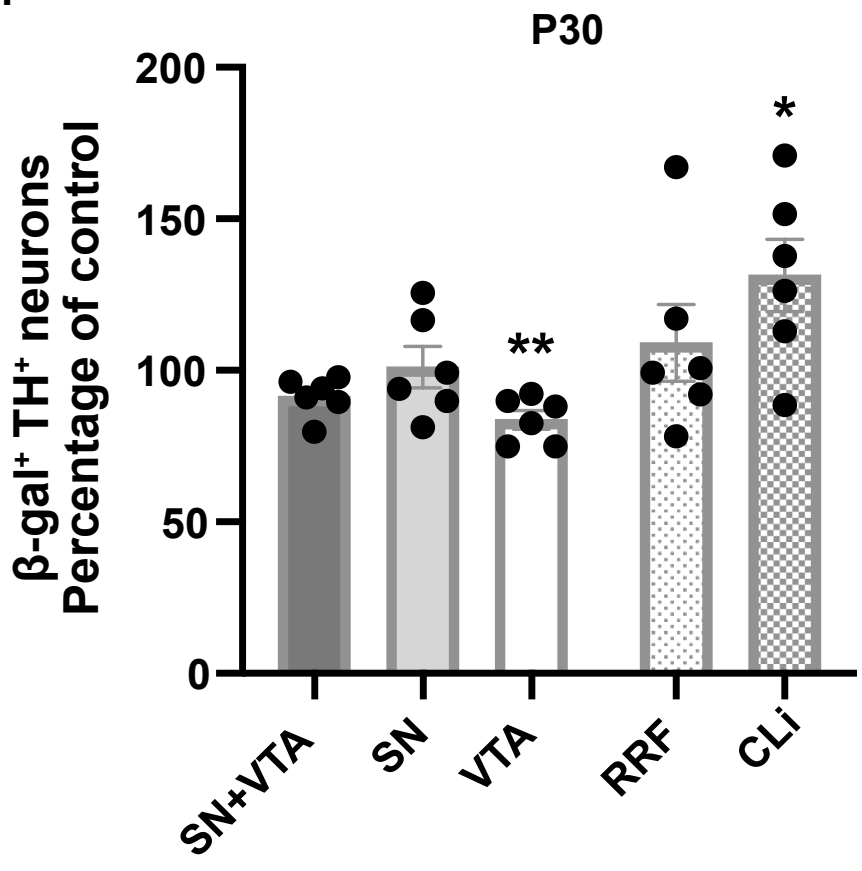

Figure 5 


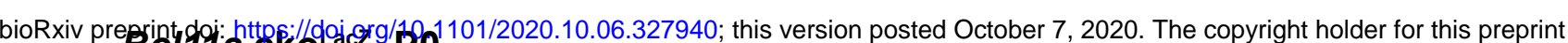

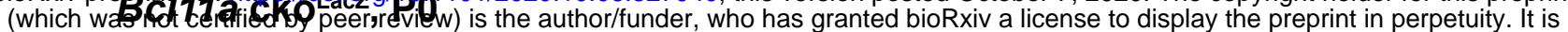
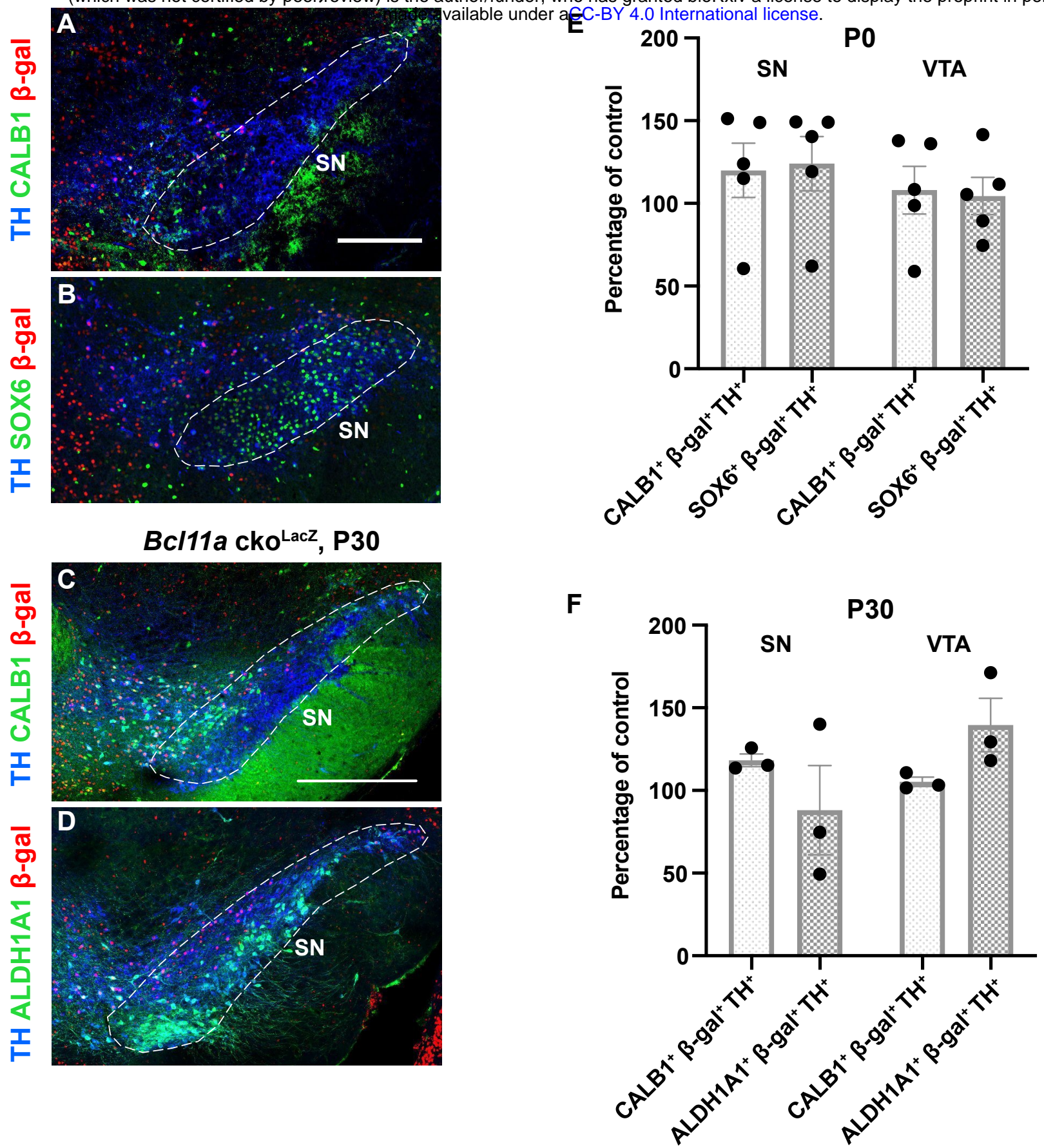

Figure 6 
A Open Field

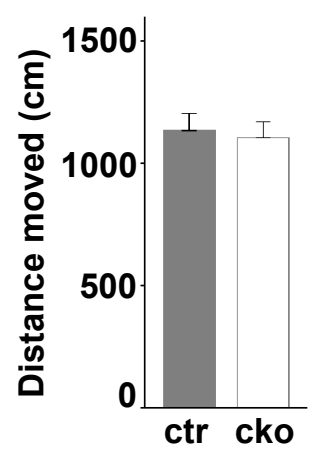

D

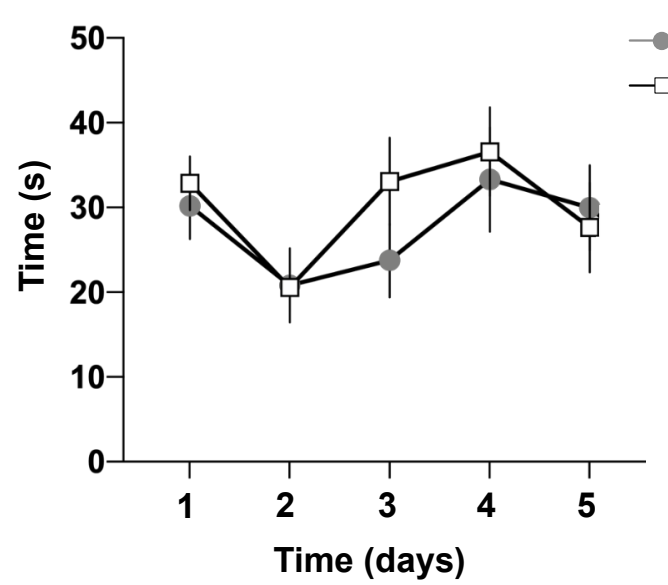

C Open Field

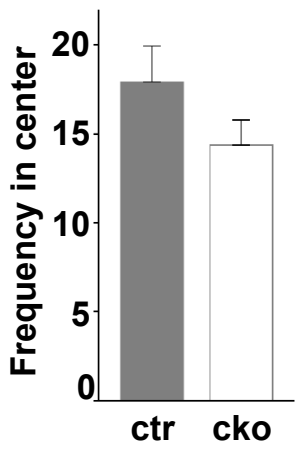

E

\section{RotaRod}

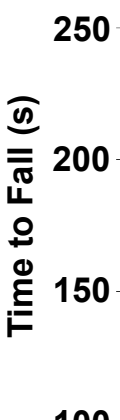

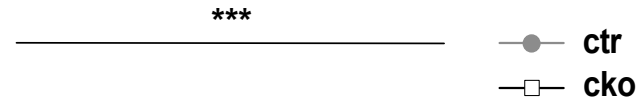

100

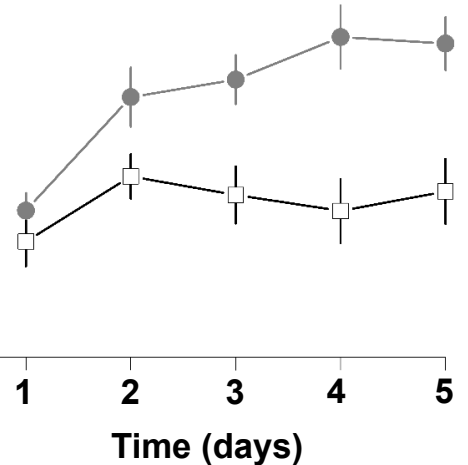

$* * * *$ 
A

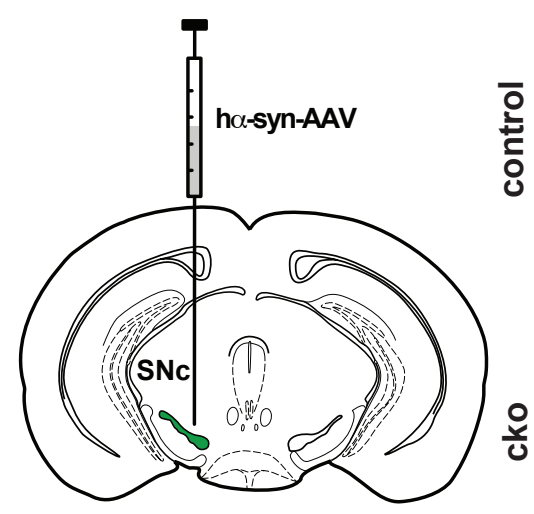

B
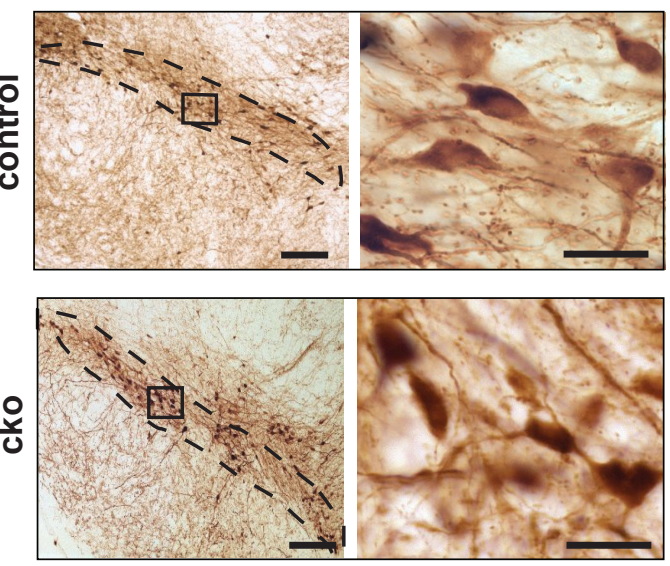

C
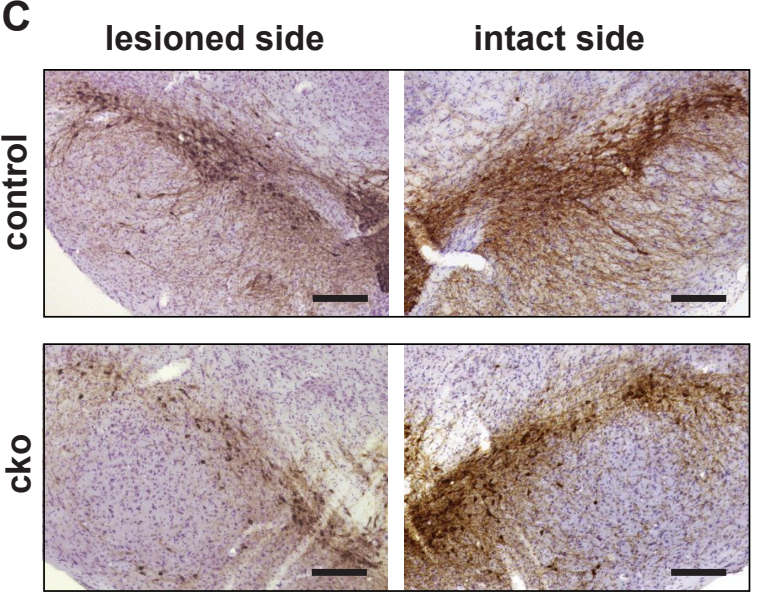

D

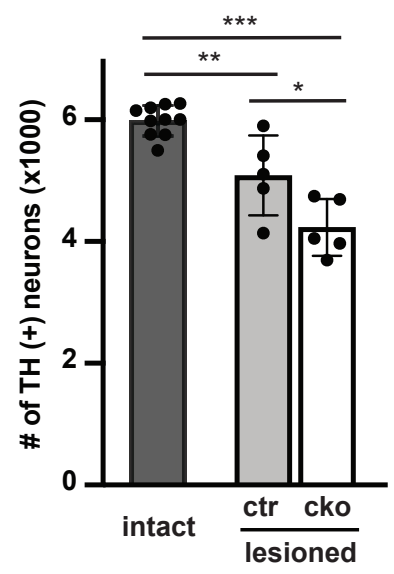

$E$

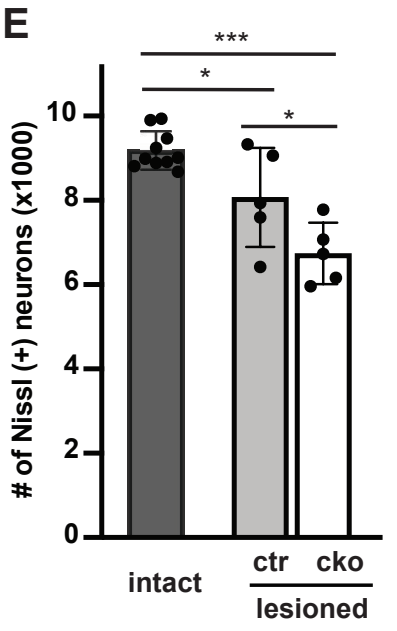

F

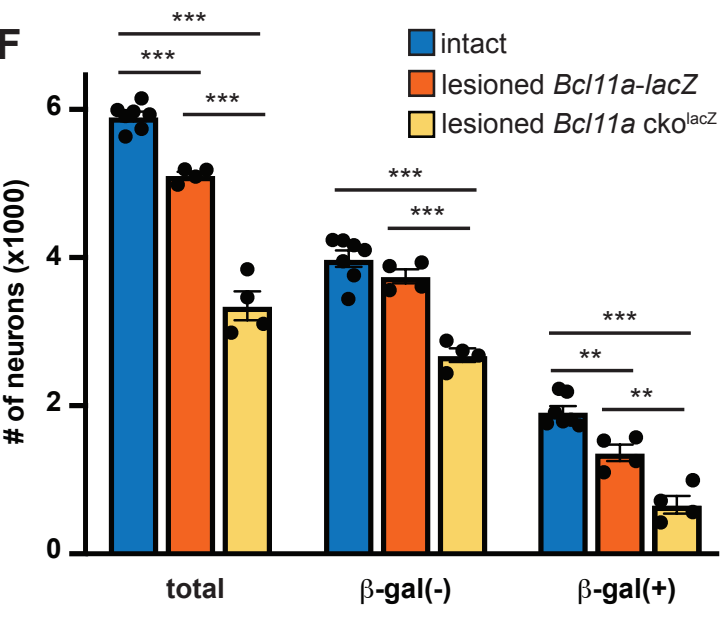


bioRxiv preprint doi: https://doi.org/10.1101/2020.10.06.327940; this version posted October 7, 2020. The copyright holder for this preprint (which was not certified by peer review) is the author/funder, who has granted bioRxiv a license to display the preprint in perpetuity. It is TH/ $\beta$-gal

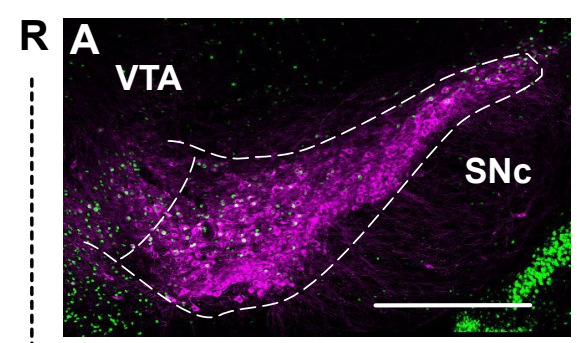

made available under aC TH $^{Y} 4.0$ International license.

$\beta$-gal
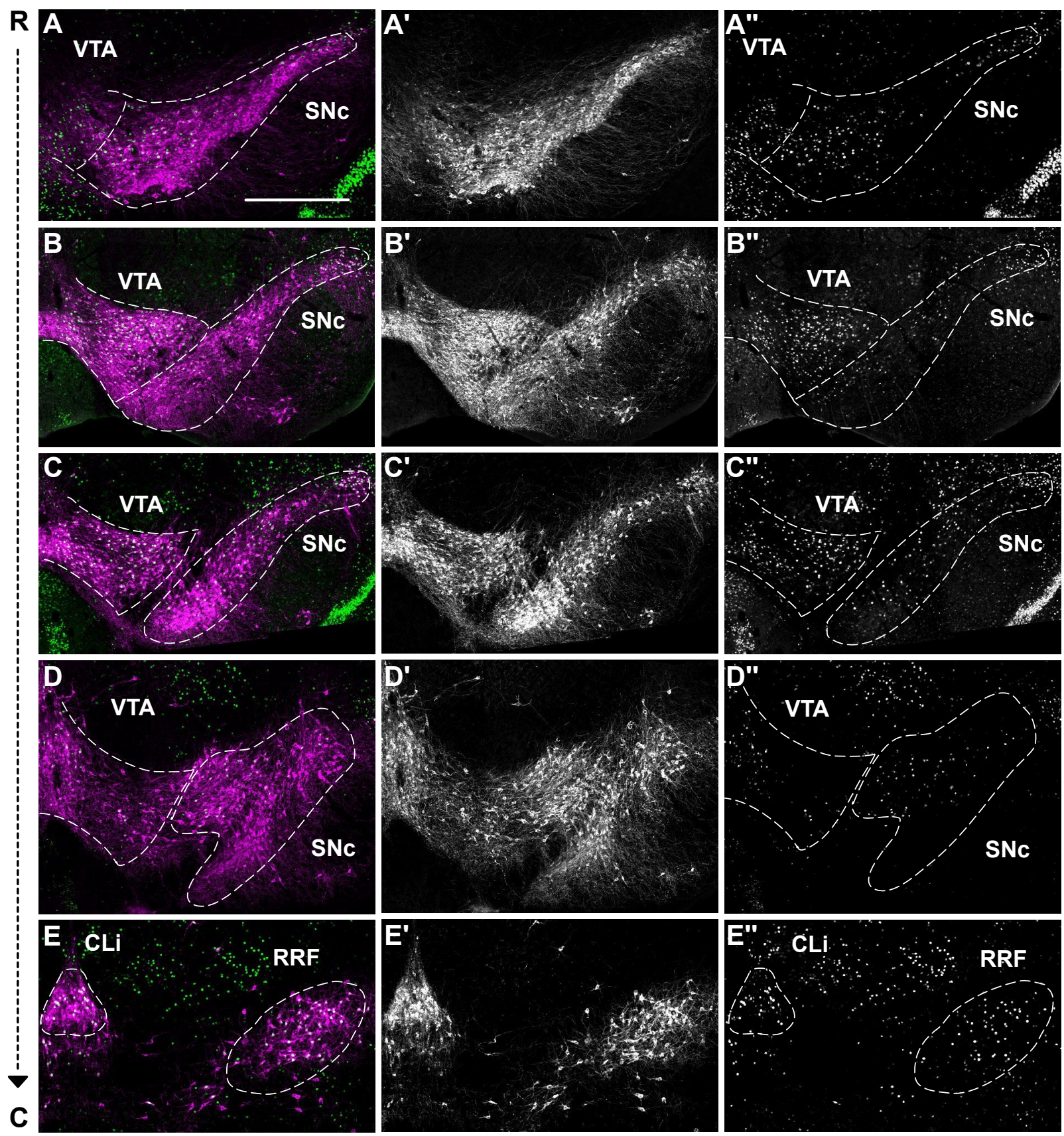
bioRxiv preprint doi: https://doi.org/10.1101/2020.10.06.327940; this version posted October 7, 2020. The copyright holder for this preprint

(which was not certified by peer review) is the author/funder, who has granted bioRxiv a license to display the preprint in perpetuity. It is made available under aCC-BY 4.0 International license.

TH/BCL11A/B-gal
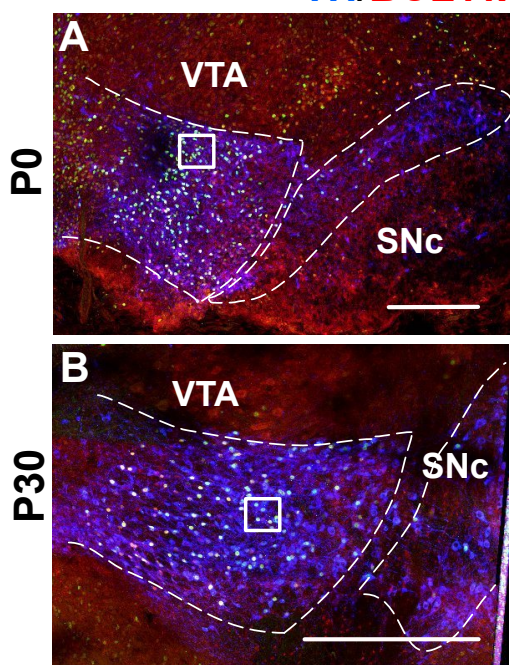

Hoe/BCL11A/ $\beta-g a l$
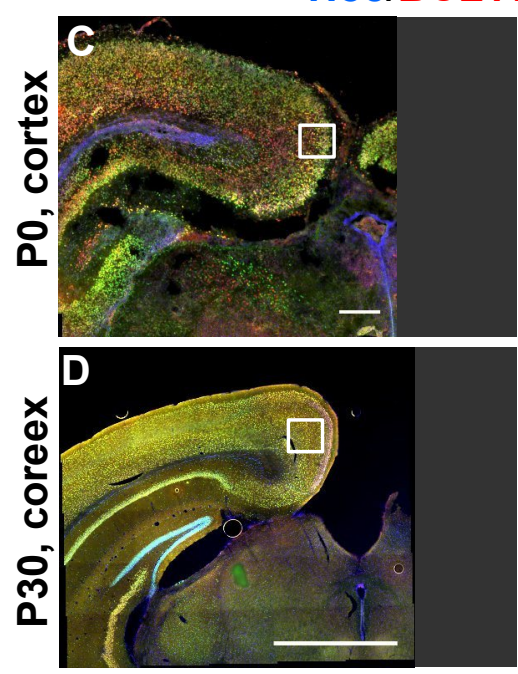

BCL11A
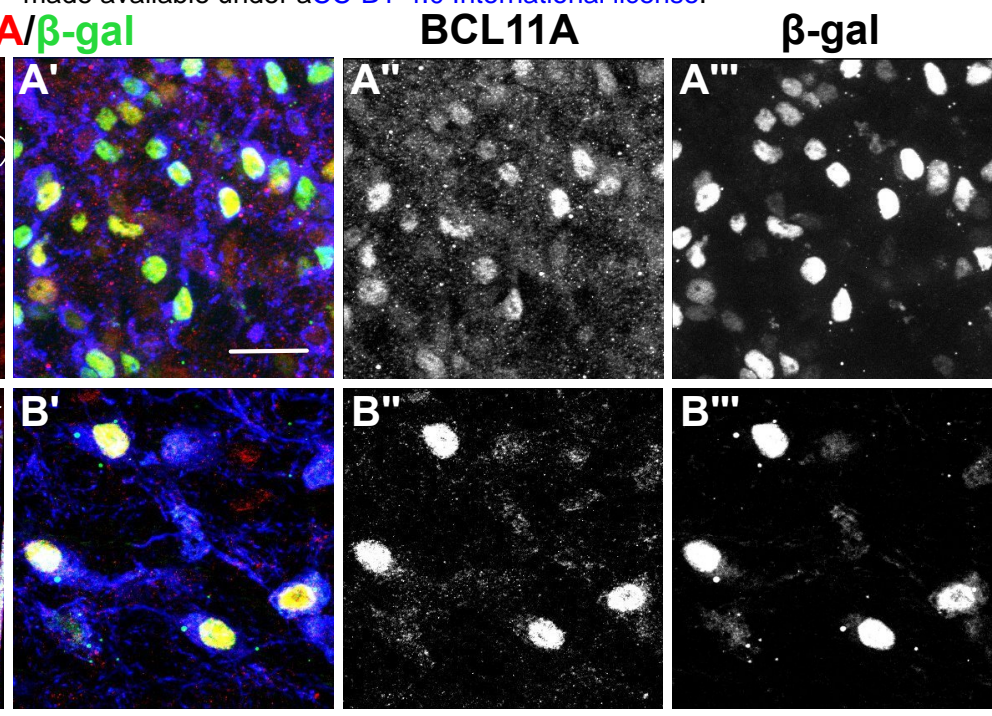

BCL11A/ $\beta=$ gal

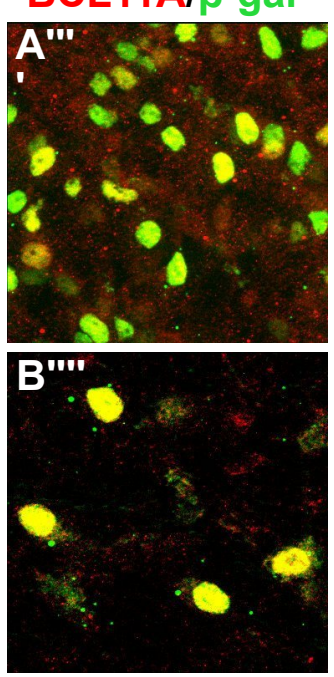

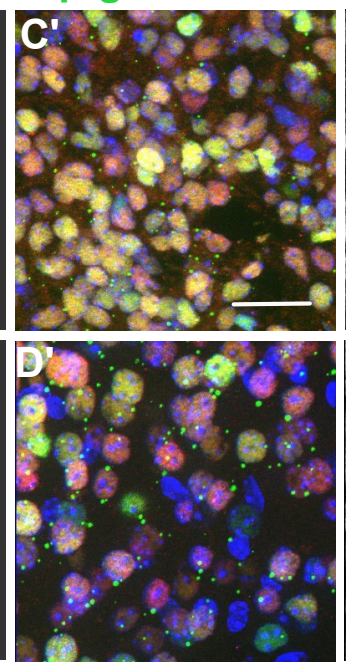
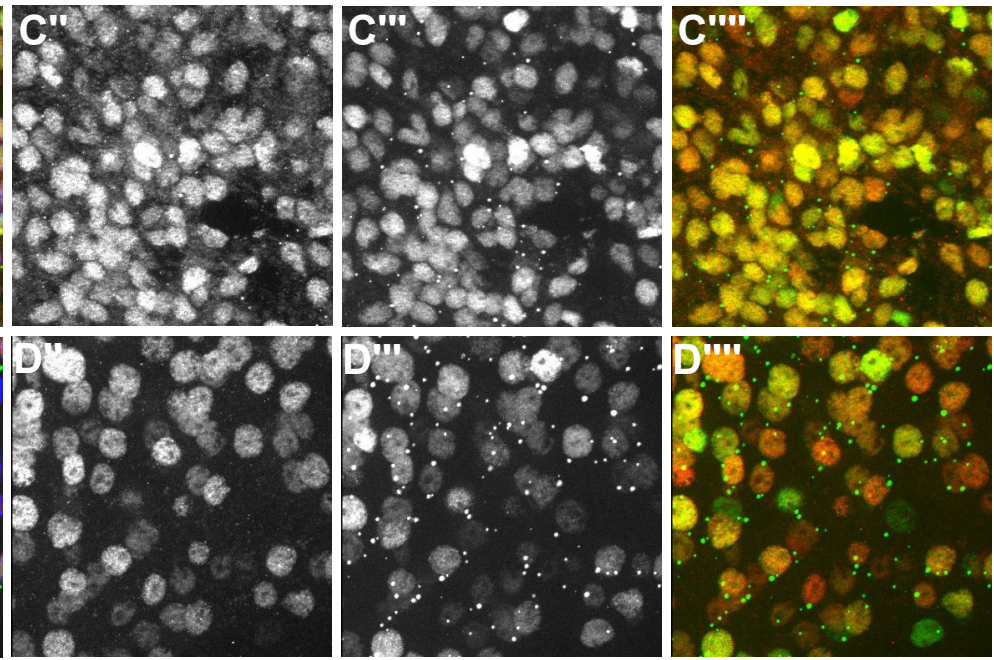
bioRxiv preprint doi: https://doi.org/10.1101/2020.10.06.327940; this version posted October 7, 2020. The copyright holder for this preprint

(which was not certified by peer review) is the author/funder, who has granted bioRxiv a license to display the preprint in perpetuity. It is made available under aCC-BY 4.0 International license.

TH/BCL11A
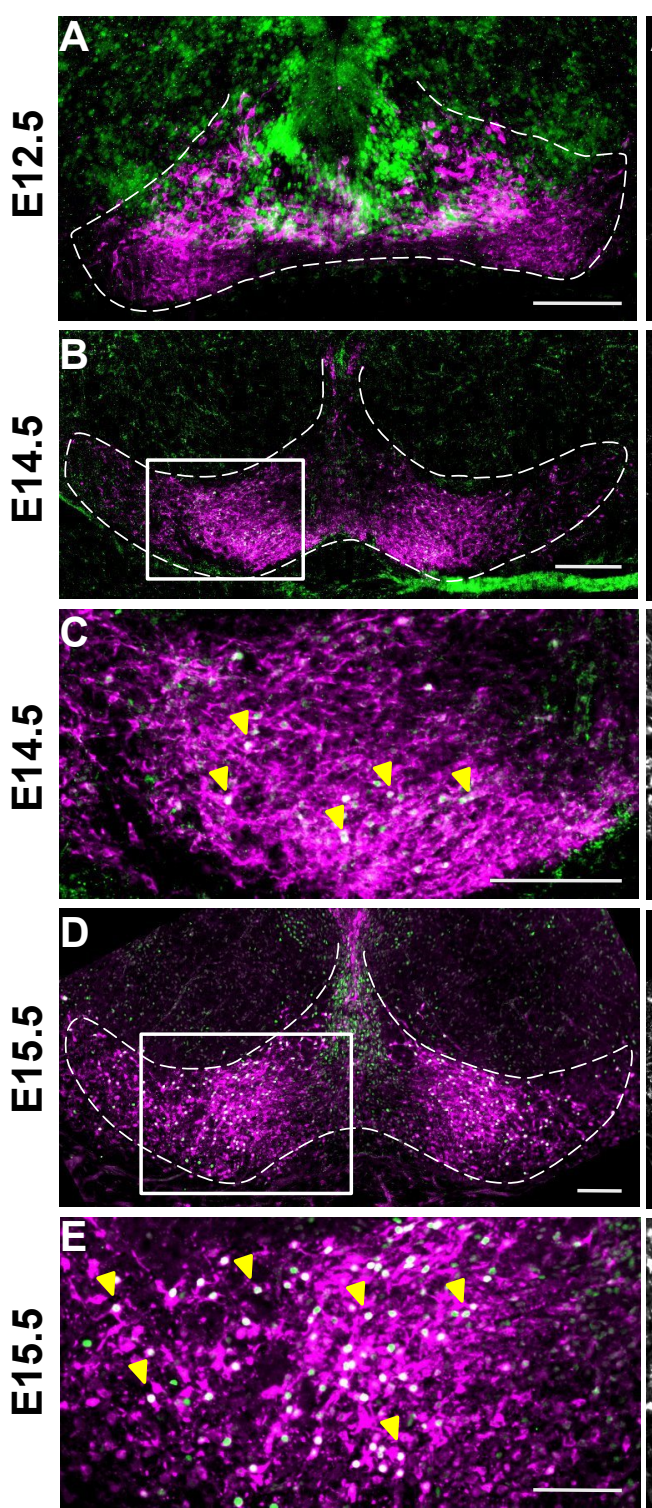

TH
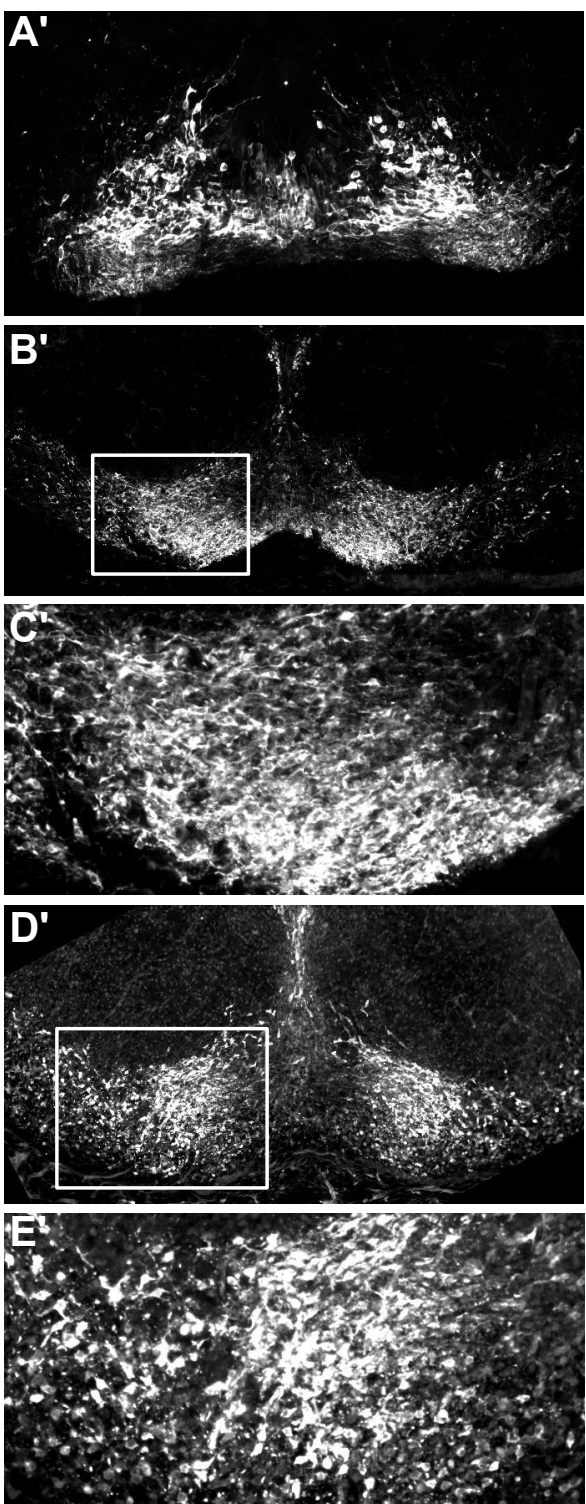

BCL11A
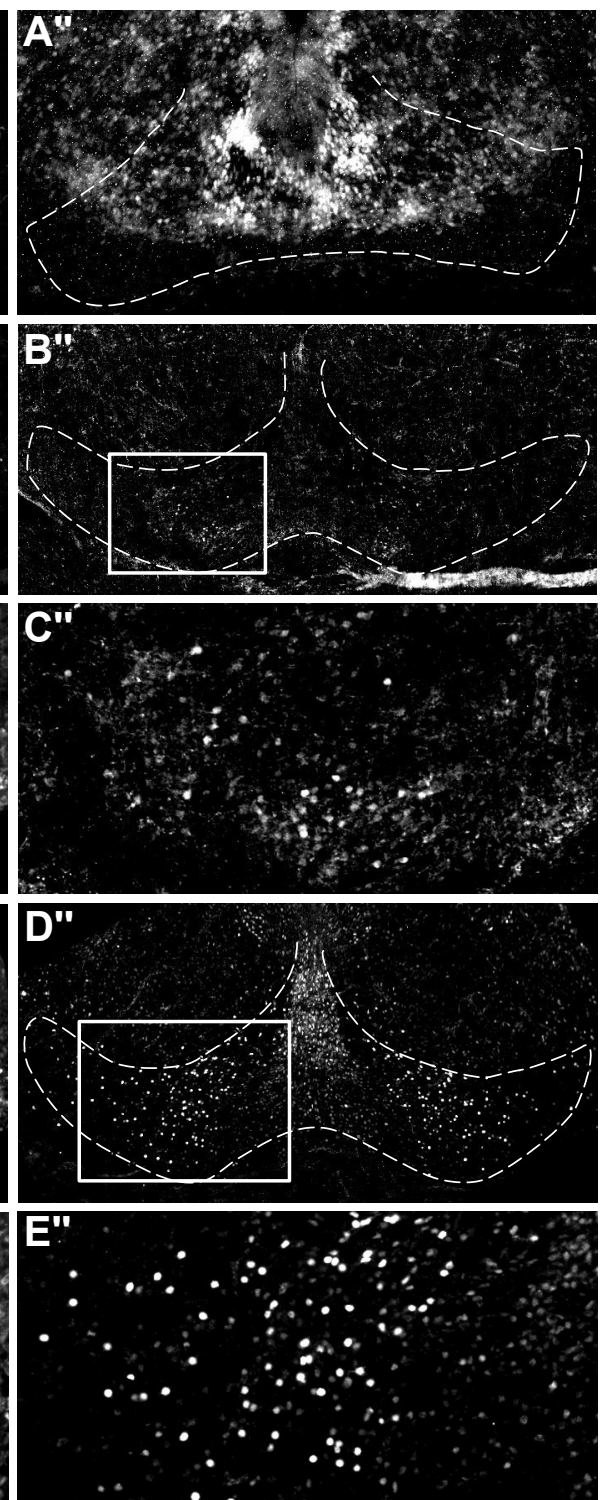

\section{Supplemental Figure 3}


bioRxiv preprint doi: https://doi.org/10.1101/2020.10.06.327940; this version posted October 7, 2020. The copyright holder for this preprint

(which was not certified by peer review) is the author/funder, who has granted bioRxiv a license to display the preprint in perpetuity. It is made available under aCC-BY 4.0 International license.

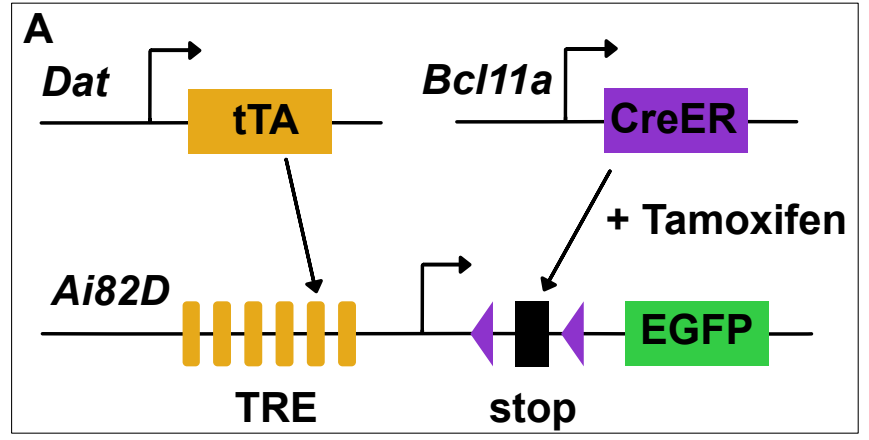

TH/EGFP

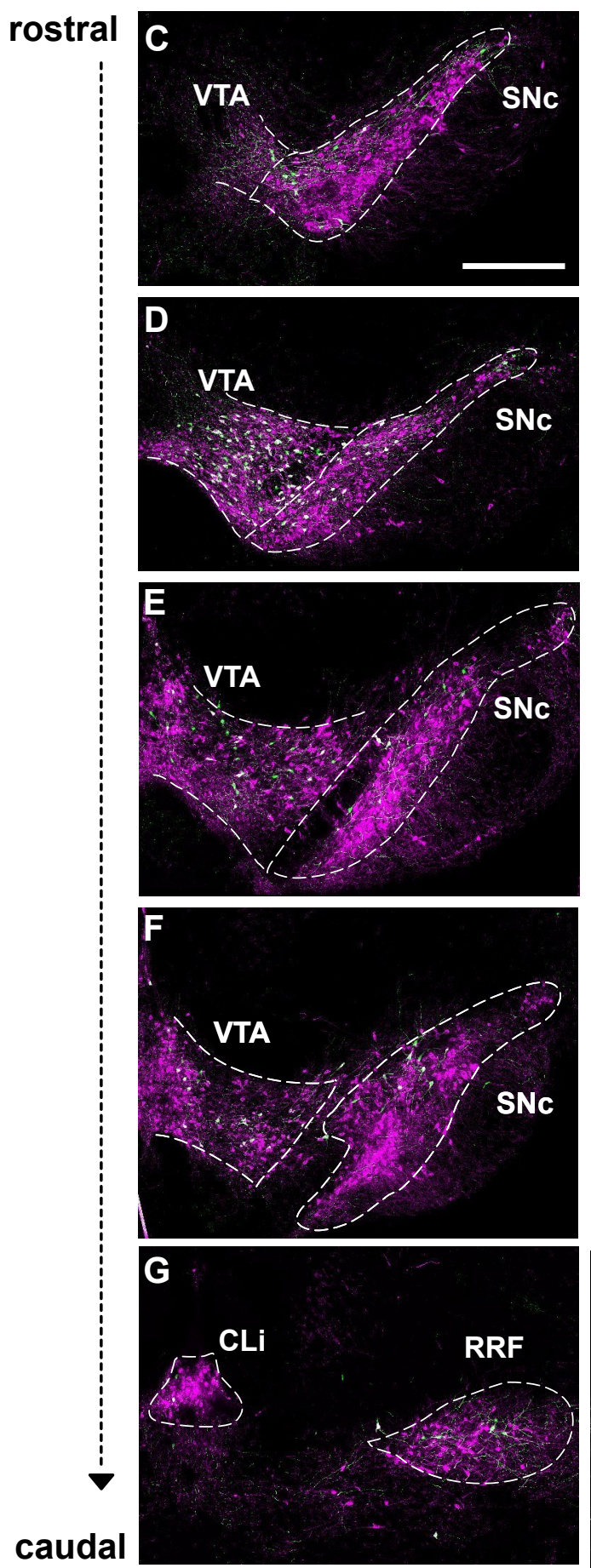

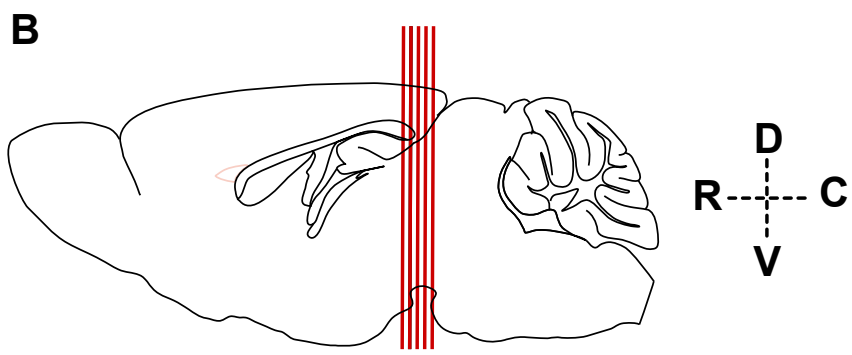

TH
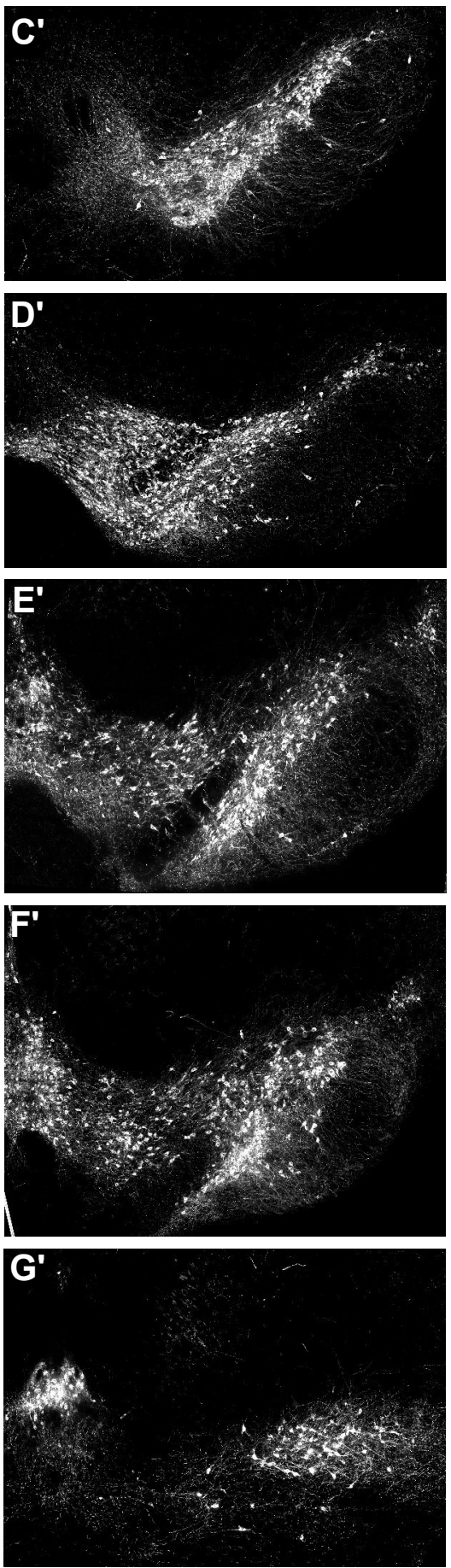
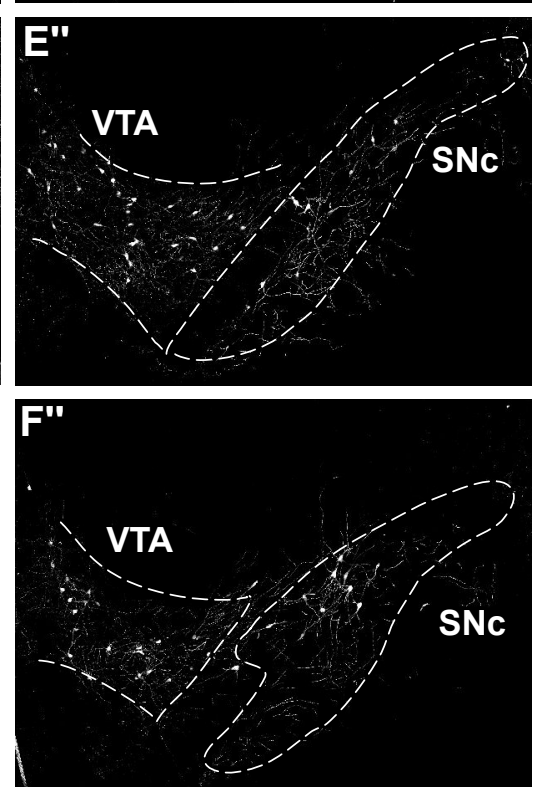

EGFP
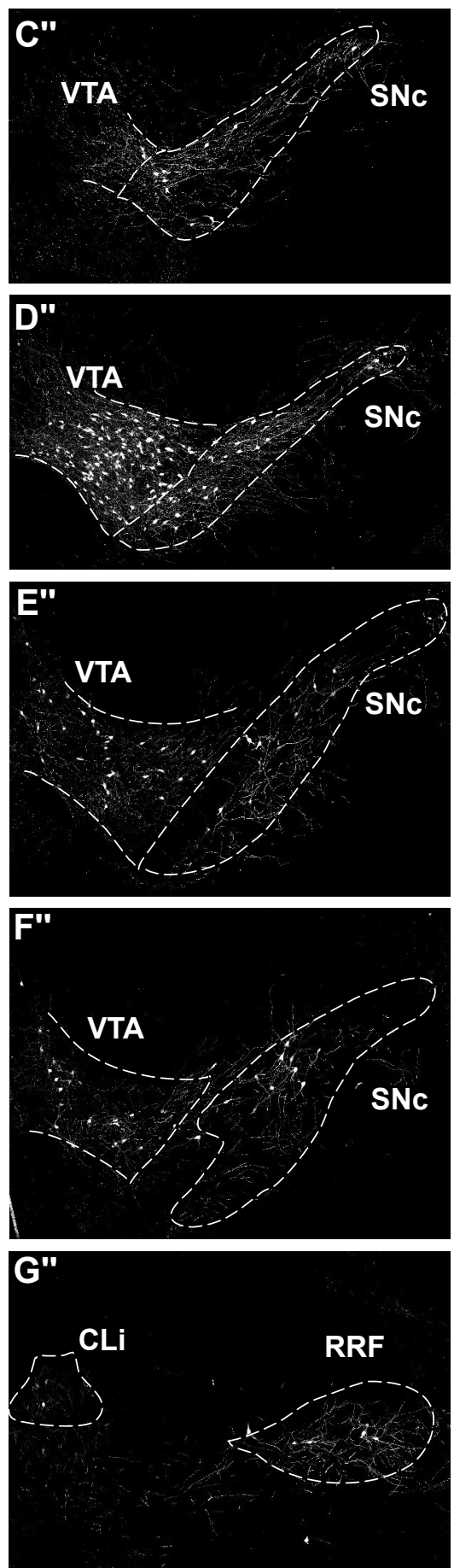
bioRxiv preprint doi: https://doi.org/10.1101/2020.10.06.327940; this version posted October 7, 2020. The copyright holder for this preprint

(which was not certified by peer review) is the author/funder, who has granted bioRxiv a license to display the preprint in perpetuity. It is

rAAV made available under ACC-BY 4.0 International license.

A $\sqsubset$ EF-1 $\alpha=$ ChR2-mCherry or -EYFP-NWPRE PolyA B Experimental timeline
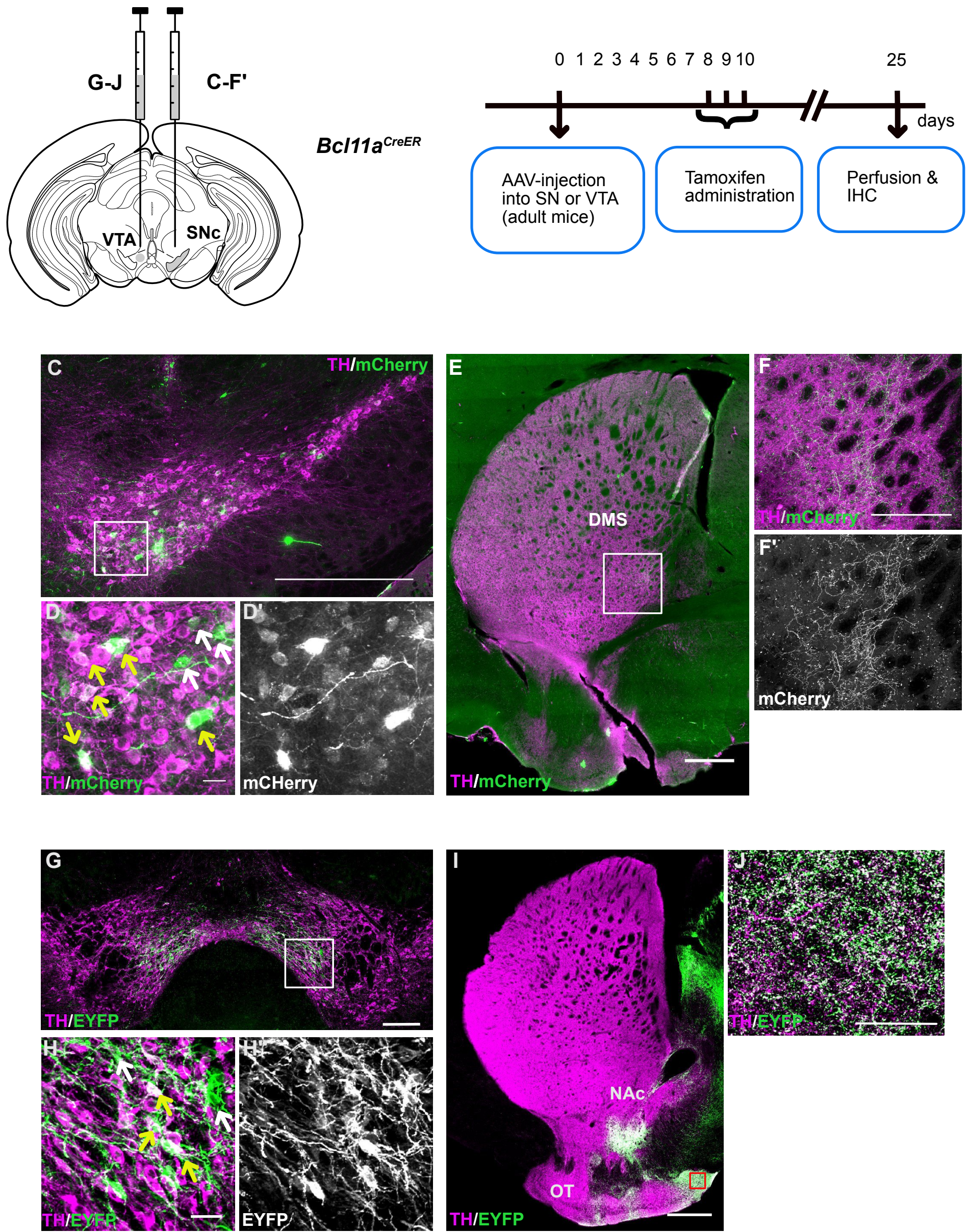

\section{Supplemental Figure 5}


bioRxiv preprint doi: https://doi.org/10.1101/2020.10.06.327940; this version posted October 7, 2020. The copyright holder for this preprint

(which was not certified by peer review) is the author/funder, who has granted bioRxiv a license to display the preprint in perpetuity. It is made available under aCC-BY 4.0 International license.
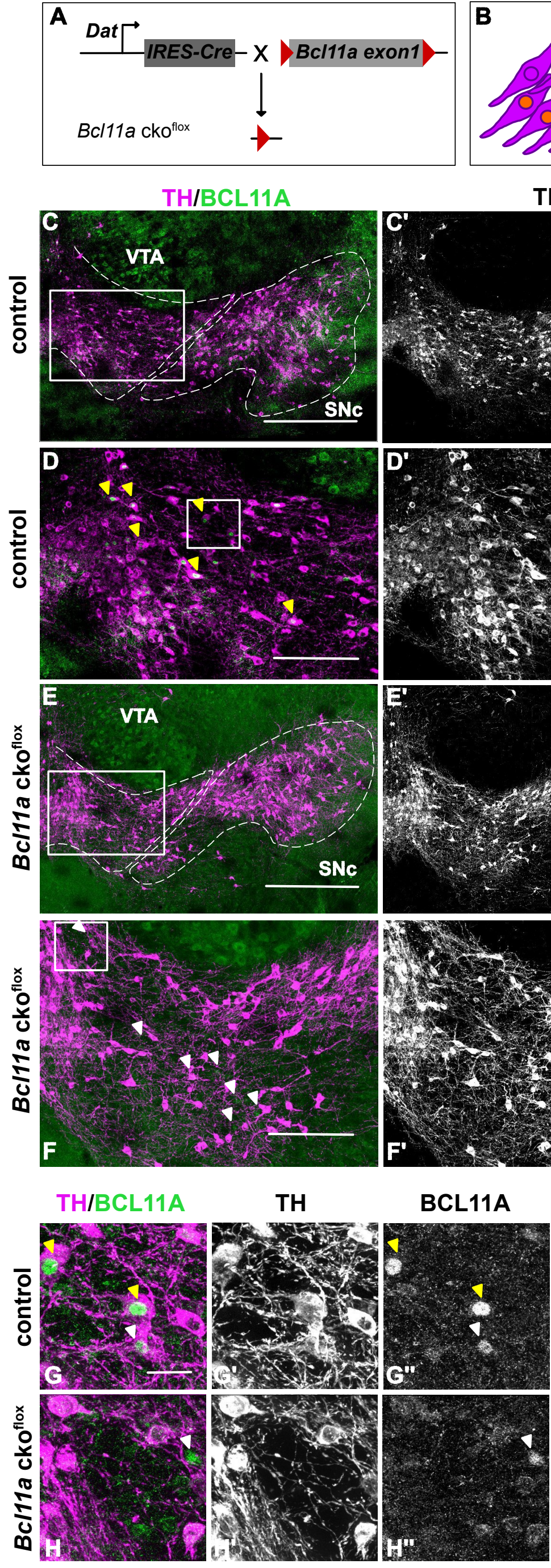

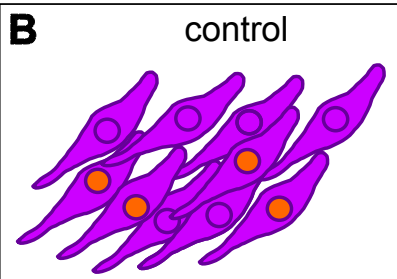

TH
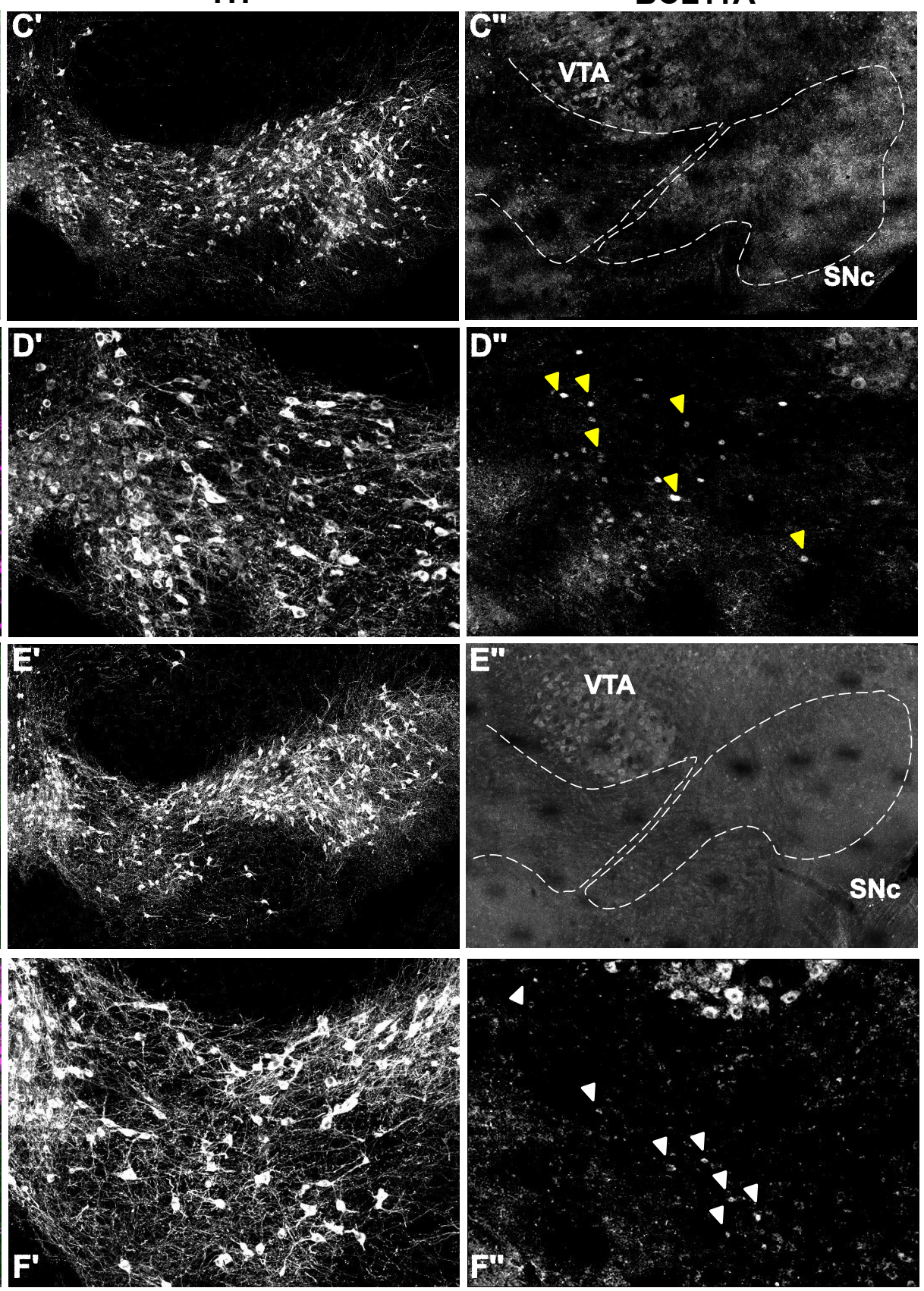

Hoe/BCL11A

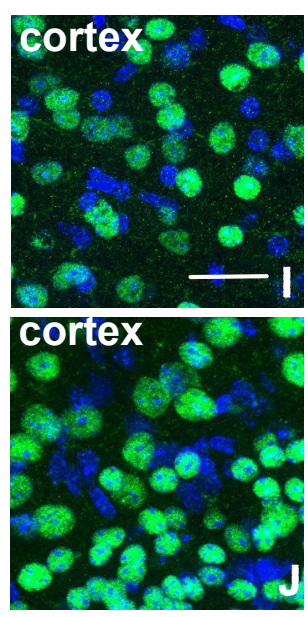

Supplemental Figure 6 

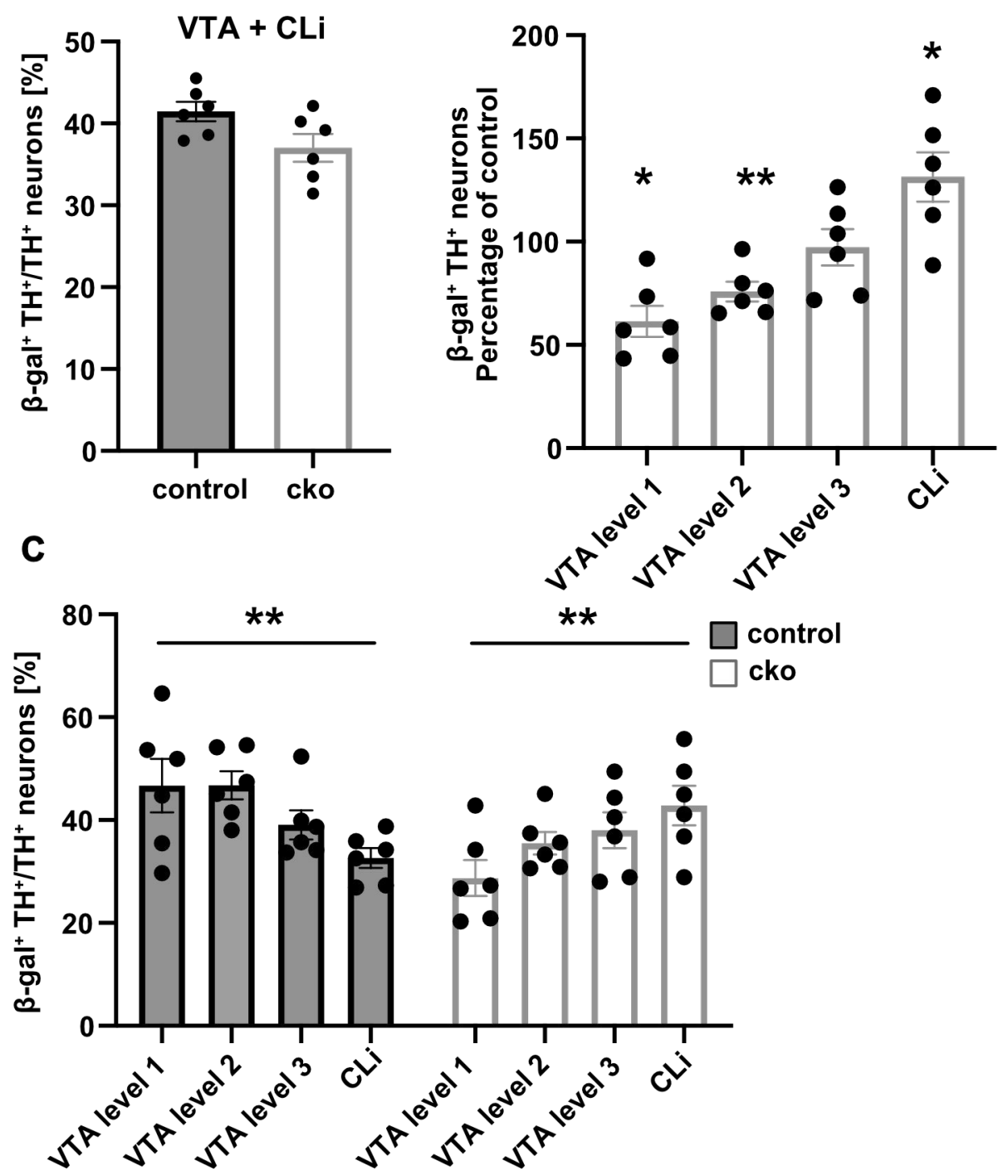
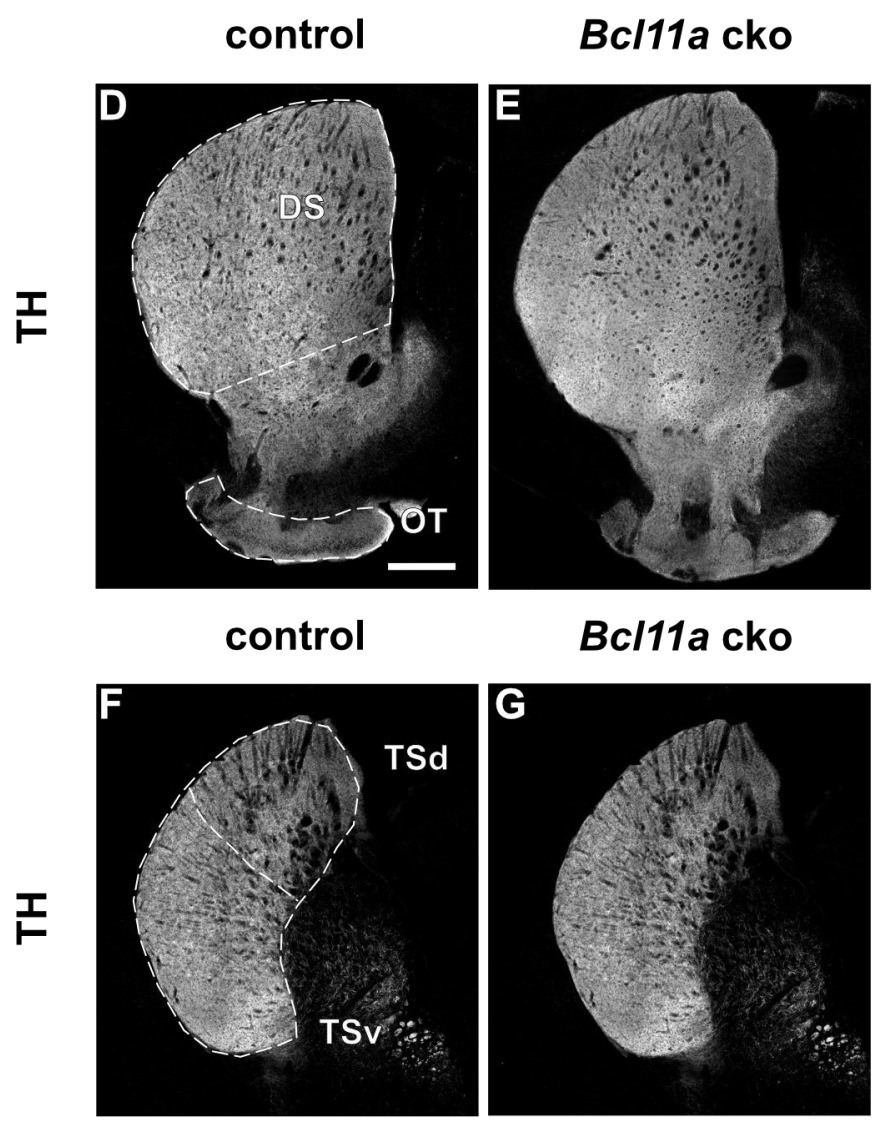

H

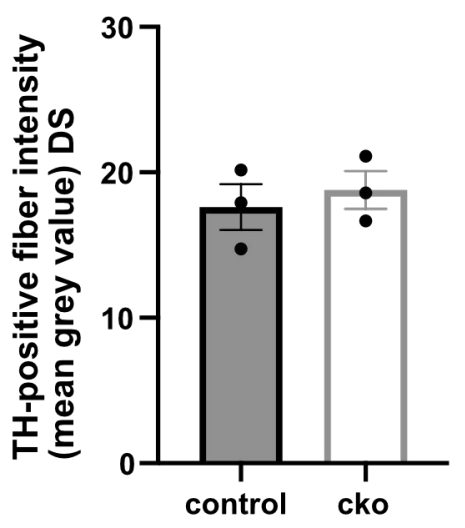

J
I
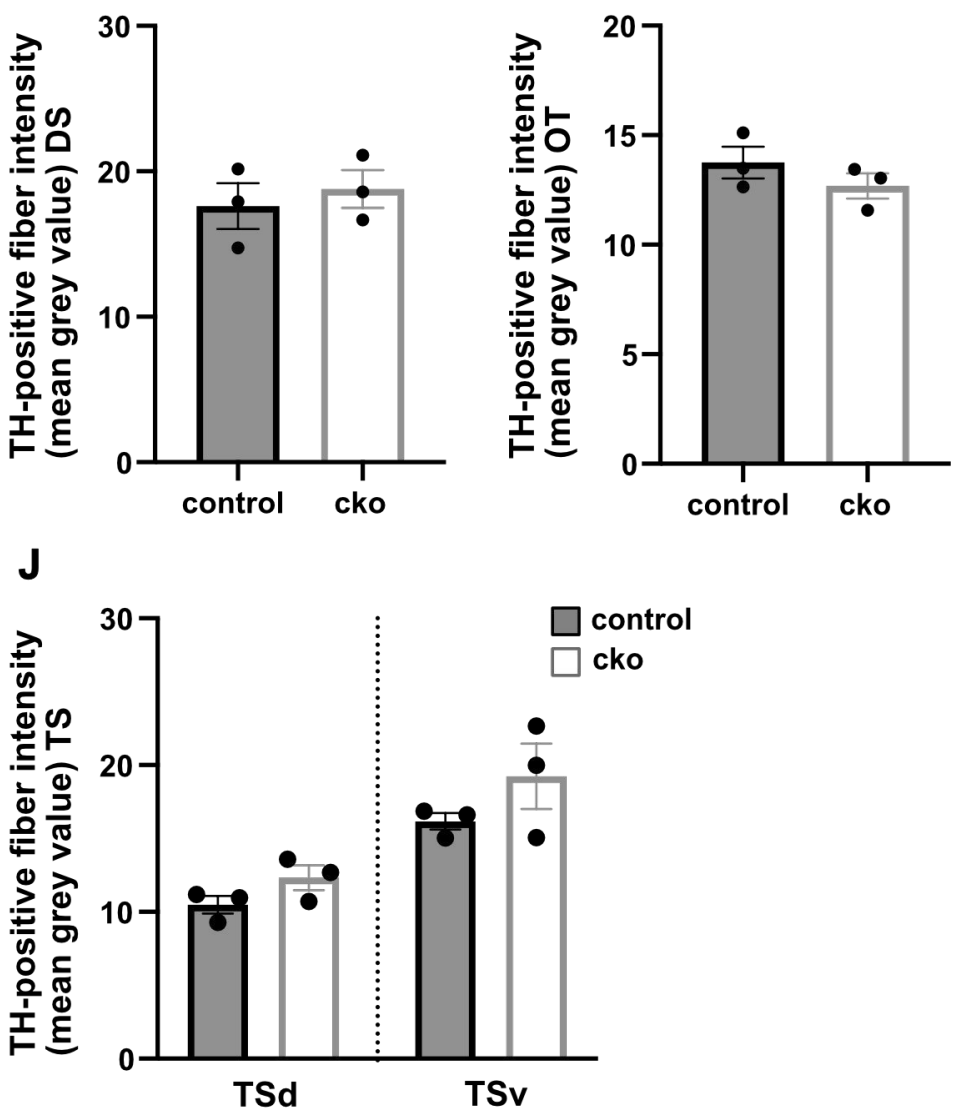